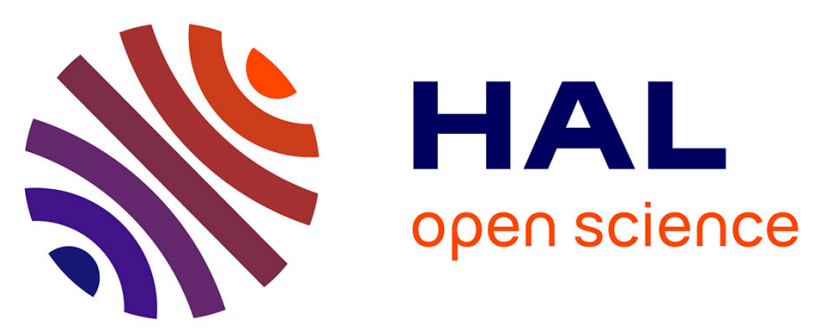

\title{
Un atelier monétaire gaulois près de Poitiers : les Rochereaux à Migné-Auxances (Vienne)
}

Assumpció Toledo I Mur, Michel Pernot, Frédéric Adamski, Laurence Benquet, Philippe Fluzin, Jean Hiernard, Lionel Orengo, Philippe Poirier

\section{To cite this version:}

Assumpció Toledo I Mur, Michel Pernot, Frédéric Adamski, Laurence Benquet, Philippe Fluzin, et al.. Un atelier monétaire gaulois près de Poitiers: les Rochereaux à Migné-Auxances (Vienne). Gallia - Archéologie de la France antique, 2008, 65, pp.231-272. 10.3406/galia.2008.3345 . hal-01899145

\section{HAL Id: hal-01899145 \\ https://hal.science/hal-01899145}

Submitted on 19 Dec 2019

HAL is a multi-disciplinary open access archive for the deposit and dissemination of scientific research documents, whether they are published or not. The documents may come from teaching and research institutions in France or abroad, or from public or private research centers.
L'archive ouverte pluridisciplinaire HAL, est destinée au dépôt et à la diffusion de documents scientifiques de niveau recherche, publiés ou non, émanant des établissements d'enseignement et de recherche français ou étrangers, des laboratoires publics ou privés.

\section{(ㅇ)(1) $\$$}

Distributed under a Creative Commons Attribution - NonCommercial - NoDerivatives $\mid 4.0$ 


\title{
UN ATELIER MONÉTAIRE GAULOIS PRESS DE POITIERS
}

\section{Les Rochereaux à Migné-Auxances (Vienne)}

\author{
Sous la direction d'Assumpció TOLEDO I MUR ${ }^{1}$ et Michel PERNOT ${ }^{2}$ \\ avec les contributions de Frédéric ADAMSKI ${ }^{3}$, Laurence BENQUET ${ }^{4}$, \\ Philippe Fluzin ${ }^{5}$, Jean HIERnARD ${ }^{6}$, Lionel ORENGO ${ }^{7}$ et Philippe POIRIER ${ }^{8}$
}

Mots-clés. Second âge du Fer, atelier monétaire, atelier métallurgique, flans, creusets, monnayage picton.

Résumé. L'attribution du statut d'atelier monétaire à l'établissement rural de plaine des Rochereaux à Migné-Auxances (Vienne) se fonde sur:

- la découverte de l'espace physique de l'atelier de bronziers, spécialisé dans la fabrication de flans monétaires, associé à des structures de combustion et à des outils;

- la présence dans les cendres du foyer central de quarante flans monétaires, dont certains sont encore associés en grappe;

- une estimation minimale qui conduit à proposer que, à partir d'une seule utilisation des 152 creusets recensés, 15 o00 flans monétaires ont pu être fabriqués ;

- les coïncidences entre alliages, modules et poids des flans et des monnaies du site ainsi que la concentration de ce type de monnaies en territoire picton.

La production des flans et leur très plausible frappe sur place eut lieu entre 130 et 100 av. J.-C. Il est fort possible que le site, situé à $5 \mathrm{~km}$ de Poitiers, ait entretenu des liens de dépendance étroits avec cet oppidum.

Key-words. Second Iron Age, mint, metal workshop, blanks, crucibles, Pictone coining.

Abstract. The attribution of the status of a mint to the rural establishment of the Rochereaux at Migné-Auxances (Vienne) plain is based on:

- the discovery of the physical space of a bronzesmith workshop specialized in the fabrication of monetary blanks, associated with combustion structures and tools;

1. INRAP, Base Perpignan, 4bis avenue Marcelin-Albert, F-66000 Perpignan. Courriel : assumpcio.toledo-i-mur@inrap.fr

2. UMR 5060 du CNRS, Université Bordeaux-III, Maison de l'archéologie, Esplanade des Antilles, F-33607 Pessac. Courriel : mpernot@ u-bordeaux3.fr

3. UMR 5060 du CNRS, Université Bordeaux-III, Maison de l'archéologie, Esplanade des Antilles, F-33607 Pessac. Courriel : dageuf@ hotmail.com

4. INRAP Grand Sud-Ouest, Centre archéologique de Saint-Orens, ZI Les Pinsons, 13 rue du Négoce, F-31650 Saint-Orens-de-Gameville. Courriel : laurence.benquet@inrap.fr

5. UMR 5060 du CNRS, Laboratoire métallurgie et cultures, Université de Technologie Belfort-Montbéliard, F-90010 Belfort Cedex. Courriel : philippe.fluzin@utbm.fr

6. Laboratoire hellénisation et romanisation dans le monde antique, Département d'histoire de l'art, 8 rue René-Descartes, BP 603 , F-86022 Poitiers Cedex. Courriel : jean.hiernard@neuf.fr

7. INRAP et UMR 5594 du CNRS, Laboratoire archéologies, culture et sociétés, Université de Bourgogne, 6 boulevard Gabriel, F-21000 Dijon. Courriel : lionel.orengo@cegetel.net

8. INRAP et UMR 5059 du CNRS, Université Montpellier-II, 163 rue Broussonet, F-34090 Montpellier. Courriel : philippe.poirier@inrap.fr 
- the presence of forty monetary blanks in the ashes of the central hearth, some of which are still associated in clusters;

- a minimal estimation that leads us to propose that, from a single utilization of the 152 crucibles recorded, 15,000 monetary blanks could be fabricated;

- the concurrence between - in alloys, proportions and weight - blanks and coins at the site, as well as the concentration of this type of coin in the Pictone territory.

The production of blanks and their very likely minting at this site occurred between 130 and 100 B.C. It is highly probable that this site, located $5 \mathrm{~km}$ from Poitiers, maintained close dependant links with this oppidum.

Translation: Magen O'FARRELL

Schlüsselwörter. Ältere Eisenzeit, Münzprägestätte, Metall verarbeitende Werkstätte, Schrötlinge, Münzwesen der Piktonen.

Zusammenfassung. Die Einordnung des bäuerlichen Betriebs der Ebene von Rochereaux in Migné-Auxances als Münzprägestätte begründet sich auf folgende Argumente:

- allein die Entdeckung in situ dieser auf die Herstellung von Schrötlingen spezialisierten Bronzewerkstätte und der damit in

Verbindung stehenden Verbrennungsstrukturen und Werkzeuge

- das Vorhandensein von vierzig zum Teil noch zusammenhaftenden Schrötlingen in der Asche der zentralen Feuerstelle

- eine minimale Schätzung, die vermuten lässt, dass wenn man von einer einzigen Benutzung der 152 erfassten Schmelztiegel ausgeht,

15000 Schrötlinge hergestellt werden konnten

- die Übereinstimmung von Legierung, Modulen und Gewichten der Schrötlinge und der Münzen der Fundstelle sowie die

Konzentration dieses Münztyps im Territorium der Piktonen.

Die Produktion der Schrötlinge und deren sehr wahrscheinliche Prägung vor Ort fand zwischen 130 und 100 v. Chr. statt. Es ist sehr wahrscheinlich, dass die fünf Kilometer von Poitiers entfernte Stätte in enger Abhängigkeit mit diesem oppidum stand.

Übersetzung: Isa ODENHARDT-DONVEZ

L'activité principale de l'établissement rural du second âge du Fer du site des Rochereaux (commune de MignéAuxances, Vienne), et vraisemblablement celle qui est à l'origine de sa fondation, est la fabrication de flans monétaires en bronze, très probablement frappés sur place ${ }^{9}$. D'après le mobilier amphorique utilisé lors de son aménagement puis de son fonctionnement, l'atelier de bronziers, installé dans une fosse creusée dans le substrat calcaire, a été en activité pendant les trois dernières décennies du $\mathrm{II}^{\mathrm{e}}$ s. av. J.-C. Cette datation est confirmée par les objets métalliques et les céramiques présents dans les couches correspondantes.

En l'état actuel de la recherche, la frappe de monnaie a été identifiée principalement dans des oppida ou des sanctuaires (Fichtl, 2000, p. 130-134 ; Poux et al., 2004) ; cependant, des indices de production monétaire ont été reconnus dans des agglomérations ouvertes à Nanterre (Hauts-de-Seine) (Viand dir., 2008, p. 46) et Saumeray (Eure-et-Loir) (Hamon et al., 1997).

L'attribution du statut d'atelier monétaire à l'établissement rural de plaine des Rochereaux, bien protégé mais non fortifié, se fonde sur :

9. Le site avait été repéré lors d'une mission de photographie aérienne de A. Olivier. En 2004, il a fait l'objet d'un diagnostic archéologique (Beausoleil et al., 2004) et d'une campagne de fouilles (Toledo i Mur et al., 2005).
- la découverte de l'espace physique de l'atelier de bronziers, spécialisé dans la fabrication de flans monétaires, associé à des structures de combustion et à des outils ;

- la présence dans les cendres du foyer central de quarante flans monétaires, dont certains sont encore associés en grappe ;

- une estimation minimale qui conduit à proposer qu'à partir d'une seule utilisation des 152 creusets recensés 15000 flans monétaires ont pu être fabriqués ;

- les coïncidences entre alliage, modules et poids des flans et des monnaies du site ainsi que la concentration de ce type de monnaie en territoire picton.

En effet, les résultats de l'étude technologique des flans monétaires issus de l'atelier et des monnaies découvertes sur le site, et de ceux de l'étude numismatique, confirment leurs ressemblances. Les monnaies sont toutes du même type, tête « aquitanique ", sur l'avers, et cheval galopant à droite, tête en arrière, sur le revers. Elles étaient traditionnellement attribuées aux Bituriges Cubi du Berry et leur datation était, jusqu'à présent, inconnue. Nonobstant, les découvertes de ce type de monnaie se concentrent sur le territoire picton (voir carte de répartition fig. 25). Proposer que les flans fabriqués dans l'atelier des Rochereaux aient été frappés sur place conduit à une hypothèse plausible ${ }^{10}$. L'établissement

10. L'absence de coin monétaire parmi le mobilier récupéré sur le site ne peut à elle seule invalider cette hypothèse. Les coins et autres ins- 
rural des Rochereaux est situé suffisamment près de Poitiers $(5 \mathrm{~km})$ pour pouvoir être considéré comme entretenant des liens de dépendance étroits avec cet oppidum (fig. 1).

Après la cessation de l'activité de l'atelier métallurgique, l'établissement continue à être occupé pendant quelques décennies. Tout indique une durée " courte " de cette occupation, tout au plus une soixantaine d'années incluses dans la fourchette chronologique maximale indiquée par le mobilier.

A. T. i M.

\section{L'ÉTABLISSEMENT}

Le plan de l'établissement comporte deux enclos trapézoïdaux, partiellement connus (Toledo i Mur, 2007a et b). L'un d'eux (enclos II), décapé sur une surface de $5000 \mathrm{~m}^{2}$, aurait eu une vocation agropastorale (fig. 2). L'enceinte de l'habitat, reconnue sur une surface de $3500 \mathrm{~m}^{2}$, présente des caractéristiques originales. Tous les côtés ne sont pas délimités par un fossé ; le côté ouest en est dépourvu. Le fossé qui délimite le côté nord est doublé d'un talus et d'une palissade. L'arrêt volontaire du fossé nord, le retour de la palissade vers le sud et un bâtiment à plan carré et à forte charpente (bât. 5), situé hors de l'enceinte, indiquent l'emplacement de l'entrée principale de l'enclos.

À l'intérieur, les constructions sont distribuées selon un ordre préétabli qui tient compte de leurs fonctions respectives. Le gabarit des trous de poteau soutenant la charpente des bâtiments, leur surface et leur positionnement montrent l'existence d'une certaine hiérarchie. La fosse qui contient l'atelier métallurgique a été creusée dans l'alignement de la palissade, près d'une entrée secondaire de l'enclos ouverte vers le nord ; elle se trouve à l'écart du bâtiment principal (bât. 1). Ce dernier présente une forte charpente ; il sera remplacé par un autre (bât. 2), deux fois plus grand, qui le chevauche partiellement. Ce bâtiment est situé au fond de l'enceinte, en face de la grande entrée. Il réunit les conditions nécessaires à l'exécution des tâches d'une officine de frappe : un espace suffisant pour pouvoir installer le dispositif spécifique, qui comporte le coin fixe, de la clarté pour pouvoir observer minutieusement le résultat et procéder au décompte des monnaies, et enfin un endroit pour les entreposer en attendant leur mise en circulation. Une construction avec un toit à deux versants (bât. 6), accolée

truments nécessaires à la frappe ont pu être emportés, ou détruits, au moment de l'arrêt de la production. Notons qu'il a déjà été démontré que les indices de fabrication monétaire sont étroitement liés à un atelier de bronziers (Fichtl, 2000, p. 133).

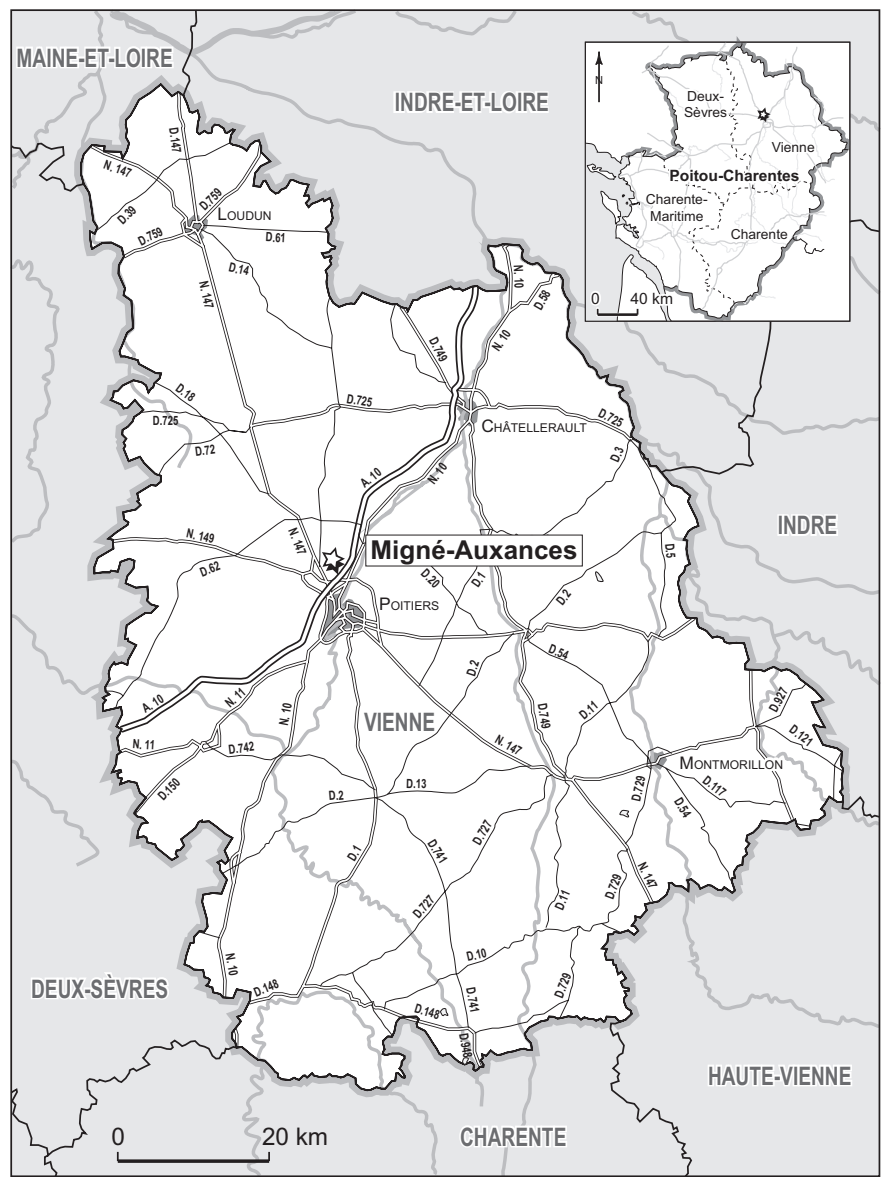

Fig. 1 - Carte de localisation de la commune (DAO : S. Dalle, INRAP).

à la palissade à proximité de la fosse-atelier, pourrait servir de remise à l'artisan métallurgiste. Enfin viennent s'ajouter deux bâtiments plus modestes à la charpente légère (bât. 3 et 4) dont les emplacements, à l'intérieur de l'enceinte, ne sont guère significatifs.

\section{LA FOURCHETTE CHRONOLOGIQUE DE L'OCCUPATION}

Les sols de l'établissement n'étant pas conservés, la seule série stratigraphique provient des différents états de la fosse-atelier. Ainsi, les niveaux d'aménagement, de fonctionnement, de destruction et d'abandon de l'atelier (installé dans la fosse 1002), de même que les couches de dépotoirs remplissant la moitié supérieure, fournissent les éléments de datation de l'établissement, corroborée par le mobilier exhumé des fossés. 


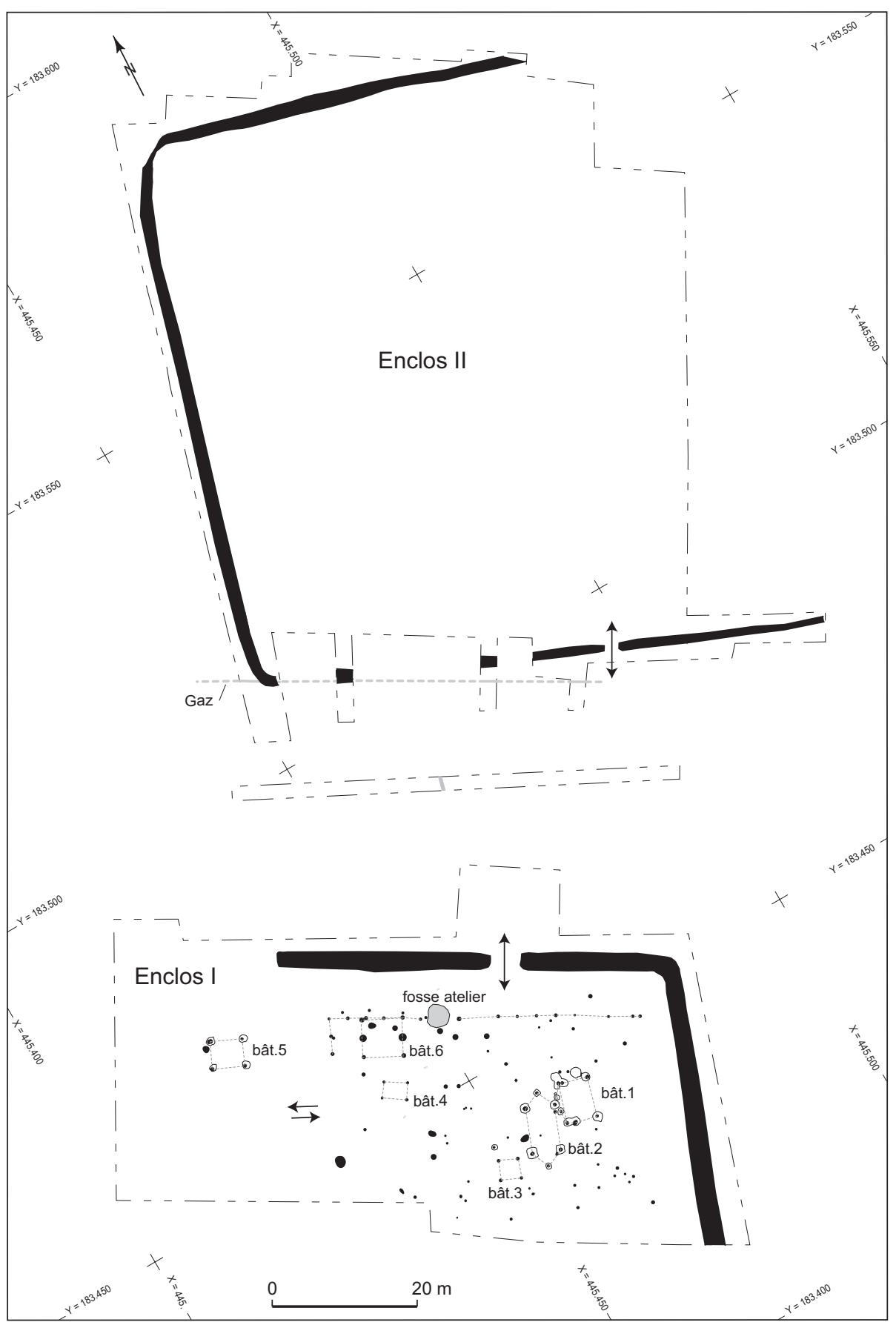

Fig. 2 - Plan du site (relevé topographique : R. Bernard, INRAP; DAO : S. Dalle, INRAP).

La mise en place de l'atelier de bronziers et sa période d'activité se situent dans une fourchette chronologique allant de 130 à 100 av. J.-C., établie à partir de l'association des amphores gréco-italiques, de transition et Dressel 1 (voir infra, p. 263). Cette fourchette est confirmée par des objets métalliques provenant des couches de fonctionnement du foyer de l'atelier, notamment par un umbo en fer, à rebords bien marqués, daté entre 150 et 100 av. J.-C. et, dans le même contexte, par un pied de fibule en alliage cuivreux, du type « La Tène II », daté entre 250 et 150 av. J.-C. Il faut également noter la présence de deux pendentifs en alliages cuivreux datés du II ${ }^{\mathrm{e}}$ s. av. J.-C. L'un, en forme de clochette, se trouve 
dans la couche d'éboulis couvrant le foyer, et l'autre, en forme de serpe, dans une des couches inférieures du dépotoir (voir infra, p. 257). Les objets de comparaison relatifs à un certain nombre de vases en céramique fine tournée, provenant des couches d'aménagement, de fonctionnement et d'abandon de l'atelier, concordent avec les estimations chronologiques précédentes. On les retrouve, avec les mêmes profils et les mêmes décors, dans des ensembles céramiques de sites du Centre-Ouest du dernier quart du $\mathrm{II}^{\mathrm{e}} \mathrm{s}$. av. J.-C.

Les couches de dépotoirs comblant la moitié supérieure de la fosse montrent que, après la cessation d'activité de l'atelier qui marque le déclin du site, il a continué à être habité pendant quelques décennies ${ }^{11}$. Les restes de vidange d'un foyer et des ossements d'animaux domestiques comportant des traces de découpe bouchère en apportent la preuve (Vallet, 2005).

La désertion du site a dû avoir lieu au cours du premier quart du $\mathrm{I}^{\mathrm{er}}$ s. av. J.-C., comme en témoigne la présence, dans le remplissage des fossés, de fragments d'amphores Dr. 1B et de céramiques tournées fines grises, décorées de baguettes. Des fragments de ce type de céramique ont été récupérés dans les deux dernières couches de remplissage de la fosse 1002 et dans le comblement des trous de poteau du bâtiment 2 .

\section{LA FOSSE CONTENANT L'ATELIER MÉTALLURGIQUE}

Creusée dans le substrat calcaire, la fosse a un profil qui se rétrécit sur sa moitié supérieure (fig. 3). Le diamètre est de 2,30 $\mathrm{m}$ à l'ouverture, de 2,80 $\mathrm{m}$ au niveau du sol de fonctionnement de l'atelier et de 2,50 $\mathrm{m}$ au fond. La profondeur conservée est de 2,10 m. Sur les parois nord et sud, deux rangées de petites niches se situent à une hauteur d'environ 0,70 m. La moitié inférieure des parois sud et ouest présente une coloration grisâtre, probablement en rapport avec l'activité métallurgique. En revanche, le fond de la fosse ne présente aucune trace de rubéfaction ni d'enfumage.

\section{LA MISE EN PLACE DE L'ATELIER}

L'installation d'un atelier de métallurgie à l'intérieur d'une fosse nécessite l'aménagement du fond de la cavité afin

11. L'abandon de l'atelier s'est très probablement produit à la suite d'un important éboulement. Bien entendu, l'abandon de la fabrication des flans peut être dû à des circonstances socio-économiques, voire politiques, difficiles à cerner à partir des vestiges matériels. de mettre en place ce qui est nécessaire à l'artisan. Isoler le niveau de circulation de l'atelier du substrat calcaire, pour limiter l'humidité, est une priorité. C'est pourquoi le fond de la cavité est remblayé par une couche de gros blocs et de plaquettes de calcaire ; celle-ci est ensuite recouverte d'un matériau argileux fin constituant ainsi le sol de l'atelier.

Au sein de la couche pierreuse, en dessous de l'atelier, les gros blocs se situent au centre et les plaquettes sur les côtés. Ceci fait office de «vide sanitaire ", permettant ainsi de limiter l'humidité, tout en concentrant les eaux de ruissellement et de condensation. La présence d'une herminette en fer entre les gros blocs, d'un crâne de cheval décharné et de la moitié d'une meule dans un angle du fond de la fosse peut faire penser qu'il s'agit d'un dépôt.

Notons la présence d'une panse complète d'amphore du type Dr. 1 qui s'appuie contre la paroi sud de la fosse et qui contribue à l'épaisseur du vide sanitaire de ce côté.

Sur tout le pourtour interne de la fosse, une bande, large de $0,40 \mathrm{~m}$, où affleure le remplissage de plaquettes, n'a pas été recouverte de sédiment argileux. Elle permet d'évacuer la condensation ambiante vers le vide sanitaire. Elle sert également à ranger des outils (creusets), des récipients (fonds d'amphores plantés entre les plaquettes) et des supports (cols d'amphores mis à l'envers). Un certain nombre de creusets étaient rangés dans les petites niches des parois nord et sud.

La plate-forme de travail ainsi créée se situe à une profondeur de $1,50 \mathrm{~m}$ par rapport à ce qui est conservé. Sa surface mesure un peu plus de $6 \mathrm{~m}^{2}$. Au centre de la zone de travail, des blocs de calcaire, posés à plat, composent le radier du foyer de l'atelier (fig. 4, no 1 ). Le dispositif de stabilisation est renforcé par le col d'une amphore Dr. 1, situé juste au-dessous (fig. 4, $\mathrm{n}^{\mathrm{o}}$ 2). La base du foyer est recouverte d'un microlitage de couches charbonneuses en forme de dôme, d'une épaisseur de 0,20 m, résultant de son fonctionnement.

L'atelier était nécessairement couvert. Un certain nombre d'anomalies situées du côté nord-est de la fosse, relevées après décapage, n'ont pas pu être fouillées. Il s'agissait très probablement de trous de poteau qui auraient pu supporter un toit ${ }^{12}$. L'accès à l'atelier se faisait vraisemblablement par une simple échelle en bois, posée sur le sol et appuyée

12. La couche de gros blocs scellant les niveaux de dépotoir du comblement de la fosse pourrait correspondre à l'écroulement d'un mur longeant la moitié nord du périmètre de la fosse-atelier. Il aurait pu faire partie d'une structure de couverture (interprétation de C. Vallet). Dans ce cas, il aurait résisté après l'abandon de l'activité métallurgique de la fosse. 

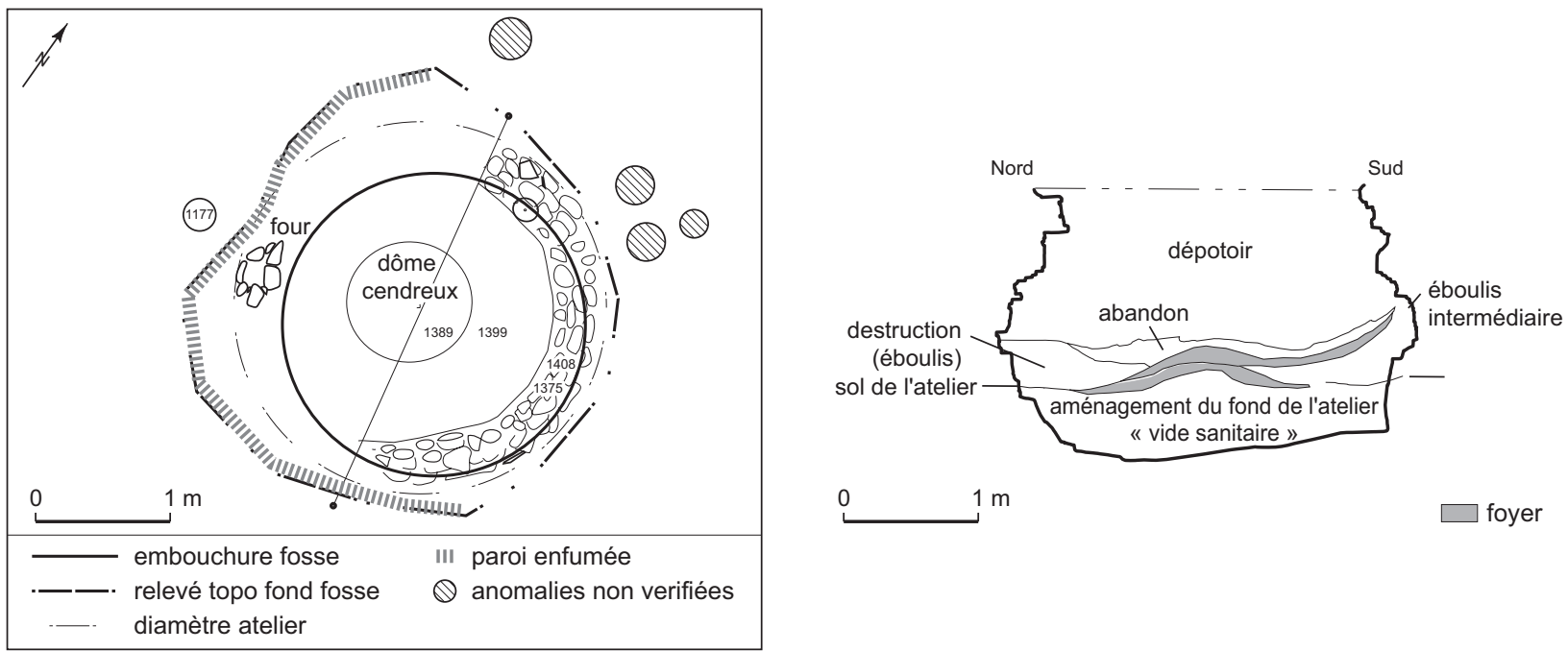

foyer

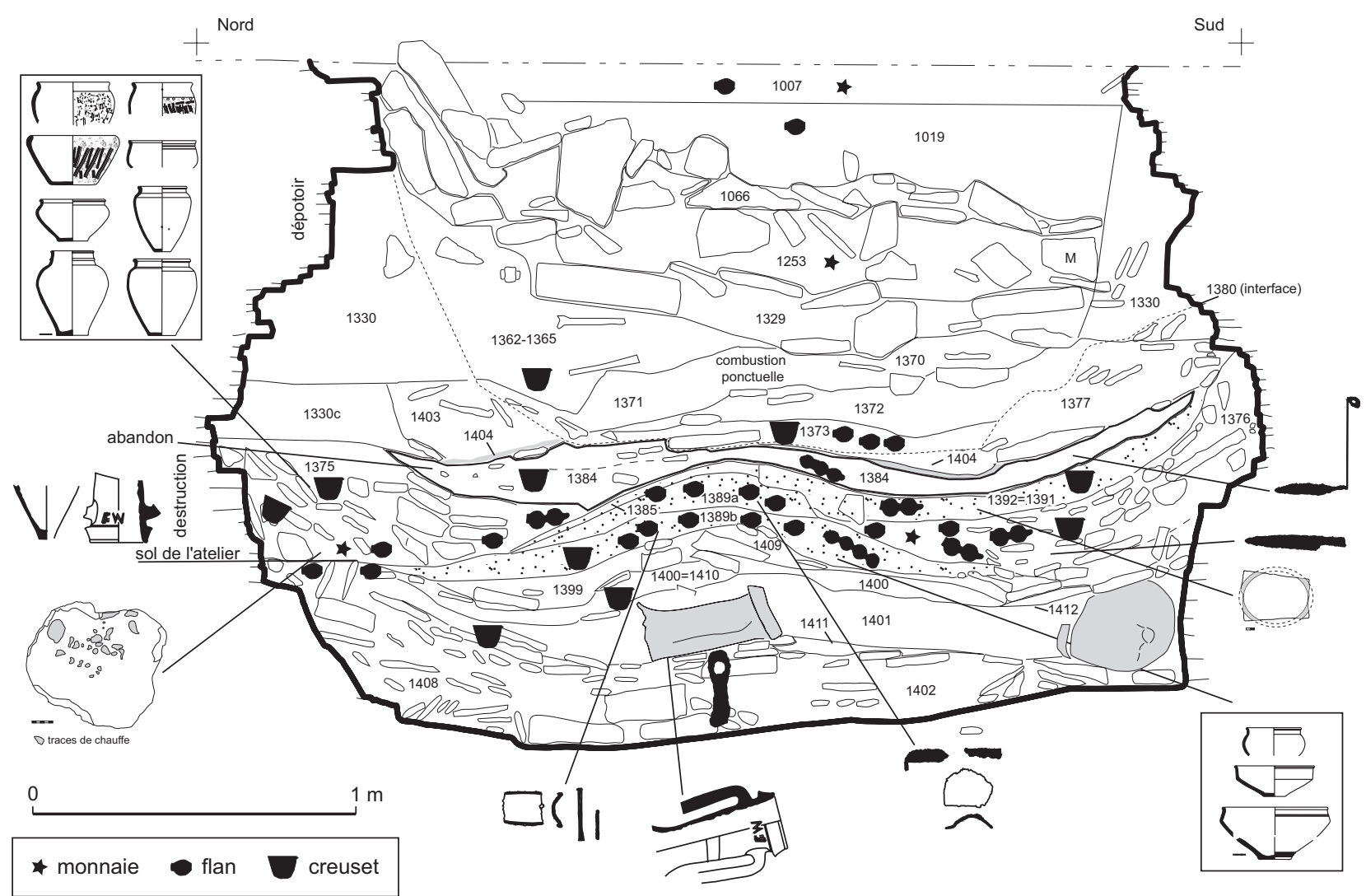

Fig. 3 - Coupe de la fosse-atelier 1002. Les deux vignettes du haut présentent un plan reconstitué à partir des relevés topographiques et des photographies ainsi qu'un croquis interprétatif de la coupe (relevés : E. Galtie et A. Toledo i Mur; DAO : S. Dalle et A. Toledo i Mur, INRAP). 


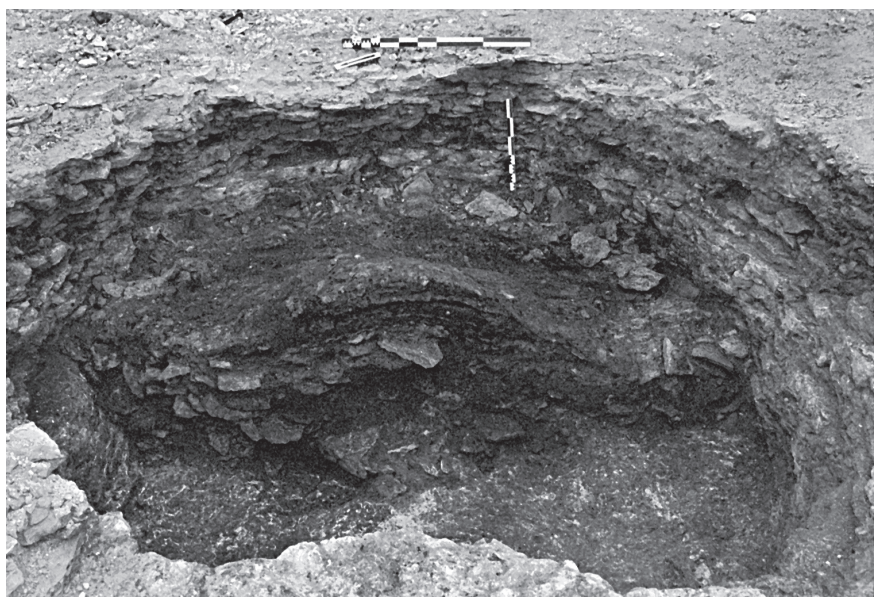

1

Fig. 4 - 1, vue générale de la coupe du sol de l'atelier avec le dôme du foyer central. Le cliché a été pris lors de la deuxième phase de fouille, après terrassement du pourtour de la fosse sur une hauteur de $0,80 \mathrm{~m}$; 2, vue de détail (dans une étape de fouille antérieure à celle de la photo $\left.n^{o} 1\right)$ du radier sur lequel est installé le foyer central de l'atelier avec les microcouches cendreuses déposées lors de son fonctionnement (clichés: E. Galtié, INRAP).

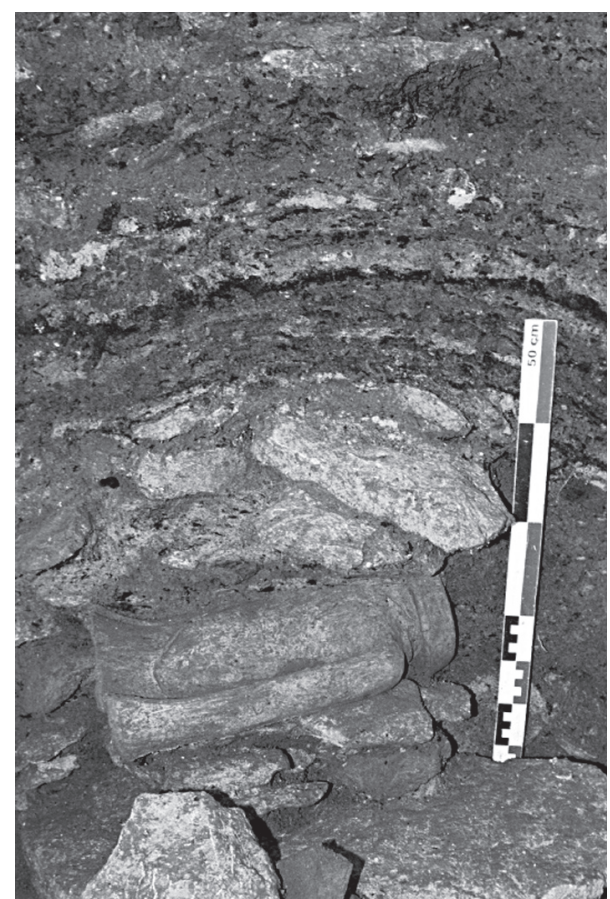

2 contre le bord de la fosse ; elle pouvait être enlevée ou rabattue en cas de besoin.

L'interprétation de la coupe stratigraphique de la fosse contenant des vestiges du travail de bronziers peut susciter un certain scepticisme ; en effet, le profil de la fosse et la disposition des couches de remplissage évoquent aussi un silo comblé par un cône d'effondrement et une série de couches de dépotoir. Cependant, nous privilégions l'interprétation en termes d'atelier, et ne retenons pas la seconde hypothèse que nous ne discuterons pas plus avant. En effet, lors de la fouille, l'expérience de terrain de l'équipe a permis de reconnaître des aménagements que les représentations graphiques ne rendent pas évidents ; cette lecture directe est, comme nous le verrons dans la suite de cet article, en permanence confortée par la description et l'étude détaillée de documents archéologiques objectifs.

\section{LES AMÉNAGEMENTS, OUTILS ET PRODUITS DE L'ATELIER DE BRONZIERS}

Outre le foyer central, d'environ $0,90 \mathrm{~m}$ de diamètre, des blocs de taille moyenne délimitaient un four rectangulaire de $0,20 \mathrm{~m}$ x $0,40 \mathrm{~m}$. Aménagé près de la paroi ouest de l'atelier, il se trouvait dans une zone abritée, en dessous de l'embouchure de la fosse. En Europe centrale, des petits fourneaux, ventilés par des soufflets, ont été retrouvés ; ils servaient pour la fabrication de monnaies en or (Gebhard et al., 1999). Les fragments de parois de four, dont certains sont perforés, ont été récupérés dans les couches de l'atelier et sont sans doute à rattacher à ces structures de combustion. Leur fragmentation est trop importante pour qu'on puisse en déduire la forme initiale ou leur disposition. Les segments percés participaient sans doute d'un dispositif de soufflerie destiné à aviver les braises et atteindre la température de coulée - environ $1100{ }^{\circ} \mathrm{C}$ pour un bronze à $10 \%$ d'étain - et celle de recristallisation - vers $700{ }^{\circ} \mathrm{C}-$ (Pernot, 1993, p. 48).

Un total de 152 creusets, utilisés pour la fusion des alliages cuivreux, a été récupéré dans le dôme du foyer, dans les niches des parois et notamment dans la couche de destruction de l'atelier. À l'exception d'un seul, tous les creusets ont un profil conique inversé avec un bec verseur (fig. 5). Le diamètre d'ouverture, de même que la hauteur, mesure environ $5,5 \mathrm{~cm}$. Le seul exemplaire ansé a les mêmes dimensions. Mis à part trois exemplaires sans trace de chauffe, les creusets ont subi de fortes températures : leurs surfaces sont craquelées et souvent vitrifiées. La plupart contiennent des restes de coulée. Leur contenance est d'environ $32 \mathrm{~cm}^{3}$.

Les objets manufacturés, soit un total de 40 flans monétaires, isolés ou groupés en chapelets de deux, trois ou quatre unités, se concentraient dans les couches du dôme 


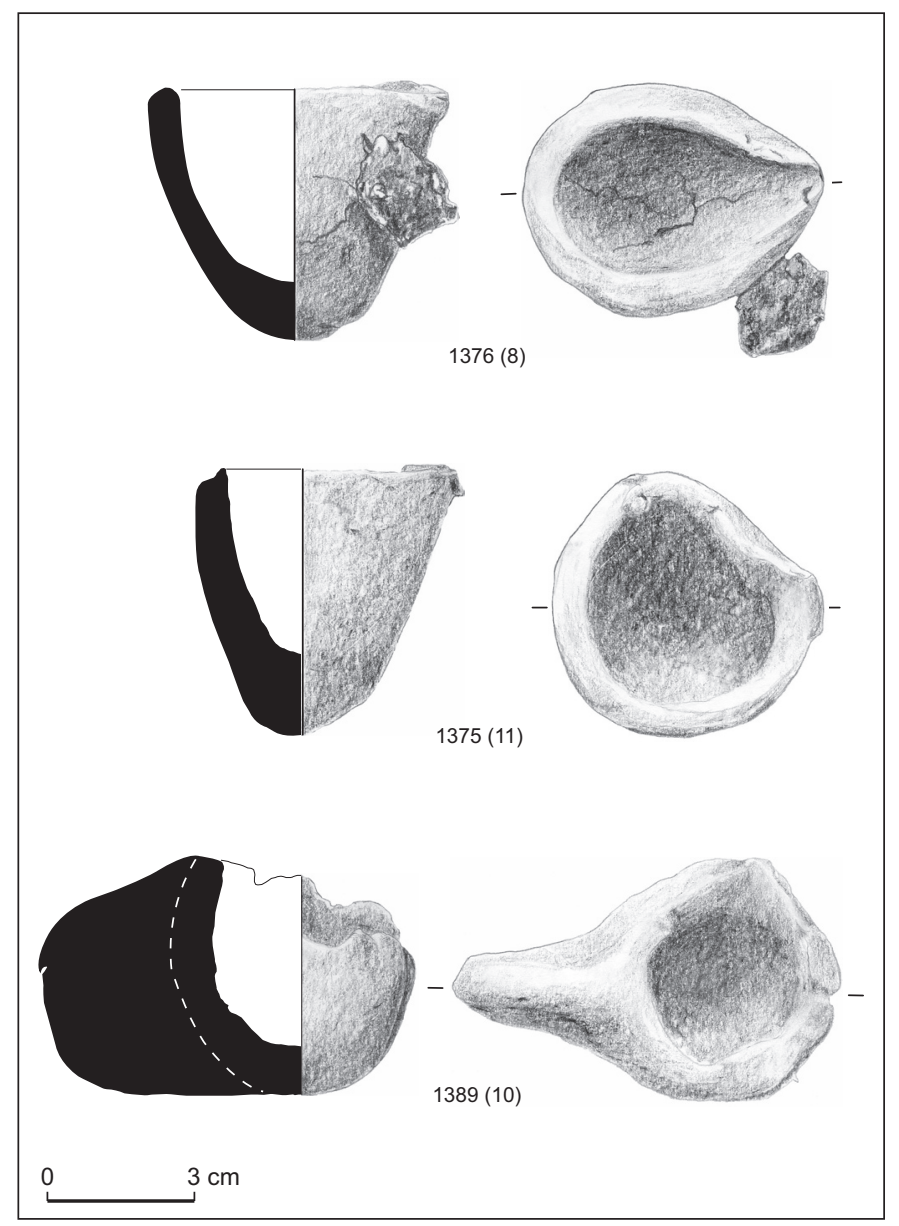

Fig. 5 - Trois des creusets mis au jour

(dessin et DAO : C. Fouilloud, INRAP).

du foyer. De section légèrement tronconique, le diamètre moyen des flans monétaires est de $1,5 \mathrm{~cm}$ et leur épaisseur est de $2 \mathrm{~mm}$ (fig. 6). Les déchets de production représentent $2124 \mathrm{~g}$ de chutes de coulée, récupérées dans les couches de fonctionnement de l'atelier. Notons que $664 \mathrm{~g}$ proviennent des couches cendreuses du dôme du foyer.

À partir de la contenance d'un creuset $\left(32 \mathrm{~cm}^{3}\right)$ et du volume de métal nécessaire pour chaque flan $\left(0,35 \mathrm{~cm}^{3}\right)$, on estime à une centaine le nombre de flans fabriqués à partir d'un creuset. En supposant que les 152 creusets (NMI) n'ont servi qu'une seule fois, la quantité de flans manufacturés se situe aux alentours de 15000 pièces. Or, il est techniquement possible que les creusets aient été utilisés plusieurs fois : il est donc très difficile, voire impossible, d'estimer la quantité totale de flans produits et le rythme de production. La quarantaine de flans découvert ne représente qu'une infime partie de l'ensemble des flans fabriqués. Mélangés aux couches cendreuses, les flans retrouvés ont sans doute échappé à la volonté de l'artisan de récupérer, pour le recyclage, un maximum de bribes de métal de bonne qualité.

Les vases, au nombre d'une dizaine, fragmentés mais complets, la plupart en céramique tournée fine, fournis par les couches du dôme du foyer ou récupérés sur la bande de plaquettes longeant la périphérie du sol de l'atelier, présentent des surfaces craquelées et marquées par des cupules thermiques. Ces vases contenaient certainement des matériaux nécessaires au travail de l'artisan : argile humide pour les moules, eau, sable, cire, etc.

Parmi les objets en fer exhumés, le ciseau à métaux à bout biseauté, long de $13 \mathrm{~cm}$, peut être rattaché au travail du bronzier (fig. 19, $\mathrm{n}^{\mathrm{o}} 5$ ).

Des plaquettes calcaires, qui se débitent naturellement à partir du substrat, ont été utilisées comme supports. Ainsi, six plaquettes, dont quatre provenant des niveaux de fonctionnement de l'atelier, présentent des traces de chauffe. Deux d'entre elles offrent un intérêt particulier. La première est une plaque rectangulaire $(30 \mathrm{~cm}$ x $27 \mathrm{~cm})$, dont une des deux faces a été fortement altérée par l'action de la chaleur et qui présente des traces rouges et noires pouvant correspondre, soit à des gouttes de coulée, soit au démoulage des flans monétaires. Les fortes températures auxquelles cette plaque a été soumise ont provoqué un début de calcination de la roche. La deuxième est une plaque trapézoïdale $(15 \mathrm{~cm} \times 11 \mathrm{~cm} \times 9 \mathrm{~cm})$, dont les quatre angles présentent les traces noirâtres d'un objet circulaire d'environ $16 \mathrm{~cm}$ de diamètre qui aurait reposé sur la plaque pendant qu'il était soumis à une haute température. Le cercle noir est bordé d'une bande rose, témoin de chauffe. En outre, deux polissoirs en grès rouge, roche très abrasive, ont été récupérés dans la couche de destruction de l'atelier ${ }^{13}$.

\section{LES AVANTAGES D'UN ATELIER EN PROFONDEUR : D'AUTRES EXEMPLES}

Le modèle théorique de l'organisation de l'espace dans un atelier de fabrication de petits objets en bronze comporte une zone sombre, abritée des vents et protégée des intempéries, où ont lieu les opérations de fonderie (fusion et coulée) et une zone éclairée dans laquelle se déroulent les

13. Identification F. Milor (INRAP). De tels grès se rencontrent ponctuellement sous forme de petits blocs ou de galets au sein des formations résiduelles tertiaires qui recouvrent la quasi-totalité des plateaux calcaires au sud de l'Auxance. Ces matières premières proviennent donc probablement de ramassages, soit à la surface des plateaux, soit dans le lit des cours d'eau (Auxance, Clain) non loin du site. 


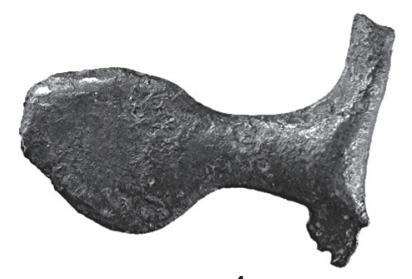

1

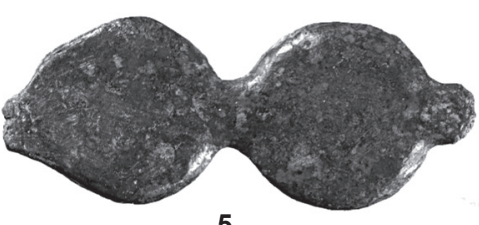

5

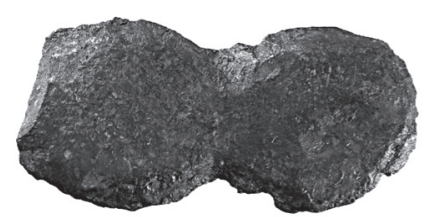

9

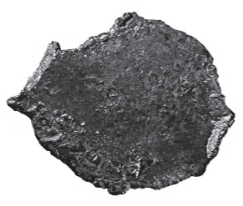

12

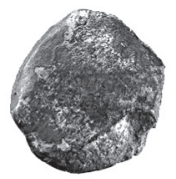

15

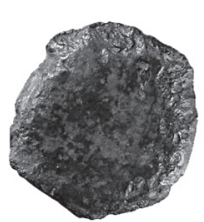

20

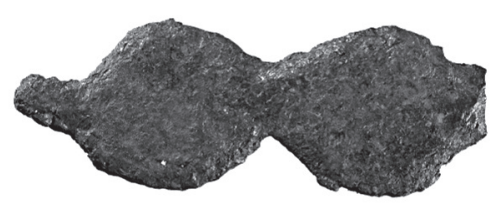

25

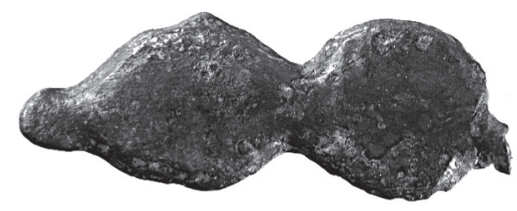

2

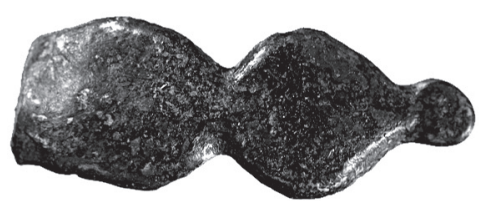

6
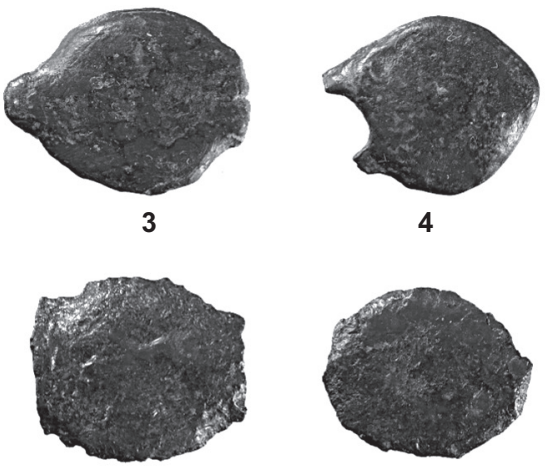

7

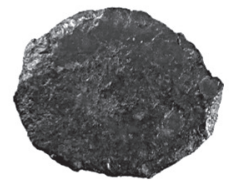

8

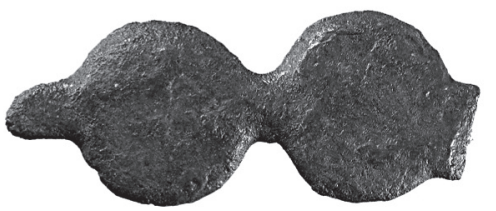

10

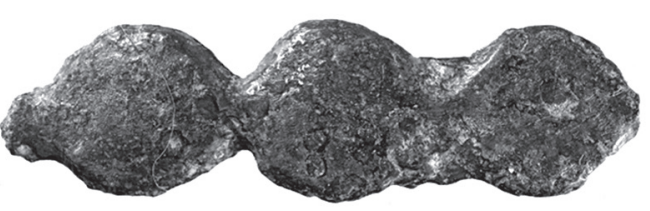

11

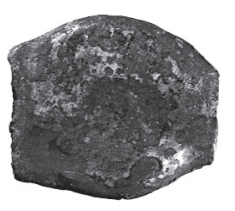

13

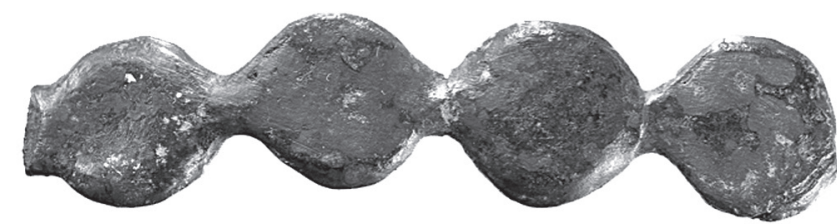

14

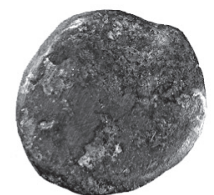

17

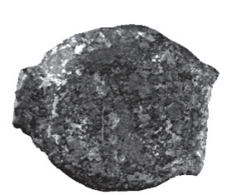

21

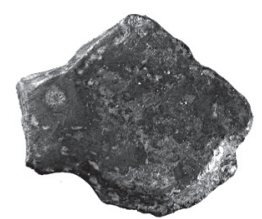

22

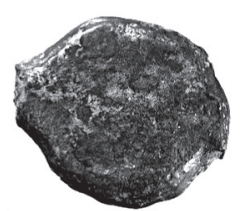

26

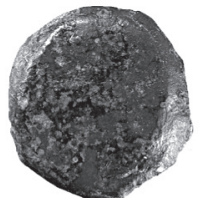

18

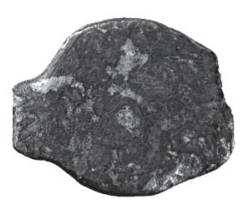

23

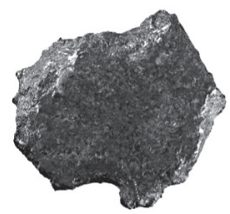

27

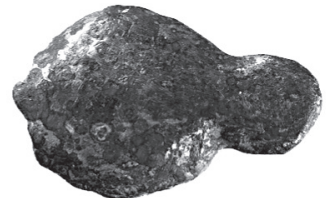

19

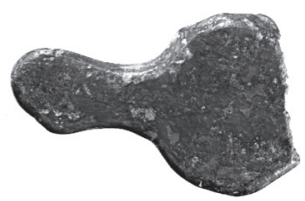

24

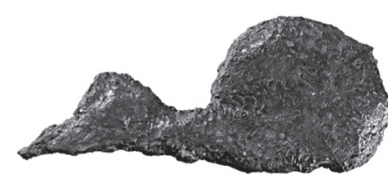

28

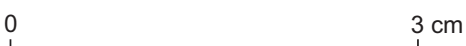

Fig. 6 - Photos des flans monétaires : 1, 1019-3 ; 2, 1373-1 ; 3, 1373-2 ; 4, 1374 ; 5, 1375-1 ; 6, 1375-2 ; 7, 1376-1 ; 8, 1376-2 ; 9, 1376-4 ; $10,1376-5$; 11, 1384 ; 12, 1385 ; 13, 1388-1 ; 14, 1388-2 ; 15, 1389-1; 16, 1389-2 ; 17, 1389-3 ; 18, 1389-4; 19, $1389-5$; $20,1007-1$; 21, 1389-6 ; 22, 1389a-7; 23, 1389a-8 ; 24, 1389a-9; 25, 1392 ; 26, 1405-5 ; 27, 1408-1 ; 28, 1408-2 (clichés : P. Ernaux, INRAP). 
opérations de déformation (martelage, recuit) et de finition (polissage) (Pernot, 1998, p. 113).

L'aménagement d'un atelier de bronziers dans une fosse pour la fabrication de petits objets, à 1,50 m de profondeur, permettait à l'artisan de travailler dans la pénombre pour estimer correctement la température à partir de la couleur de l'alliage en fusion. La profondeur de la fosse favorisait également le contrôle et la stabilité de la température.

Dotée d'une couverture, la surface de $6 \mathrm{~m}^{2}$ au sol, aménagée à l'intérieur de la fosse 1002, suffisait parfaitement à l'artisan bronzier et à son « assistant »; ils pouvaient travailler accroupis autour du foyer et manipuler les creusets et les moules avec une économie de gestes due à une parfaite maîtrise de leur métier. Le stockage des matières premières nécessaires à la fabrication d'objets de petite taille, tels les flans, devait occuper une place assez restreinte. Les métaux (cuivre, étain), les matériaux pour les moules (cire, argile), les creusets (argile) et le combustible (charbon de bois) pour alimenter le foyer, y trouvaient leur place sans encombre. Les creusets étaient rangés dans les niches des parois. Les récipients pour les différents produits (eau, cire...) étaient déposés sur la bande du pourtour interne, de même que les outils nécessaires au travail du bronzier: plaquettes de calcaire avec traces de chauffe, polissoirs, pinces, ciseaux, pelle, éventuellement moules en bois. Les cendres étaient les seuls résidus non métalliques à évacuer. Les fragments de moules en terre, indispensables au procédé de la cire perdue, très friables, étaient très vite broyés et s'incorporaient au sol par piétinement. L'étude des flans permet de dresser la liste des activités ayant eu lieu à l'intérieur de l'atelier : la coulée, le décochage, la division des chapelets (grappes) de flans et le recuit préalable à la frappe, celle-ci étant réalisée à froid (voir p. 250-252).

L'activité principale de l'atelier métallurgique était donc certainement la fabrication de flans monétaires en alliage cuivreux. Des vestiges sidérurgiques, présents à l'intérieur et autour du foyer central, montrent que cette installation a servi, de façon ponctuelle, au travail de forge. Celui-ci se cantonnait au recyclage d'objets et éventuellement à l'entretien des outils. Le travail de forge est secondaire et il est exercé simultanément à celui du bronzier, comme en témoignent des inclusions d'alliage cuivreux dans les calottes de forge.

Le parallèle le plus proche de l'atelier des Rochereaux est l'atelier métallurgique de Sévaz à Tudinges (Suisse). Situé à $12 \mathrm{~m}$ de la zone d'habitat, il est daté du milieu du $\mathrm{V}^{\mathrm{e}}$ s. av. J.-C. L'espace réservé aux activités métallurgiques est de $40 \mathrm{~m}^{2}$. Il comporte plusieurs structures en creux et d'autres aménagements. Le travail de forge, qui était l'activité principale, a laissé $140 \mathrm{~kg}$ de déchets. L'activité de bronzier semble secondaire ; elle est attestée par la présence de fragments de creusets dans le remplissage d'une structure de combustion. Ce qui caractérise l'atelier métallurgique, ce sont les deux fosses, de 1,90 $\mathrm{m}$ de diamètre et d'environ $1 \mathrm{~m}$ de profondeur, à l'intérieur desquelles l'artisan forgeron aurait travaillé. Le centre de l'une de ces deux fosses est occupé par un comblement d'origine anthropique, en forme de dôme, provenant de dépôts successifs riches en déchets métallurgiques; il s'élève sur une cinquantaine de centimètres. Cette accumulation en dôme et les sédiments périphériques correspondent probablement à l'utilisation répétée de la zone centrale comme aire de combustion à vocation métallurgique (Mauvilly et al., 1998).

D'autre part, des témoins d'activité métallurgique (scories, fragments de moule de fonderie) ont été récupérés dans les foyers en place au fond des puits verticaux d'accès de certains souterrains armoricains. Ceux-ci, mis en service au cours du premier âge du Fer, ont perduré durant le second âge du Fer ; il semblerait que leur usage ait pu se raréfier ou cesser après 100 av. J.-C. (Giot et al., 1979, p. 292-301).

A. T. i M.

\section{L'APPROVISIONNEMENT EN COMBUSTIBLE : LE CHARBONNAGE}

L'étude anthracologique de la fosse-atelier permet d'aborder la question relative à l'approvisionnement en combustible pour la fabrication de flans monétaires à l'époque laténienne, dans le centre-ouest de la France ${ }^{14}$. De ce fait, on peut se poser trois questions : Quelles sont les espèces employées ? Quelle est leur provenance ? Y a-t-il eu des difficultés pour s'approvisionner?

Les prélèvements de sédiment ont été tamisés à jet doux sur une maille de $2 \mathrm{~mm}$. Les identifications ont été réalisées en se fondant sur les critères de la xylologie (Schweingruber, 1990 ; Vernet et al., 2001). Les dénombrements sont exprimés en nombre de charbons identifiés (N) par taxon (tabl. I). Les résultats, les deux spectres obtenus, permettent de constater que :

- la richesse taxonomique globale de 15 taxons anthracologiques est significative ( 7 et 14 taxons pour les spectres pris individuellement). Cet ordre de grandeur est conforme à ce qui est habituellement constaté dans les études de

14. Il existe peu de données anthracologiques relatives à la paléométallurgie et, plus particulièrement, à la fabrication de monnaies (Poirier, 1999 ; Dabas et al., 2002 ; Tereygeol, Dubois, 2003). 
Tabl. I - Dénombrements de charbons de bois par taxon.

\begin{tabular}{|c|c|c|c|c|c|}
\hline \multirow{2}{*}{ Taxon } & \multirow{2}{*}{ Type de dépôt } & \multicolumn{2}{|c|}{ Rejet d'activité } & \multicolumn{2}{|c|}{ Foyer } \\
\hline & & $\mathbf{N}$ & $\%$ & $\mathbf{N}$ & $\%$ \\
\hline Monocotyledonae & Monocotylédones & - & - & 1 & $1,8 \%$ \\
\hline Quercus sp. FC & chênes caducifoliés & 346 & $85,4 \%$ & 41 & $73,2 \%$ \\
\hline Quercus sp. FP & chênes sempervirents & 2 & $0,5 \%$ & - & - \\
\hline QFC/Castanea & chênes ou châtaignier & 3 & $0,7 \%$ & 1 & $1,8 \%$ \\
\hline Acer type campestre & érable type champêtre & 28 & $6,9 \%$ & 1 & $1,8 \%$ \\
\hline Acer type monspessulanum & érable type Montpellier & 1 & $0,2 \%$ & - & - \\
\hline Cornus sp. & cornouillers & 2 & $0,5 \%$ & - & - \\
\hline Corylus avellana & noisetier & 6 & $1,5 \%$ & 1 & $1,8 \%$ \\
\hline Fagus sylvatica & hêtre & 1 & $0,2 \%$ & - & - \\
\hline Ligustrum vulgare & troène & 1 & $0,2 \%$ & - & - \\
\hline Frangula alnus & bourdaine & 4 & $1,0 \%$ & - & - \\
\hline Populus sp. & peupliers & 1 & $0,2 \%$ & - & - \\
\hline Pomoïdeae & aubépines, poirier, pommier, cognassier & 1 & $0,2 \%$ & 2 & $3,6 \%$ \\
\hline Prunus sp. & pruniers & - & - & 1 & $1,8 \%$ \\
\hline Prunus type avium-padus & pruniers rayons étroits & 6 & $1,5 \%$ & 6 & $10,7 \%$ \\
\hline Prunus type mahaleb-spinosa & pruniers rayons larges & 2 & $0,5 \%$ & 2 & $3,6 \%$ \\
\hline Rhamnus cathartica & nerprun purgatif & 1 & $0,2 \%$ & - & - \\
\hline & Total & 405 & $100 \%$ & 56 & $100 \%$ \\
\hline & Nombre minimal de taxons & 14 & & 7 & \\
\hline
\end{tabular}

sites intégrés au domaine phytogéographique atlantique, à savoir entre 10 et 15 taxons (Marguerie, 1992 ; Pernaud, 1997 ; Poirier, 1999). En remarque, les taxons QFC/Castanea (chênes ou châtaignier) et Prunus sp. (pruniers sans précisions) témoignent des difficultés de détermination liées à des charbons de petites dimensions ;

- la contribution majoritaire aux spectres est due aux chênes caducifoliés ; celles des érables type champêtre, du noisetier et des prunoïdés peuvent être qualifiées de secondaires. Les taxons indicateurs des végétations hygrophiles (bords d'eau), tels que les aulnes, les frênes et les saules, ont une très faible contribution. Il en est de même pour le hêtre ;

- les listes taxonomiques présentent une cohérence écologique. L'ensemble des taxons peut appartenir aux végétations potentielles du secteur, et plus précisément aux chênaies pubescentes (tabl. II). Ceci est conforté par la présence d'espèces à affinité méditerranéenne dont les chênes sempervirents, taxon comprenant le chêne vert et l'érable de Montpellier.

À partir des conclusions concernant la cohérence écologique des spectres, on peut émettre l'hypothèse d'un approvisionnement en combustible privilégiant une végétation mésoxérophile correspondant à la série de végétation du chêne pubescent (Quercus pubescens). Cette dernière corres- pond en termes de série de végétation aux potentialités des alentours du site. Cette hypothèse est confortée par la structuration de l'assemblage anthracologique qui présente des similitudes avec ceux de Poitiers, situé à 5 km (Poirier, 1999 ; Poirier, Ali, 2003).

Le caractère répétitif, durant toute la durée d'activité de cette stratégie d'approvisionnement, est mis en évidence par la comparaison des données anthracologiques du foyer (US 1379 = 1383) avec celles issues des rejets d'activité (US 1389 et US 1399). Elles présentent qualitativement de grandes similitudes : six taxons communs et une majorité de charbons de chênes identifiés dans les deux cas (tabl. I). Les différences de pourcentage des taxons observées entre le foyer et les couches de rejets peuvent s'expliquer par un temps de formation différent pour ces deux types de dépôts. Le premier est court. Il correspond à une ou plusieurs charges de combustible. Le second est long et permet l'accumulation des résidus de combustion de plusieurs feux. De ce fait, le premier a un caractère instantané, sujet potentiellement à des variations si les fonctionnements pouvaient être distingués et comparés alors que les dépôts enregistrant plusieurs vidanges constituent une «moyenne » inscrite dans la durée de l'activité. Ce principe a déjà été décrit pour des dépôts dont les charbons étaient issus d'usages domestiques (Chabal, 1997). 
Tabl. II - Végétations correspondant aux deux principaux habitats présents dans les environs du site.

\begin{tabular}{|l|l|l|}
\hline \multicolumn{1}{|c|}{ Secteur géographique } & Occupation actuelle du sol & \multicolumn{1}{|c|}{ Série de végétation potentielle et types d'habitats « naturels » } \\
\hline $\begin{array}{l}\text { Plateaux calcaires (Callovien) : } \\
\text { zone d'implantation du site }\end{array}$ & $\begin{array}{l}\text { Bois morcelés, vigne et champs } \\
\text { cultivés }\end{array}$ & $\begin{array}{l}\text { Chênaies du collinéen atlantique calciclines : chênaie-(hêtraie) pubescente avec } \\
\text { présence d'espèces xérothermophiles (ex.: érable de Montpellier et les fiches } \\
\text { Znieff de la DIREN du Poitou-Charentes concernant les coteaux de Chassac, les } \\
\text { carrières de la Pierre Levée et le Bois de Paché). La présence d'une station de } \\
\text { chênes verts en aval du site archéologique (5 km) est à noter. }\end{array}$ \\
\hline $\begin{array}{l}\text { Alluvions récentes du lit de } \\
\text { l'Auxances (= fond de vallée) }\end{array}$ & $\begin{array}{l}\text { Prairies de fauche, plantations, } \\
\text { vignes, vergers, zones maraîchères }\end{array}$ & $\begin{array}{l}\text { Forêts alluviales à Alnus glutinosa et Fraxinus excelsior (Alno-Padion, Alnion } \\
\text { incanae, Salicion albae). }\end{array}$ \\
\hline
\end{tabular}

La nature de l'activité induit l'emploi de charbons. Ceci est compatible avec la contribution majoritaire d'espèces arborescentes (chênes et érables) permettant d'obtenir un bon rendement en charbons. À titre d'exemple, les chênes sont recensés dans l'étude de charbonnières (Dubois, 1990 ; Fabre, 1996 ; Nelle, 2002) et les érables sont présents de manière significative dans le sud de l'Allemagne (Ludemann, 2002). On retrouve aussi ce taxon dans les activités liées au travail de forge du fer en Angleterre (Fulford, Allen, 1992), en France dans le Gard (Maufras et al., 1998) ou l'Aude (Passelac et al., 1998). Mais pour le site de Migné-Auxances leur emploi n'est pas exclusif. Les espèces secondaires, en termes de contribution, peuvent correspondre soit à leur présence dans les zones d'approvisionnement, soit à du menu bois nécessaire au démarrage $\mathrm{du}$ feu. Ces constats sont donc conformes aux conclusions qui peuvent être tirées d'autres études abordant la paléométallurgie (travail du fer en particulier), à savoir : l'usage d'espèces contribuant aux végétations locales dont certaines permettent d'obtenir, en abondance et de manière régulière, les calibres nécessaires pour un bon rendement (Briane, Doat, 1985 ; Eschenlohr et al., 1991 ; Espérou et al., 1994 ; Dunikowski, Cabboi, 1995 ; Rovira, 1998 ; Marziani, Citterio, 1999 ; Dabas et al., 2002).

En conclusion, les restes prélevés dans l'espace de la fosse-atelier témoignent des faits suivants : les modalités d'approvisionnement en charbons soulignent le caractère local de celui-ci, sans doute porteur d'une végétation calcicline (chênaie pubescente) ; il n'y a pas eu de difficultés pour disposer de combustible; les espèces caractéristiques des friches ne forment pas en termes d'abondance la contribution majoritaire (Dupias, Vilks, 1979 ; Baron et al., 1982 ; Baron, 1996) ; en outre, la régularité dans la nature de la source d'approvisionnement conforte cette interprétation. Les espèces ayant des contributions majoritaires (chênes et érables) dans les spectres anthracologiques permettent d'obtenir aisément du charbon de bois.

\section{ÉTUDE TECHNOLOGIQUE DES FLANS MONÉTAIRES ET DES MONNAIES}

Des analyses ont été effectuées sur neuf échantillons, prélevés sur sept flans monétaires et deux monnaies. Les flans monétaires peuvent se trouver encore en chapelet de deux à quatre flans, alors que les monnaies sont bien entendu individuelles. Il est à noter aussi la présence d'un jet de coulée sur un des échantillons; ceci nous prouve que nous sommes bien en présence d'un objet en cours de fabrication.

Sur la figure 7 sont reportés les objets analysés, les prélèvements effectués à l'aide d'une scie d'horloger, ainsi que les micrographies des coupes de ces prélèvements. Il est très important de noter le côté du prélèvement que l'on observe en métallographie, car la microstructure doit être directement reliée aux observations macroscopiques afin d'en retirer le maximum d'informations technologiques.

\section{ANALYSE ÉLÉMENTAIRE}

La méthode EDXS (analyse par dispersion d'énergie des rayons X) couplée au MEB (microscope électronique à balayage) a été utilisée pour les analyses élémentaires des objets métalliques. Sur le tableau III et les figures 8 et 9 sont reportées les analyses élémentaires effectuées ; les éléments traces avec des teneurs inférieures à $0,5 \%$ n'ont pas été retranscrits ; seules des traces d'argent et de soufre ont été trouvées dans la corrosion interne de l'échantillon 1388-1 et des traces de fer dans la corrosion interne de l'échantillon 1376-3. Le carbone et l'oxygène, qui sont détectés mais ne peuvent être parfaitement quantifiés par l'analyse EDXS (leur numéro atomique étant trop faible), n'ont pas non plus été retenus dans le tableau. En effet, d'une part, la majorité de l'oxygène détecté provient de l'oxydation en surface de l'échantillon, principalement due à l'attaque chimique utilisée pour révéler la microstructure et, d'autre part, le carbone provient principalement de pollutions (vide P. P. non parfait, traces de doigts, etc.). Nous avons fait ce choix 

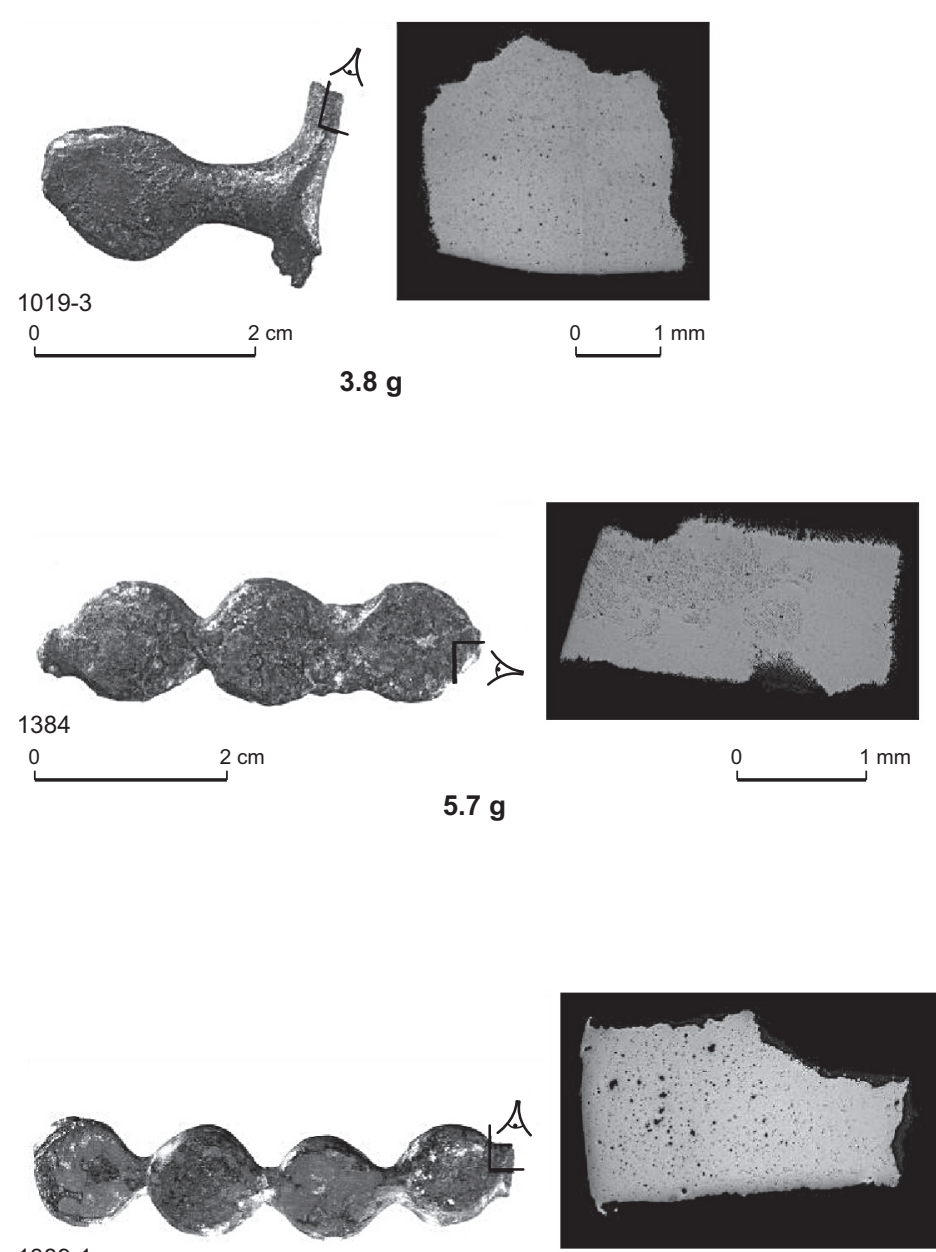

1389-1

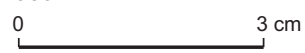

$6.3 \mathrm{~g}$

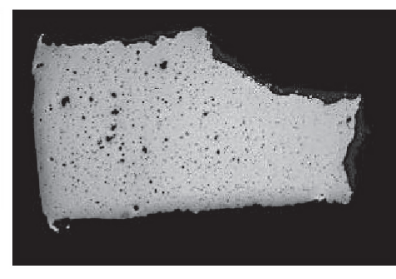

$\underbrace{0 \quad 1 \mathrm{~mm}}$
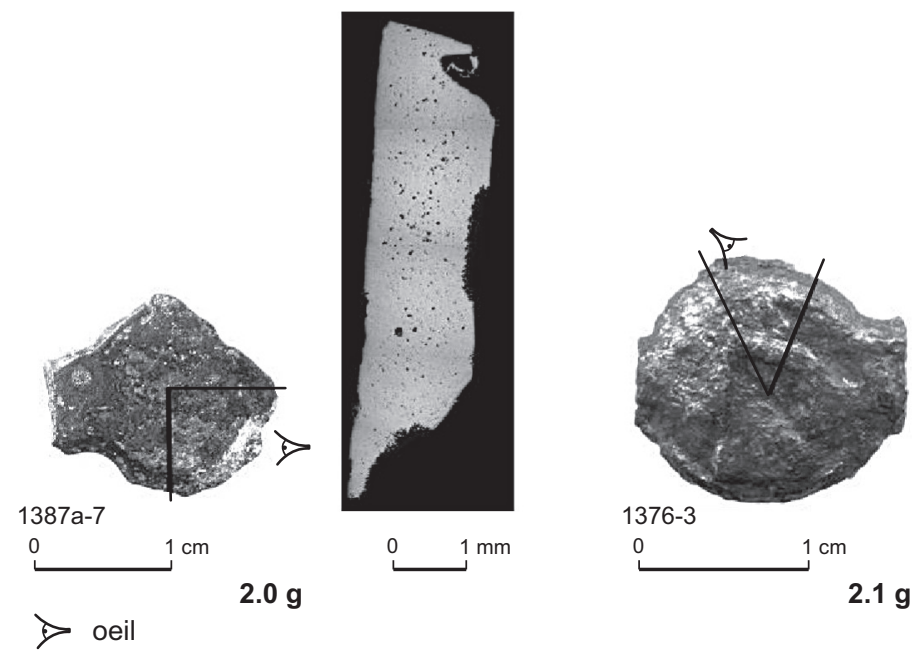

$2.1 \mathrm{~g}$

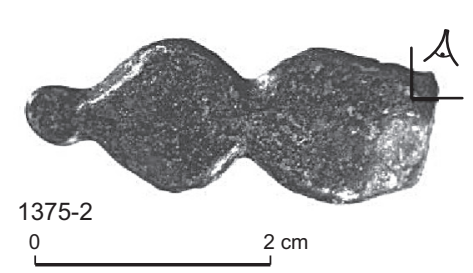

$4.3 \mathrm{~g}$
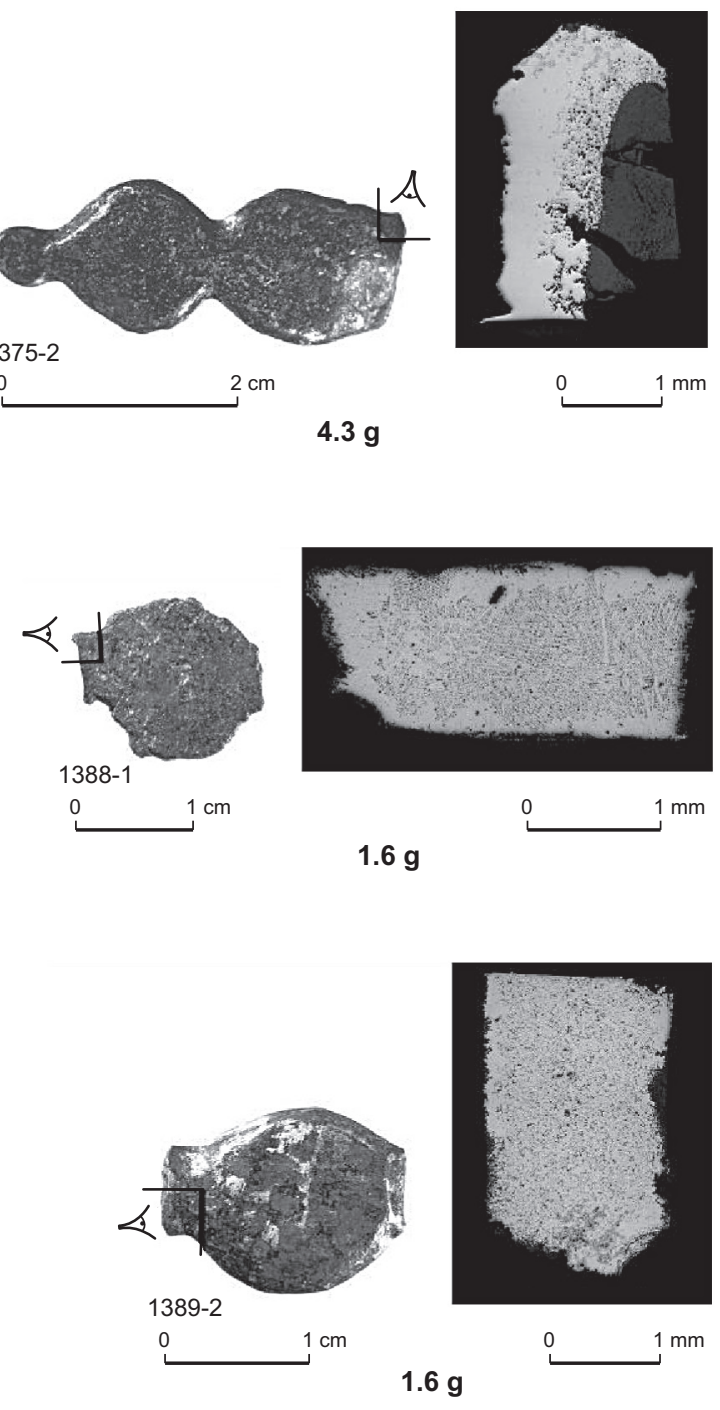

$1 \mathrm{~cm}$
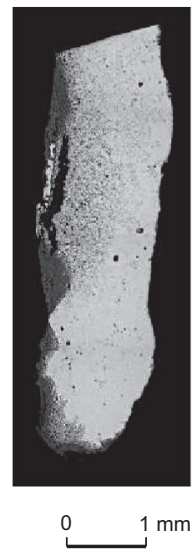

0

Fig. 7 - Flans monétaires et monnaies (les trois derniers objets présentés) : découpes et micrographies des échantillons (clichés : flans P. Ernaux, INRAP; micrographies F. Adamski, CNRS-IRAMAT). 
Tabl. III - Compilation des informations relatives aux monnaies et flans pris en considération dans les études technologique et numismatique. Il s'agit toujours d'alliages binaires cuivre-étain qui sont caractérisés par la seule teneur en étain ; les mesures notées * ont été réalisées à l'IRAMAT-Orléans, celles notées ** à l'IRAMAT-Bordeaux; la notation (ci) après la mesure indique qu'une corrosion interne a été observée. Pour obtenir le poids d'un individu dans un chapelet, le poids total a été divisé par le nombre des flans qui le constituent, sachant que l'opération de séparation ne comportait aucun rebut sinon celui du pédoncule de coulée (pour cette raison, nous n'avons pas tenu compte

de 1019-3, flan encore solidaire du pédoncule de coulée).

\begin{tabular}{|c|c|c|c|c|c|c|}
\hline Provenance & Type & Référence & $\begin{array}{c}\text { Teneur en étain } \\
\text { de l'alliage } \\
\text { (\% massique) }\end{array}$ & $\begin{array}{l}\text { Diamètre } \\
(\mathrm{mm})\end{array}$ & $\begin{array}{l}\text { Épaisseur } \\
\quad(\mathrm{mm})\end{array}$ & $\begin{array}{l}\text { Poids } \\
\text { (g) }\end{array}$ \\
\hline \multirow[t]{6}{*}{$\mathrm{BnF}$} & & 4298 & $11,1^{*}$ & 16 & - & 2,62 \\
\hline & & 4299 & $17,1^{*}$ & 18 & - & 3,29 \\
\hline & & 4300 & $11,5^{*}$ & 18 & - & 2,42 \\
\hline & & 4301 & 11,2 * & 17 & - & 3,11 \\
\hline & & 4302 & 10,4 * & 16 & - & 1,95 \\
\hline & & 4303 & $12,2^{*}$ & 15 & - & 1,88 \\
\hline Bourges (musée) & & D.965.1.4902 & - & - & - & 1,70 \\
\hline Zurich (musée) & & SLM 703 & - & 16 & - & 2,64 \\
\hline Lyon (musée) & & 658 & - & - & - & 3,39 \\
\hline Niort & & - & - & - & - & 1,40 \\
\hline Mouliets & & - & - & - & - & 1,38 \\
\hline Mouliets & & - & - & - & - & 2,77 \\
\hline Les Alleuds & & - & - & - & - & 2,49 \\
\hline \multirow[t]{33}{*}{ Migné-Auxances } & \multirow[t]{5}{*}{ Monnaies } & $1007-2$ & - & $16,5-14$ & - & 1,8 \\
\hline & & 1253 & - & $17-13$ & - & 2,4 \\
\hline & & 1350 & - & $15-14$ & - & 1,6 \\
\hline & & $1376-3$ & $10,2(\mathrm{ci})$ ** & $16-14$ & $1,3^{* *}$ & 2,1 \\
\hline & & 1397 & $13,1^{\text {** }}$ & $15-12$ & $1,4^{* *}$ & 1,1 \\
\hline & \multirow[t]{20}{*}{ Flans isolés } & $1007-1$ & - & $14-13,5$ & - & 2,09 \\
\hline & & $1019-3$ & $9,1^{* *}$ & $15-11,5$ & - & 3,6 \\
\hline & & $1373-2$ & - & $17,5-13,5$ & - & 1,97 \\
\hline & & 1374 & - & $15-13$ & - & 1,75 \\
\hline & & $1376-1$ & - & $15,5-13,5$ & - & 2,16 \\
\hline & & $1376-2$ & - & $15-12$ & - & 1,50 \\
\hline & & 1385 & - & $11,5-10,5$ & - & 1,42 \\
\hline & & $1388-1$ & 12,3 (ci) ** & $16,5-13$ & $1,4^{* *}$ & 1,6 \\
\hline & & $1388-2$ & - & $15-13$ & - & 1,66 \\
\hline & & $1389-2$ & 12,1 (ci) ** & $16-12$ & $1,5^{* *}$ & 1,6 \\
\hline & & $1389-3$ & - & $14-13$ & - & 1,58 \\
\hline & & $1389-4$ & - & 14 & - & 1,98 \\
\hline & & $1389-5$ & - & $16-14,5$ & - & 3,404 \\
\hline & & 1389a-6 & - & $14-12$ & - & 1,52 \\
\hline & & 1389a-7 & $11,2^{* *}$ & $17,5-14$ & $1,4^{* *}$ & 2 \\
\hline & & 1389a-8 & - & $16-13$ & - & 1,79 \\
\hline & & 1389a-9 & - & $15-13$ & - & 2,086 \\
\hline & & $1405-5$ & - & $16-14$ & - & 2,135 \\
\hline & & $1408-1$ & - & $15,5-13,5$ & - & 1,89 \\
\hline & & $1408-2$ & - & $14-12$ & - & 2,456 \\
\hline & \multirow[t]{8}{*}{ Chapelets } & $1373-1(2)$ & - & $15-13$ & - & 2,18 \\
\hline & & $1375-1(2)$ & - & $16-13,5$ & - & 2,12 \\
\hline & & $1375-2(2)$ & $5,8^{* *}$ & $13,5-12,5$ & $1,8^{* *}$ & 2,15 \\
\hline & & $1376-4(2)$ & - & $14,5-14$ & - & 2,02 \\
\hline & & $1376-5(2)$ & - & $15-14$ & - & 1,88 \\
\hline & & $1384(3)$ & $13,5(\mathrm{ci})^{* *}$ & $14-13$ & $1,3^{* *}$ & 1,9 \\
\hline & & $1389-1(4)$ & $10,1^{* *}$ & $15-12,5$ & $1,3^{* *}$ & 1,57 \\
\hline & & $1392(2)$ & - & 12 & - & 1,65 \\
\hline
\end{tabular}




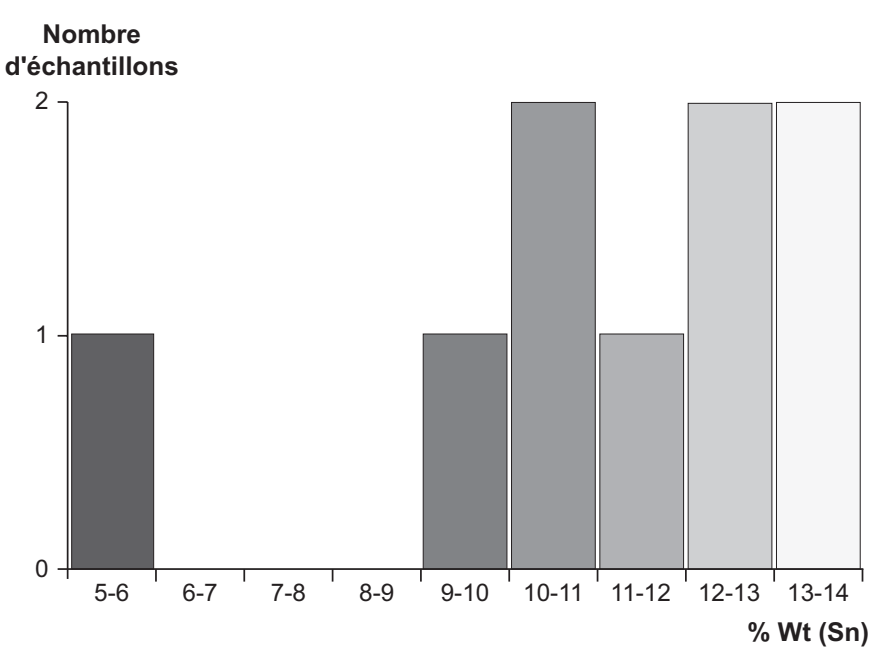

Fig. 8 - Répartition des flans et monnaies en fonction de leur teneur en étain.

de présentation des résultats afin de comprendre la recette utilisée par l'artisan et pour apprécier la qualité du métal produit, et les teneurs en éléments traces (moins de $0,5 \%$ ) ne résultent certainement pas de la volonté de l'artisan. Le but est donc de retrouver le choix technologique de l'artisan bronzier qui a conçu ces monnaies.

En recoupant ces analyses élémentaires avec les premières observations au microscope optique (avant attaque chimique), il est possible de dire que le métal utilisé est un bronze (alliage cuivre-étain), très propre du fait qu'il n'y a que peu de porosité et très peu d'inclusions d'oxyde et de sulfure de cuivre. Nous pouvons également remarquer l'absence de toute trace de plomb, élément très courant sous forme de nodules dans les bronzes, qui leur confère moins de plasticité. Il est possible que cette absence totale de plomb soit un choix délibéré de la part de l'artisan afin de disposer d'un flan qui se frappe plus facilement. Il nous apparaît en effet de plus en plus probable que les artisans de cette époque possédaient un choix d'alliages de diverses qualités, et les choisissaient en fonction de leurs besoins. Il semble ainsi logique de trouver un métal très propre (peu pollué) pour fabriquer des monnaies.

En dépouillant ensuite les résultats analytiques, nous pouvons observer une certaine dispersion dans la composition élémentaire des différents échantillons. En effet, ces flans monétaires et monnaies ont été coulés à partir de bronzes contenant de $6 \%$ à $14 \%$ d'étain (fig. 8). Cependant, cette dispersion dissimule certainement une seule et même recette d'alliage. D'abord, on peut considérer que l'échantillon à $6 \%$ est une anomalie, du fait que tous

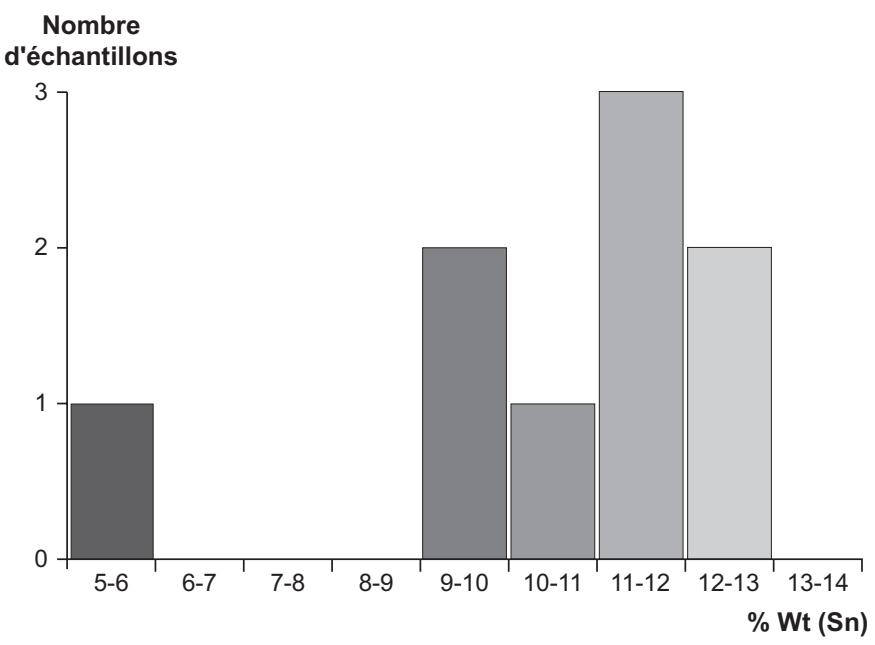

Fig. 9 - Répartition des flans et monnaies en fonction de leur teneur en étain avec une correction des résultats pour les échantillons ayant de la corrosion interne.

les autres sont compris entre $9 \%$ et $14 \%$ d'étain. Ensuite, cinq des échantillons analysés possèdent leur seconde phase corrodée. Même s'il est difficile de chiffrer l'erreur induite par cette corrosion interne de la seconde phase, qui entraîne une surestimation de la teneur en étain, quelques mesures sur des coupes d'échantillons ayant certaines zones corrodées et d'autres qui en sont dépourvus nous ont démontré que cette erreur peut être évaluée entre $1 \%$ et $2 \%$. Si on réévalue par une baisse de $1 \%$ les échantillons corrodés, nous obtenons des résultats analytiques encore plus homogènes (fig. 9).

En outre, dans la fourchette de teneurs en étain considérée, la couleur varie peu (quelques nuances de couleur dorée) et la recherche des propriétés mécaniques n'a pas besoin d'être nécessairement très poussée dans le cas présent ; la seule passe de déformation que subit le flan par la suite est la frappe de la monnaie, ce qui n'induit pas beaucoup de déformation en comparaison des passes de martelage. De ce fait, l'artisan n'a pas besoin d'une très grande précision dans la réalisation du mélange et peut donc introduire l'étain au jugé dans le cuivre en fusion. Il est également possible que cette dispersion provienne d'un recyclage d'autres objets de bronze dont la composition n'est pas forcément maîtrisée par l'artisan, bien qu'il en connaisse la propreté (notamment l'absence de plomb).

Ainsi, malgré la dispersion des résultats, les analyses des flans monétaires et des monnaies ne contredisent pas le fait qu'ils peuvent provenir d'un même atelier et que les monnaies peuvent avoir été frappées à partir des flans monétaires retrouvés sur le site. 


\section{ÉTUDE MÉTALLOGRAPHIQUE}

Afin d'en savoir plus sur la technique de mise en forme des flans monétaires et des monnaies, nous avons également procédé à une étude des microstructures des coupes des échantillons sélectionnés, selon les méthodes de la métallographie classique (Pernot, 1999). Nous avons ainsi effectué une attaque chimique par une solution de perchlorure ferrique alcoolique diluée sur les échantillons préalablement polis jusqu'à une granulométrie de $0,25 \mu \mathrm{m}$. Ceci a pour but d'accentuer certains défauts du métal ; les joints de grains, de macles et les concentrations différentes en étain, qui sont attaqués différemment, peuvent ressortir et ainsi laisser apparaître la microstructure de l'alliage. Les coupes polies et attaquées peuvent ensuite être observées au microscope optique.

Il est apparu que pratiquement tous les échantillons présentent une microstructure dendritique, caractéristique des bronzes bruts de fonderie (fig. 10). Il n'y a donc aucun doute que ces objets aient été moulés. Seuls les échantillons 1375-2 et 1389-1 contiennent une zone qui a recristallisé (fig. 11). Cette partie de la surface de la coupe correspond, pour les deux échantillons, à l'endroit où un outil (probablement un burin) est venu séparer le flan du chapelet, c'est-à-dire à l'endroit où ils ont subi une forte déformation plastique. Or, le bronze ne recristallise que s'il a subi une déformation plastique suffisante (ici le coup de l'outil) et s'il a été par la suite recuit à une température minimale de $500^{\circ} \mathrm{C}$. On peut se demander ici quel a été le but de ce recuit. En effet, l'intérêt de recuire un métal déformé est de lui rendre sa plasticité d'origine, car il durcit lors de cette déformation (on parle alors d'écrouissage). Dans le cas présent, la déformation n'est pas assez importante pour écrouir le métal de manière à le rendre cassant, et donc nécessiter un recuit. Cependant, il est possible que l'artisan bronzier, qui connaît empiriquement l'effet d'un recuit sur l'alliage cuivreux, ait décidé de l'appliquer au flan afin de radoucir le métal et qu'il y ait ainsi moins de risque de fissuration lors de la frappe de la monnaie.

Nous pouvons observer sur tous les échantillons des macles mécaniques (dites aussi macles de déformation), qui apparaissent sous la forme de fines stries dans les grains, caractéristiques de la déformation à froid. Pour les flans monétaires, on les observe sur une faible profondeur, de l'ordre de quelques centaines de micromètres (fig. 12). Ceci correspond à de très faibles déformations pouvant résulter par exemple d'un fort polissage. Il est alors important de remarquer que les zones maclées des flans n'ont pas recristallisé, alors que l'on vient de mettre

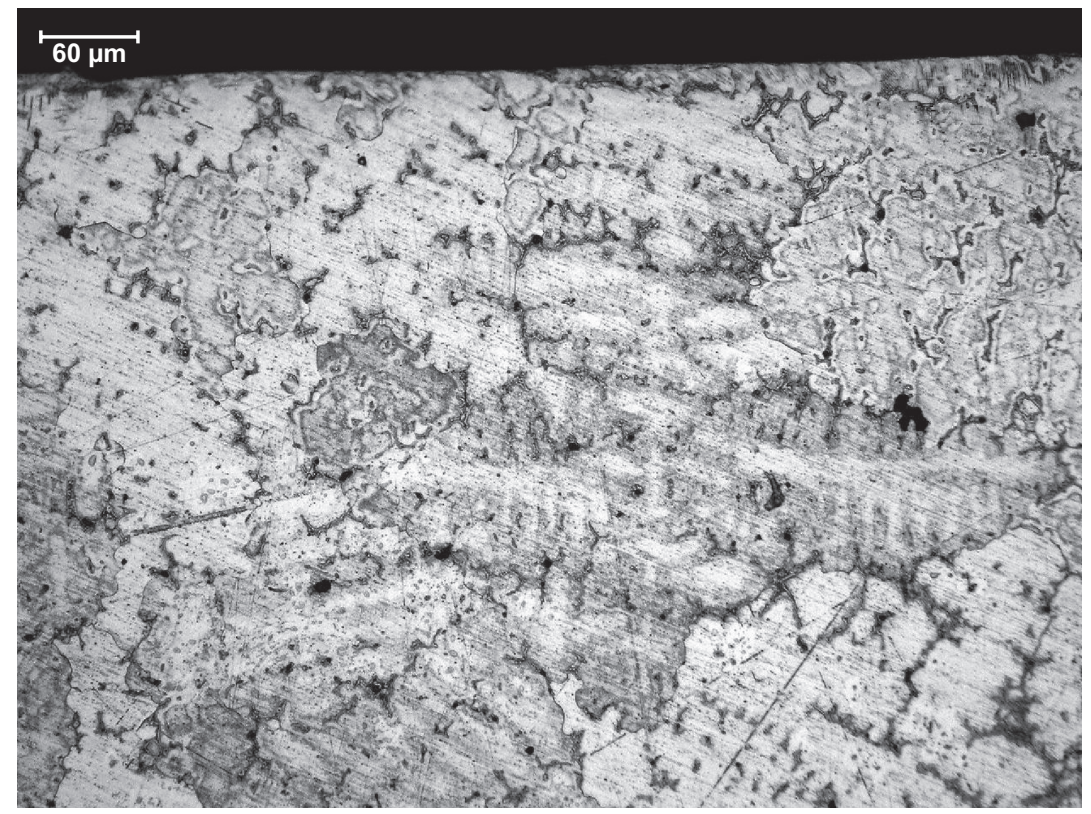

Fig. 10 - Microstructure dendritique de l'échantillon 1019-3. On observe bien la ségrégation intradendritique, c'est-à-dire le gradient de teneur en étain, qui se traduit par un gradient de couleur sur la micrographie. Cet échantillon est donc brut de fonderie (micrographie : F. Adamski, CNRS-IRAMAT). 


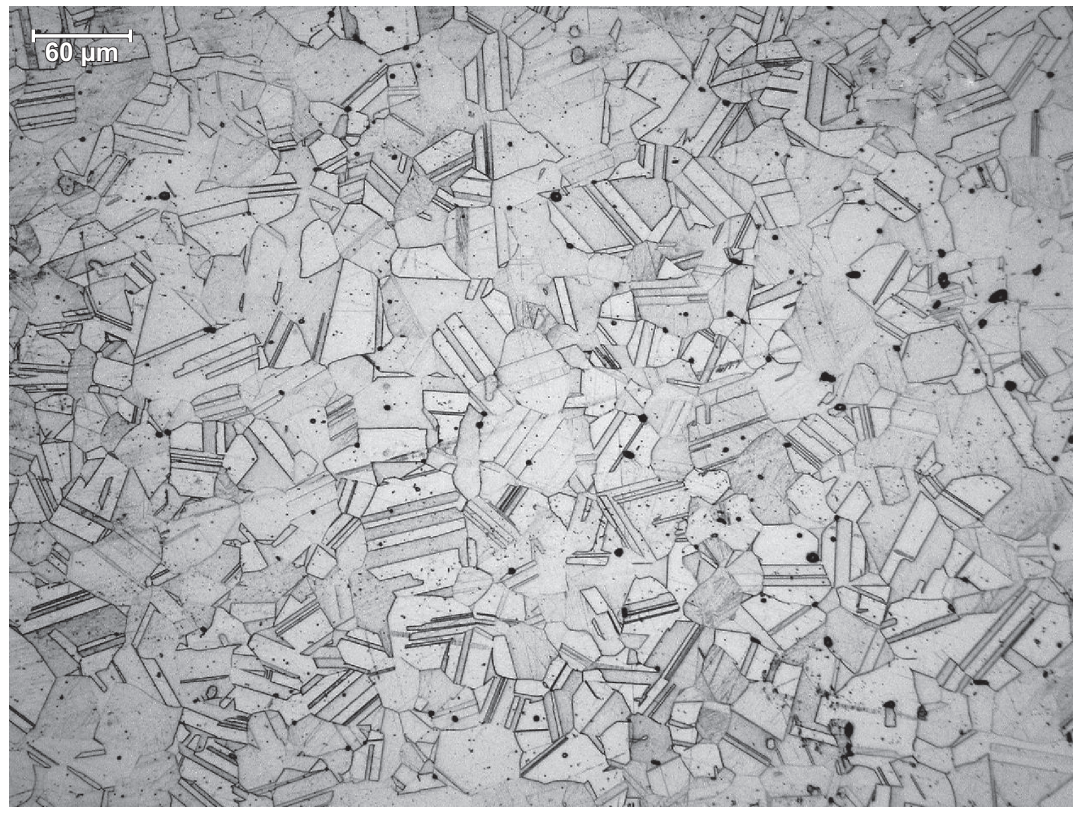

Fig. 11 - Microstructure en grains polygonaux observée sur un plan de coupe du flan 1389-1. Ceci correspond à une recristallisation du bronze après déformation plastique et recuit (micrographie : F. Adamski, CNRS-IRAMAT).

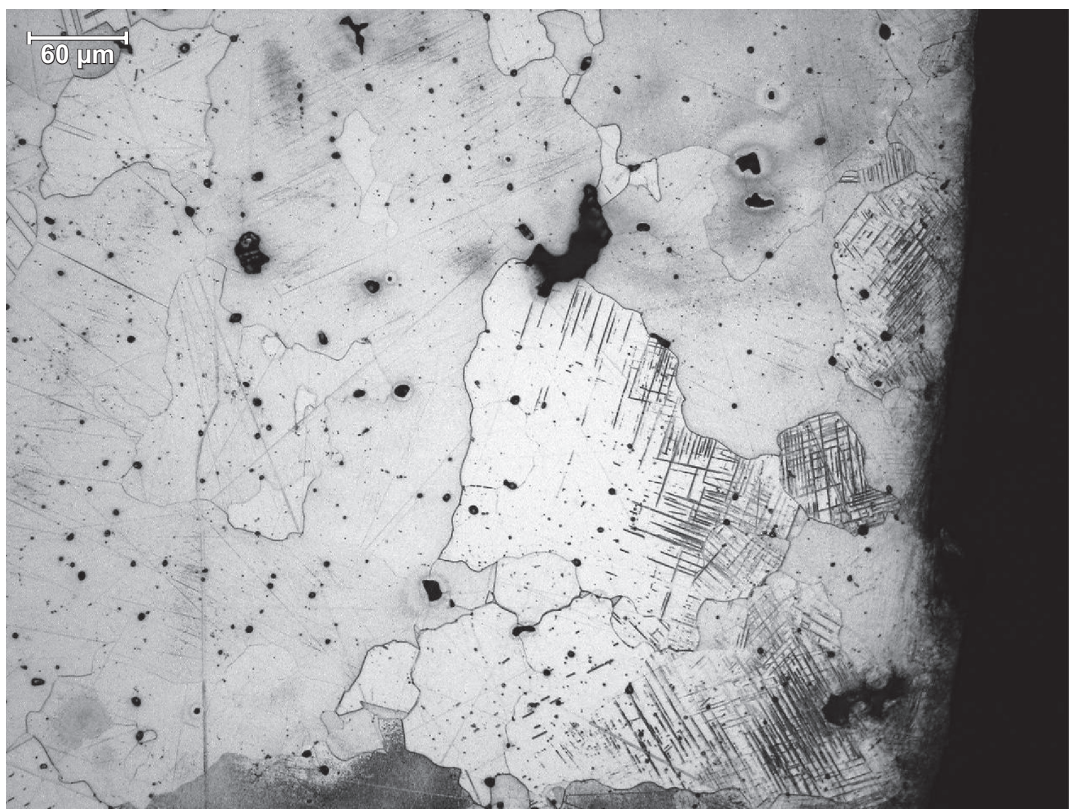

Fig. 12 - Microstructure de l'échantillon 1389-1, observée sur une plage différente de celle de la fig. 11. Les fines stries, présentes en bas à droite, sont des macles mécaniques qui témoignent d'une faible déformation plastique; elles sont présentes seulement sur une faible profondeur dans ce cas (micrographie : F. Adamski, CNRS-IRAMAT). 


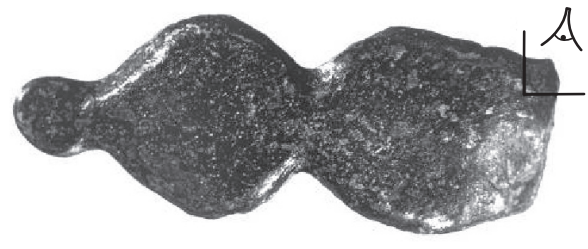

$1375-2$

0

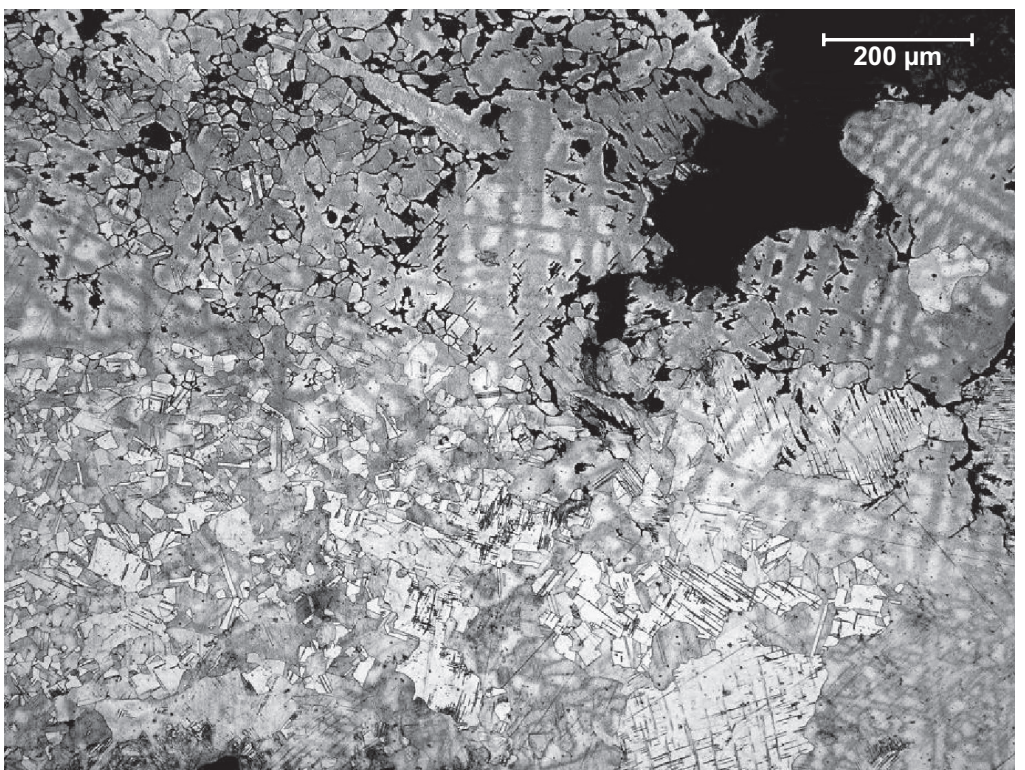

Fig. 13 - Microstructure de l'échantillon 1375-2. On observe à la fois la partie recristallisée (en bas à gauche) et la partie non recristallisée contenant encore la ségrégation dendritique (en haut à droite). La partie recristallisée correspond à la zone touchée par la déformation plastique. Les plus gros grains contenant encore une ségrégation correspondent aux grains dendritiques qui ont commencé à s'homogénéiser sous l'effet du recuit (il n'y a pas de seconde phase visible) (micrographie : F. Adamski, CNRS-IRAMAT; cliché du flan : P. Ernaux, INRAP).

en évidence le fait qu'un recuit était effectué avant la frappe de la monnaie. Cependant, comme nous l'avons vu plus haut, lorsque l'on observe les coupes des flans déformés par l'outil, on remarque que la surface de la coupe de l'échantillon n'a pas recristallisé dans sa totalité. Seules les parties ayant subi le plus de déformation ont pu recristalliser (fig. 13). En effet, pour une même durée et une même température de recuit, le métal recristallisera d'autant plus vite qu'il a été fortement déformé. Ainsi, avec un recuit court ou à une température peu élevée, les parties peu écrouies ne recristalliseront pas. Sur les flans qui ont seulement été polis, il est possible qu'un recuit court à une faible température n'affecte pas de manière visible la microstructure. Il aurait fallu une température supérieure ou un temps de recuit plus long pour pouvoir activer le processus de recristallisation. Autre hypothèse : il se peut que les autres flans polis n'aient pas encore été recuits lors de leur abandon sur le site. En revanche, les grains dendritiques visibles sur les coupes des monnaies possèdent de très nombreuses macles mécaniques, sur toute l'épaisseur de l'échantillon (fig. 14 et fig. 15), correspondant à de plus grandes déformations. Il est donc fort probable que la monnaie ait été frappée à froid à partir d'un flan monétaire tels ceux que nous avons étudiés ici.

\section{ÉTUDE MACROSCOPIQUE}

Nous avons également procédé à des observations macroscopiques des flans et des monnaies. Tout d'abord, l'échantillon 1019-3 possède encore un jet de coulée, caractéristique que l'on retrouve principalement sur un modèle initial en cire (fig. 7). En outre, si ces chapelets avaient été coulés en moules permanents, on observerait des traces de bavure au niveau du joint séparant les deux parties du moule, or ce n'est pas le cas dans le contexte présent. Nous pouvons ainsi supposer que les chapelets ont été coulés grâce au procédé de la cire perdue. Il est en revanche possible de se demander si les chapelets initiaux de cire ont eux-mêmes été moulés. Pour cela, nous avons étudié plusieurs paramètres macroscopiques (diamètre, épaisseur des flans, forme des sections). D’abord, en étudiant les épaisseurs des chapelets et les diamètres des flans, nous pouvons nous apercevoir qu'il y a une certaine homogénéité dans les résultats (tabl. III). L'épaisseur des flans et des monnaies se situe entre $1,3 \mathrm{~mm}$ et $1,5 \mathrm{~mm}$, si l'on considère toujours que l'échantillon 1375-2 est une anomalie (il a une épaisseur de $1,8 \mathrm{~mm}$ ). Le diamètre des flans se situe entre $1,3 \mathrm{~cm}$ et $1,5 \mathrm{~cm}$. Ces objets semblent donc suivre une certaine norme de fabrication. Cependant, lorsque l'on observe les formes proprement dites des chapelets (en effet, les flans ne sont pas ronds comme il est possible de le voir 


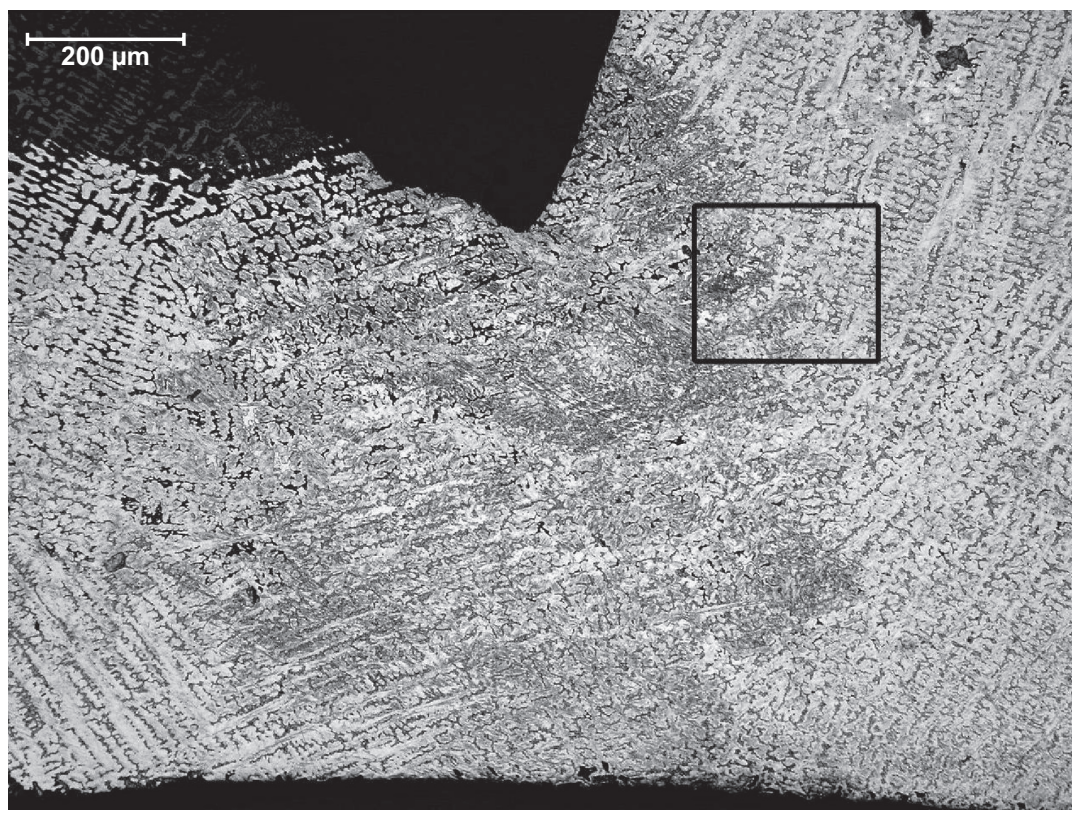

Fig. 14 - Macles mécaniques observées sur toute l'épaisseur de l'échantillon 1397 (monnaie) (micrographie: F. Adamski, CNRS-IRAMAT).

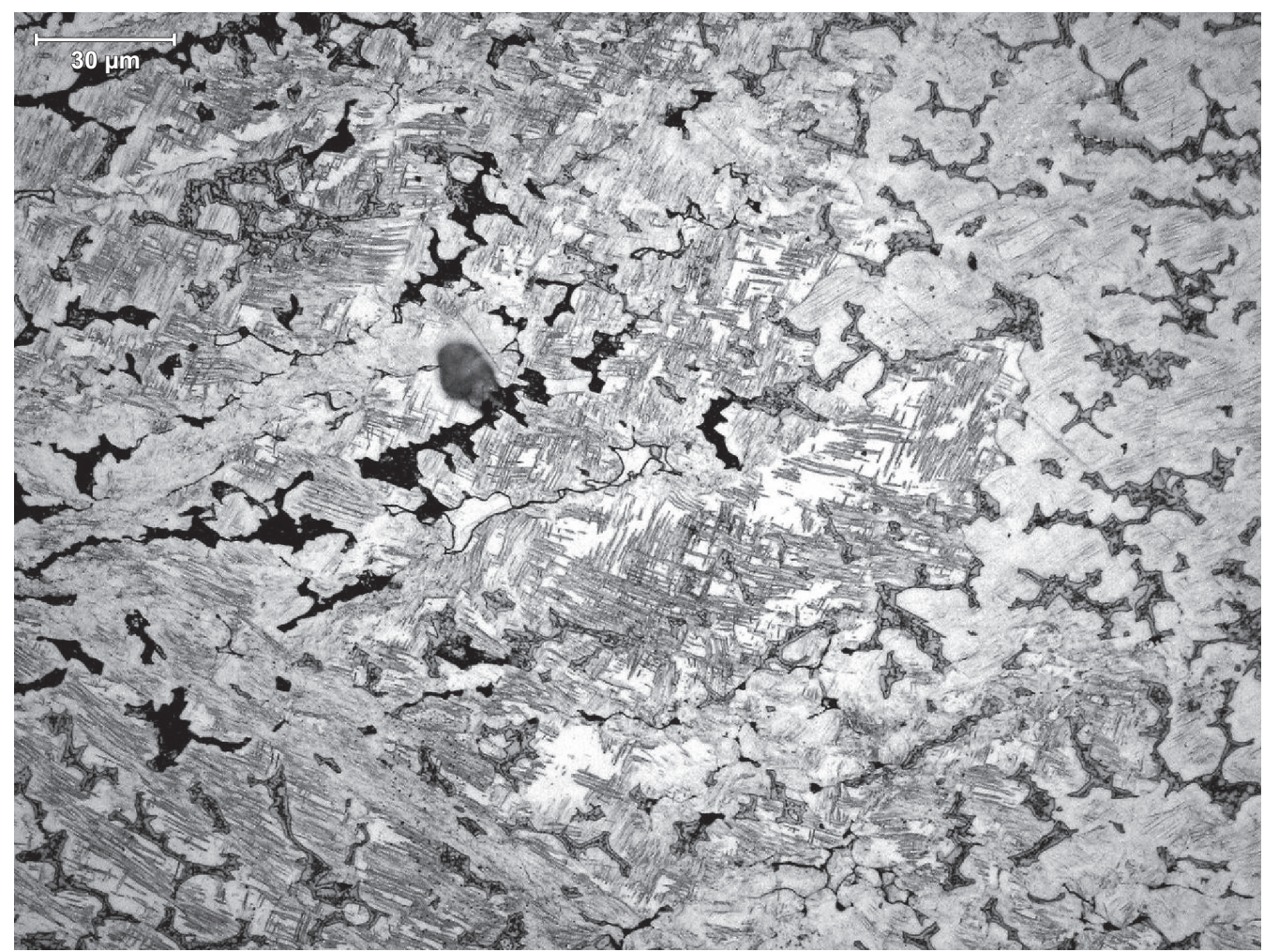

Fig. 15 - Détail de la figure 14 : macles mécaniques observées sur l'échantillon 1397 (monnaie) (micrographie: F. Adamski, CNRS-IRAMAT). 


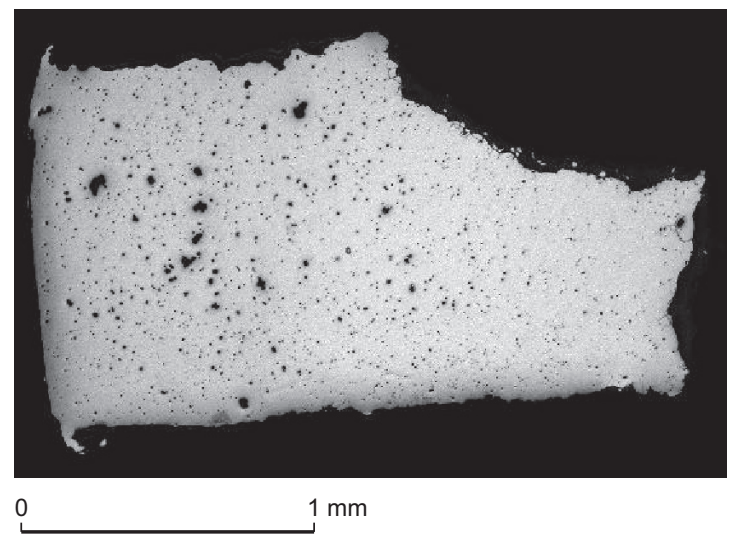

Fig. 16 - Trace du burin qui a séparé le flan du bout du chapelet sur l'échantillon 1389-1 (micrographie : F. Adamski, CNRS-IRAMAT).

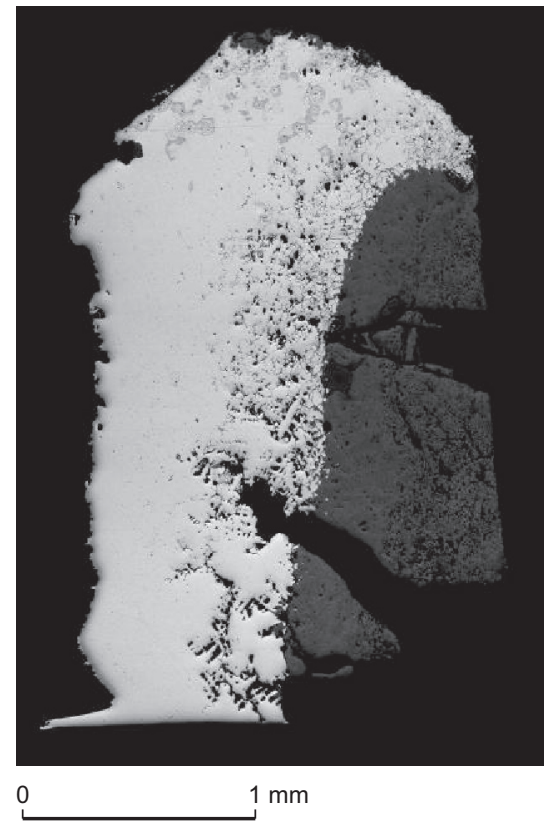

Fig. 17 - Faciès de la cassure de l'échantillon 1375-2 (micrographie : F. Adamski, CNRS-IRAMAT).

sur la fig. 7), il est difficile de trouver une correspondance entre tous. Ensuite, si l'on s'intéresse aux sections en coupe des monnaies et des flans, on peut retrouver une forme plutôt trapézoïdale. Or, si la cire avait été simplement coulée en moule ouvert, on pourrait s'attendre à la présence d'un ménisque due au mouillage de la cire liquide sur le moule. Il est cependant possible que les chapelets aient été façonnés à l'aide d'un moule (peut-être en bois) lorsque la cire était encore à l'état pâteux. Dans ce cas, c'est cette opération qui permet de calibrer le poids des flans, les densités de la cire et du métal étant directement proportionnelles.
Nous pouvons également observer le profil des cassures au niveau de la séparation du flan et du chapelet, afin d'avoir une idée de l'outil utilisé à cet effet. Le profil le plus éloquent correspond à la coupe du flan 1389-1 sur lequel on peut observer la trace de l'outil (fig. 16). On peut penser que le chapelet était posé à plat sur un support certainement solide (pierre, bois) et qu'un instrument du type burin (par exemple l'outil en fer de l'US 1389b) est venu indenter par percussion indirecte le métal à l'endroit voulu. Sur la section de la coupe du flan 1989-1, on remarque très nettement l'écrasement du métal dont l'épaisseur a diminué de moitié après la séparation. L'extrémité du burin avait probablement une largeur se situant entre $1 \mathrm{~mm}$ et $2 \mathrm{~mm}$. En observant les cassures des autres flans sans coupe, il est possible d'observer de manière macroscopique le même type de faciès de rupture. Seul l'échantillon 1375-2 semble détonner par rapport aux autres avec une cassure qui est totalement différente (fig. 17). Ceci est peut-être dû à la forte proportion de corrosion présente, et la forme très courbée du chapelet nous indique qu'il a probablement souffert et été déformé pour des raisons parfaitement inconnues. Il est à noter qu'il s'agit toujours de l'échantillon dont la teneur en étain est de $6 \%$, l'épaisseur de $1,8 \mathrm{~mm}$ et que nous l'avions déjà considéré comme une anomalie.

\section{DISCUSSION}

Nous sommes à présent en mesure de proposer un protocole de fabrication des flans monétaires et des monnaies retrouvés à Migné-Auxances. Sur la figure 18 est schématisée la fabrication des monnaies par la méthode de la cire perdue, reconstituée en partie à l'aide du mobilier retrouvé sur le site des Rochereaux.

Des modèles de chapelets sont d'abord façonnés en cire (1). Un entonnoir et des jets de coulée sont ensuite ajoutés et les chapelets sont assemblés en grappe (2). Le moule est ensuite façonné par application de couches successives de terre délayée autour du modèle de cire (3). Le tout est enfin chauffé, ce qui permet au moule de cuire et à la cire liquéfiée de s'écouler par l'entonnoir de coulée (4). Il ne reste alors plus que l'empreinte dans le moule (5), à l'intérieur duquel peut ensuite être coulé le bronze en fusion. Lorsque le métal est refroidi (6), l'artisan casse le moule (7) et n'a plus qu'à retirer les jets et l'entonnoir de coulée afin d'obtenir les chapelets de flans monétaires (8). Les différents flans sont ensuite séparés avec un outil approprié fonctionnant à la manière d'un burin (9). Cette opération est suivie d'un recuit des flans afin de radoucir le métal et 


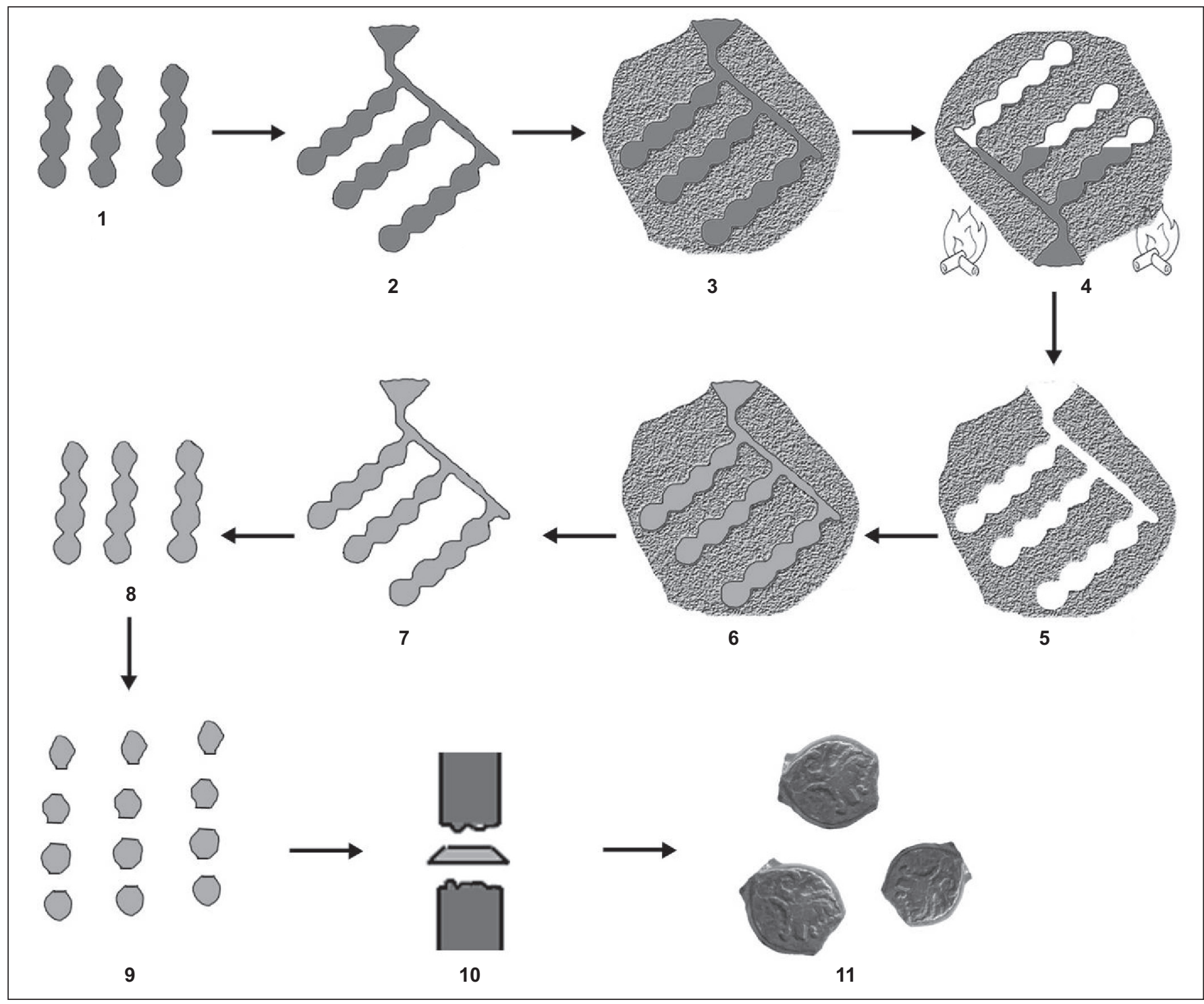

Fig. 18 - Schéma proposant une reconstitution de la chaîne opératoire de fabrication des monnaies telles qu'elles ont pu être fabriquées dans l'atelier (conception et DAO : F. Adamski, CNRS-IRAMAT; clichés monnaies : P. Ernaux, INRAP).

de faciliter la frappe (10). Les monnaies sont finalement frappées entre deux coins pouvant être en bronze (11) qui sont des matrices gravées en creux représentant le négatif de la figure de la monnaie.

Nous avons choisi de représenter l'angle formé par l'entonnoir de coulée et le canal de coulée, ainsi que celui qui est constitué par le canal et les chapelets à l'aide de l'échantillon 1019-3. En effet, bien qu'aucun entonnoir de coulée n'ait été retrouvé sur le site, il nous semble que la direction ainsi choisie est la plus efficace pour que le métal en fusion s'écoule aussi bien le long du canal de coulée que dans l'empreinte du chapelet. En outre, cette position permet également aux gaz de s'échapper plus facilement et de ne pas rester dans le métal en fusion ; il est ainsi possible d'éviter une trop forte porosité du métal final. Ce genre de dispositif en grappe avec une position similaire de l'objet (c'est-à-dire coulé avec un certain angle par rapport à la verticale) est d'ailleurs très bien connu, par exemple dans les moules à fibules trouvés sur le site du lycée militaire à Autun (Chardron-Picault, Pernot, 1999). Notre schéma présente une coupe de moule, mais il est possible que d'autres chapelets soient présents sur tout le volume du moule. Ils peuvent être disposés en étoile par rapport à l'entonnoir de coulée, ou encore installés par couches successives. 
Ainsi, l'observation et l'analyse des flans monétaires et des monnaies retrouvés sur le site des Rochereaux ne contredisent pas le fait que les monnaies aient pu être frappées à partir des flans monétaires retrouvés sur le site, malgré la dispersion des résultats analytiques. D’autre part, l'étude macroscopique des objets et l'étude métallographique des coupes des échantillons nous ont permis de proposer une reconstitution de la technique de fabrication des flans monétaires, et de nous informer sur la technique employée lors de la frappe de la monnaie.

F. A. et M. P.

\section{LES VESTIGES SIDÉRURGIQUES ET LE MOBILIER MÉTALLIQUE}

Tous les restes découverts confirment que l'activité de forge consistait à fabriquer ou à entretenir des objets en fer et non pas à produire le métal lui-même ${ }^{15}$. Aucune scorie caractéristique de la production de métal (dense et à l'aspect coulé) n'a été découverte sur le site des Rochereaux. Les vestiges mobiliers de l'artisanat du fer sont essentiellement constitués de plus de 9,6 kg de scories en forme de calotte, complètes ou fragmentées. De plus, on remarque un nombre peu significatif de battitures et de petits fragments en fer brûlés. Les 16 petits tronçons de bande de tôle en fer, dont 14 proviennent des couches du dôme cendreux et de ses alentours, sont également à rattacher à l'atelier de forge. Ils correspondent à des chutes de découpe de tôle en fer. D'une épaisseur de $1 \mathrm{~mm}$ au maximum, ils présentent au moins un bord rectiligne, parfois les deux. On peut citer deux exemples publiés à ce jour : l'oppidum de Manching, en Bavière, et le petit habitat ouvert du Clos Clidor à Aigueperse, dans le Puy-de-Dôme (Sievers, 1992, p. 195-205; Orengo, 2003, p. 83 et p. 86-87).

La majeure partie des calottes, aussi appelées « culots de forge », complètes ou fragmentées, provient des couches cendreuses du dôme, pour plus de $4,8 \mathrm{~kg}$, et des couches latérales, pour près de $4 \mathrm{~kg}$. Les pièces complètes sont peu nombreuses et de petite dimension. Leur magnétisme varie considérablement d'un exemplaire à l'autre et ce, indépendamment de la taille des calottes (tabl. IV).

L. O.

15. L'ensemble des vestiges mobiliers a été étudié macroscopiquement et inventorié par L. Orengo. Ensuite, des examens métallographiques de plusieurs pièces ont été réalisés par P. Fluzin sur la base d'une sélection d'échantillons représentatifs.

\section{EXAMEN MICROSCOPIQUE DES SCORIES EN FORME DE CALOTTE}

Deux calottes (ROCH1 et ROCH2) provenant du dôme du foyer se caractérisent par leur petite taille et la présence en leur sein de battitures, de forme lamellaire dans le premier cas, globulaire dans le second. L'examen de la coupe de ces deux exemplaires montre aussi une très faible proportion de pertes métalliques qui peuvent se présenter sous la forme de très petits nodules de métal, inférieurs à $1 \mathrm{~mm}$, ou d'éléments plus gros, atteignant le centimètre. La matrice de la calotte ROCH2 est globalement homogène, tandis que celle de ROCH1 comporte notamment une proportion non négligeable d'oxydes sous forme de globules de wustite. Ces deux échantillons orientent la réflexion vers une activité de forge produisant peu de pertes métalliques et provoquant la formation de battitures, notamment lamellaires, propres au travail du martelage. Il semble donc s'agir de deux calottes caractéristiques d'un travail de forge "classique ", alternant la chauffe de pièces en fer bien homogènes dans un foyer et le martelage sur une enclume. La petite taille de ces scories et la présence très modérée de pertes métalliques prouvent que les séquences de chauffe étaient relativement courtes. On peut en déduire qu'il s'agissait de travailler de petites pièces : menus objets, tôle.

La calotte ROCH10 provenant de la couche d'éboulis recouvrant le dôme se caractérise par sa masse importante (560 g). Cet échantillon est constitué de plusieurs calottes (au moins deux, peut-être trois). L'examen métallographique de sa coupe révèle la présence de petits nodules cuivreux et d'une matrice silicatée se caractérisant par de grosses lattes de fayalite et la présence, toutefois très faible, d'oxydes de fer (wustite). On note aussi la présence, anecdotique, de quelques battitures lamellaires et une faible proportion de pertes métalliques. La présence de cuivre dans cette calotte suggère une simultanéité des travaux des métaux cuivreux et de la forge d'objets en fer. On ne peut toutefois pas exclure que cette dernière se soit simplement effectuée dans un environnement pollué par les résidus d'une activité antérieure consacrée aux alliages cuivreux. La faible proportion de pertes métalliques dans cet échantillon permet de penser qu'il résulte, comme les exemplaires précédents de plus petite dimension, d'un travail de forge " classique». Notons toutefois que cet échantillon atteste une gestion aléatoire du foyer par le forgeron. Ce dernier a tout simplement laissé la scorie qui s'était formée lors d'un travail précédent, sans chercher à la retirer du foyer pour le nettoyer avant de se mettre à l'ouvrage. On peut y voir un 
Tabl. IV - Exemplaires complets des scories en forme de calotte.

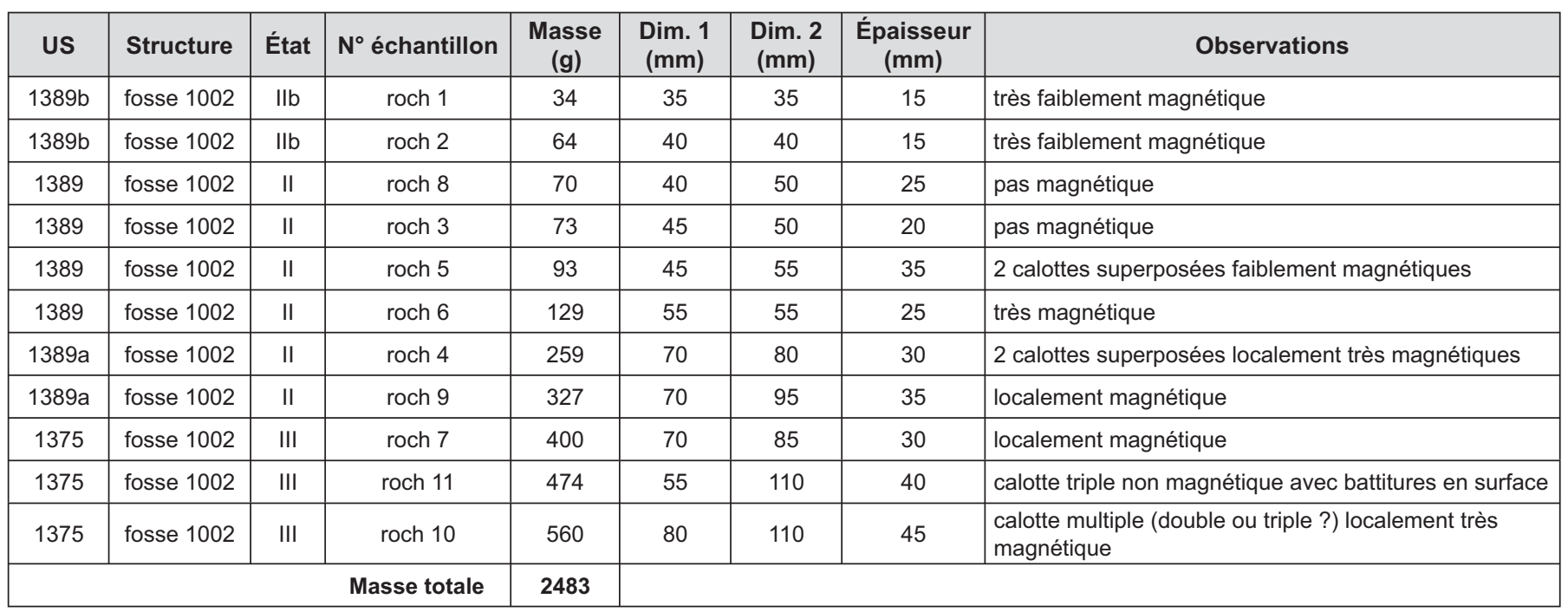

travail « grossier », ou du moins ne nécessitant pas une zone de chauffe bien maîtrisée dans le foyer.

La calotte ROCH6 provient du dôme du foyer de l'atelier. Elle pèse $129 \mathrm{~g}$ et est très magnétique. L'examen de sa section a permis de constater la présence de cuivre, comme pour l'exemplaire précédent, mais aussi de très nombreuses battitures globulaires. La très forte proportion de ces dernières suggère la chauffe d'une masse métallique relativement épaisse qui a nécessairement été maintenue à une température élevée et ce, durant un laps de temps relativement long, pour chauffer à cœur la pièce de métal plongée dans le foyer de la forge. Enfin, un fragment centimétrique de fonte blanche comportant des traces de martelage a été observé dans cet échantillon. Sa présence et le fait qu'il ait été martelé permettent de supposer que cette calotte résulte de la chauffe d'une masse de métal épaisse dont la teneur en carbone était hétérogène. Ce faisceau d'éléments conduit à penser que les forgerons ont utilisé un métal tiré d'un demi-produit incomplètement travaillé, à tel point qu'il contenait des plages très carburées, impropres au forgeage (un fragment de loupe ?).

Ph. F.

\section{LES FRAGMENTS DE PAROIS DES FOYERS MÉTALLURGIQUES}

Les nombreux fragments d'argile $(6,5 \mathrm{~kg})$, la plupart brûlés et scoriacés, proviennent des parois d'un ou de plusieurs foyers métallurgiques. Les couches qui en ont livré le plus sont celles du dôme du foyer (900 g), les couches d'éboulis en contact avec le foyer $(1,3 \mathrm{~kg})$ et les couches d'aménagement de l'atelier (1,1 kg). Leur examen apporte quelques informations sur le type de foyer utilisé par les artisans du métal, sans qu'il soit permis de préciser s'il s'agit du travail du fer, des alliages cuivreux ou des deux à la fois.

Les couches d'éboulis en contact avec le dôme cendreux ont livré plusieurs gros fragments de terre cuite brûlée mesurant $65 \mathrm{~mm}$ d'épaisseur pour le plus petit et $80 \mathrm{~mm}$ d'épaisseur pour le plus grand. L'une des couches du fond de la fosse a fourni un élément qui ressemble à un pain d'argile rouge, non cuite, grossièrement rectangulaire et mesurant $120 \mathrm{~mm}$ de long pour une épaisseur de $50 \mathrm{~mm}$. Par ailleurs, sa surface lisse et son dégraissant relativement fin $(5 \mathrm{~mm})$ font penser à une brique d'adobe. Il n'est pas exclu que ces pains d'argile aient servi à bâtir le ou les foyers des artisans qui travaillaient dans la fosse-atelier. Plusieurs petits fragments de terre cuite, provenant de la couche d'éboulis en contact avec le dôme, comportent les traces d'un canal que l'on est tenté d'identifier comme un conduit de tuyère. Leur état de fragmentation rend difficile leur restitution par le dessin. Nous avons fait le choix de mesurer leur diamètre, qui oscille entre $14 \mathrm{~mm}$ et $30 \mathrm{~mm}$, avec une constante aux environs de 18-20 mm. Malgré la petitesse de ces fragments de conduit, on peut exclure qu'ils proviennent de blocs-tuyères amovibles tels que ceux connus par ailleurs en Gaule (Orengo et al., 2000). Ces fragments de conduits appartiennent à des foyers dont la paroi était percée de simples trous à travers lesquels l'air, servant à alimenter la combustion, était envoyé à l'aide de soufflets. L'ensemble de ces éléments permet d'envisager un 
module de foyer dont les dimensions en plan sont inconnues mais dont les parois, d'une épaisseur comprise entre $65 \mathrm{~mm}$ et $80 \mathrm{~mm}$, étaient percées d'un ou de plusieurs conduits de tuyère latéraux.

\section{LE MOBILIER MÉTALLIQUE}

Mis à part un petit ciseau en fer trouvé dans le remplissage du fossé oriental et un fragment de tôle en alliage cuivreux découvert pendant le décapage, correspondant fort probablement à une partie du fond d'une pièce de vaisselle, les objets métalliques proviennent de la fosseatelier. Le lot comporte 6 objets en alliage cuivreux, 14 outils en fer, 4 fragments de ferrures et 8 fragments de tôles ou de tiges en fer. La description des objets et des outils qui suit est faite en fonction de leur contexte stratigraphique.

\section{L'AMÉNAGEMENT DE L'ATELIER}

Les couches d'aménagement de l'atelier ont livré deux outils : une herminette en fer et une douille globalement carrée (fig. $19, \mathrm{n}^{\text {os }} 1$ et 2 ). La surface supérieure du tranchant de l'herminette porte des traces rectilignes et parallèles de martelage. Son extrémité est amincie en forme de plage, décentrée, mesurant près de $30 \mathrm{~mm}$ de long. Ce détail, associé aux traces de martelage, permet de penser que cet outil a fait l'objet d'une tentative de réparation ou d'une récupération du métal qu'il contient.

\section{LE DÔME DU FOYER DE L'ATELIER}

Les couches formant le dôme du foyer ont livré un ensemble de 9 outils, 5 fragments de tôle, 2 fragments de barre et un objet indéterminé, tous en fer. Parmi eux, il y a un fragment de lame de couteau (fig. 19, $n^{\circ} 3$ ) et un fragment de plaque dont la forme rappelle celle de l'extrémité d'une pelle à feu (fig. 20, no 4).

Un ciseau de section carrée (fig. 19, n 5), étant donné son contexte, aurait pu servir à couper des pièces métalliques (Duvauchelle, Augustoni, 2002, fig. 1 et 2 ; Jacobi, 1974, pl. 7). On peut voir également dans cet outil un burin pour tailler la pierre, comme les exemplaires découverts dans certaines fermes laténiennes de Vendée, au Grand Paisilier à Pouillé, pour le $\mathrm{II}^{\mathrm{e}}$ s. av. J.-C., et aux Genâts à Fontenayle-Comte, pour la fin du $\mathrm{II}^{\mathrm{e}}$ s. et le début du I ${ }^{\mathrm{er}}$ s. av. J.-C. (Guillaumet, Nillesse, 2000, fig. 6, $\mathrm{n}^{\mathrm{o}} 7$ et fig. 8, $\mathrm{n}^{\mathrm{o}} 4$ ).

La tête d'un outil sur tige de section carrée est matée, ce qui prouve une utilisation par percussion directe (fig. 19, $\mathrm{n}^{\mathrm{o}} 9$ ). L'autre extrémité est semblable à celle d'une gouge, comme celles de l'oppidum de Manching (Jacobi, 1974, fig. 10). Sa dimension le rapprocherait des emporte-pièce du site de Larina à Hières-sur-Amby, en Isère, utilisés pour le cuir (Perrin, 1990, p. 87 et fig. 89) ou bien des gouges du ferblantier décrit dans l'Encyclopédie (Diderot, d'Alembert, rééd. 2002).

D'un premier fragment d'umbo de bouclier, seule la coque subsiste dans son intégralité, les ailettes étant totalement absentes (fig. 19, $\mathrm{n}^{\mathrm{o}} 10$ ). La coque est munie de rebords bien marqués, d'une hauteur maximale de $7 \mathrm{~mm}$. Ce fait est significatif pour les umbos datés de La Tène D1 et plus précisément de la seconde moitié du $\mathrm{II}^{\mathrm{e}}$ s. av. J.-C., comme c'est le cas dans les tombes 1178, 1216, 1228 de la nécropole de Wederath (Haffner, 1978, fig. 297, 309 et 314 ; Haffner, 1989, p. 63-67, fig. 42) ou dans l'habitat de Montmartin, dans l'Oise (Lejars, 1997, p. 158).

Un deuxième fragment d'umbo comporte un fragment d'ailette où l'on aperçoit la perforation dans laquelle était glissé le clou de maintien. On note aussi l'absence de rebord de coque. Plusieurs autres perforations, au moins quatre, sont situées sur le pourtour de la coque. Deux d'entre elles sont comblées par des rivets (fig. 19, no 11).

Un fragment de lame massive à dos courbe (fig. 20, $n^{\circ} 1$ ) rappelle celle d'un ébranchoir semblable aux exemplaires vendéens de la fin de La Tène au Grand Paisilier et aux Genâts ou ceux du dépôt de Larina (Guillaumet, Nillesse, 2000, fig. $6, \mathrm{n}^{\circ} 1$, fig. $7, \mathrm{n}^{\circ} 4$, fig. 11, $\mathrm{n}^{\mathrm{o}} 2$; Perrin, 1990, fig. $68, \mathrm{n}^{\mathrm{o}} 260$, fig. $\left.69, \mathrm{n}^{\text {os }} 261-263\right)$. Un fragment de tôle de 1,5 mm d'épaisseur, avec un bord droit et une extrémité en forme de soie de section rectangulaire, est similaire aux petits outils identifiés comme des paroirs de sabotier (fig. 20, n ${ }^{\circ}$ 5) (Perrin, 1990, fig. 268 et 269 ; Jacobi, 1974, fig. 24, $\left.\mathrm{n}^{\text {os }} 402-404\right)$. On peut aussi les identifier comme des couteaux, fixés sur un montant en bois, permettant de couper ou de rectifier des bottes de paille (Pohanka, 1986, fig. 18). Un poinçon possède une partie appointée de section circulaire alors que son extrémité est de section quadrangulaire (fig. 20, no 13). Dans l'Encyclopédie (Diderot, d'Alembert, rééd. 2002), cet objet se retrouve dans la trousse à outils du chaudronnier grossier et du ferblantier, tous deux travaillant la tôle de fer.

Dans ce contexte, les objets en alliage cuivreux sont au nombre de quatre. Outre une petite tige de section quadrangulaire, un fragment d'une bande de tôle volontairement replié sur lui-même, un ressort de fibule en partie déroulé et initialement constitué de quatre spires et d'une corde externe, on note la présence d'un fragment 


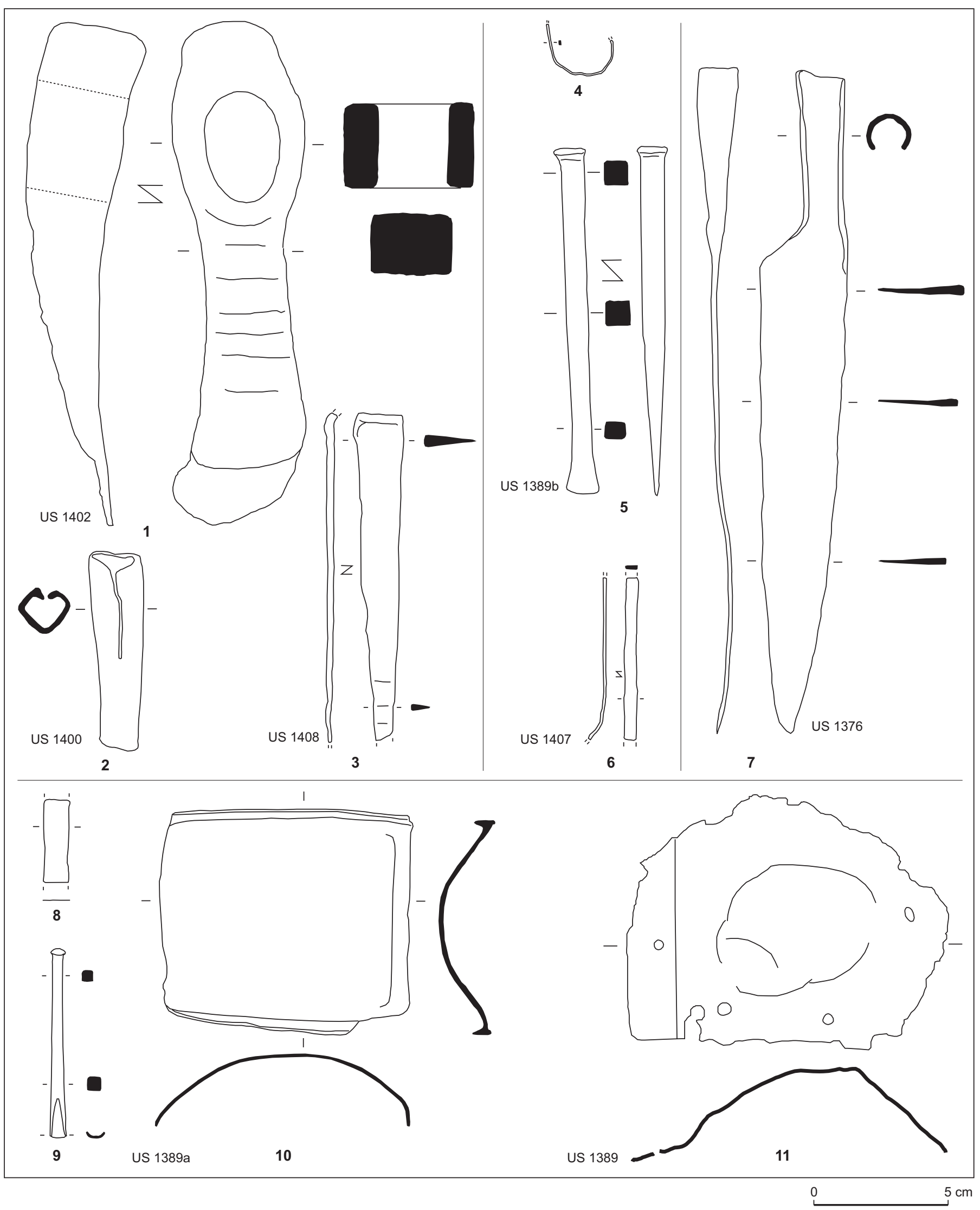

Fig. 19 - Objets en fer : 1-3, 5-11; objet en alliage cuivreux : 4 (dessin et DAO : L. Orengo). 


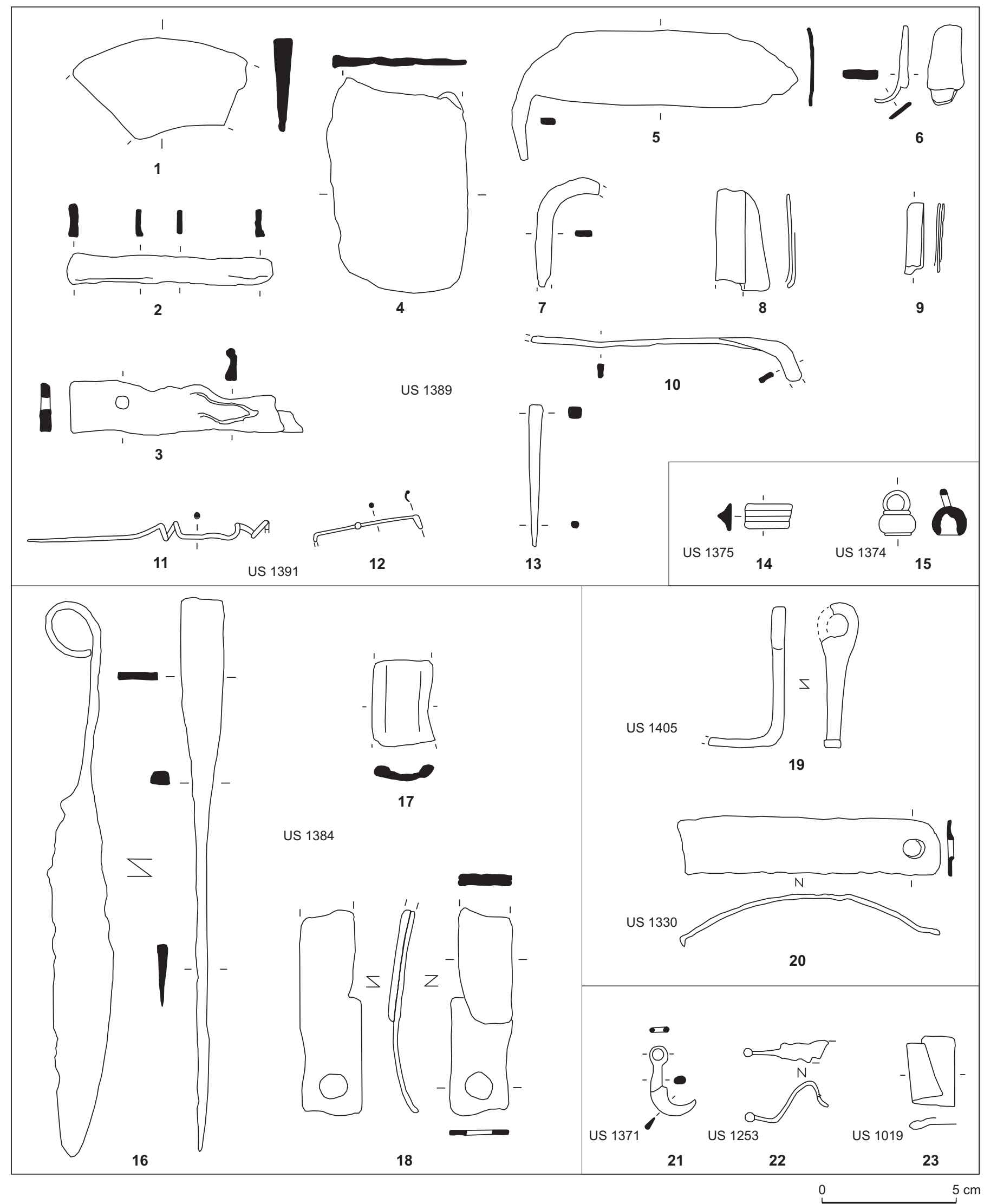

Fig. 20 - Objets en fer : 1-8, 10, 13, 16-20; objets en alliage cuivreux : 9, 11, 12, 14, 15, 21-23 (dessin et DAO : L. Orengo). 
du pied d'une fibule (fig. $19, \mathrm{n}^{\circ} 4$ et fig. 20 , $\mathrm{n}^{\text {os }} 9$, 11 et 12 ). Ce dernier comporte une petite nodosité et son extrémité conserve une partie de la pincette destinée à être sertie sur le dos de l'arc. Il s'agit du fragment d'une petite fibule de "schéma La Tène II ». On pourrait l'associer au fragment de ressort décrit précédemment ; toutefois, aucune solution de recollage entre les deux fragments n'est apparue lors de l'étude.

\section{LA DESTRUCTION DE L'ATELIER}

L'intérieur de la douille d'un couteau en fer complet, à lame tordue, recèle des vestiges de bois figés par l'oxydation. La gracilité de la lame est à souligner (fig. 19, no 7 ). Ce type de couteau est notamment bien connu dans le nord de la France, dans l'oppidum de Condé-sur-Suippe à Variscourt dans l'Aisne, dans l'habitat de Montmartin dans l'Oise, ou dans les nécropoles de la fin de La Tène en Champagne, comme celles qui se trouvent près de l'habitat d'AcyRomance dans les Ardennes (Lambot et al., 1994, p. 164 ; Brunaux, Lejars, 1997, p. 93).

La section triangulaire d'un fragment de bracelet en alliage cuivreux est un fait assez rare quand il s'agit de productions métalliques (fig. 20, $\mathrm{n}^{\circ} 14$ ). En revanche, elle rappelle celle des exemplaires en pâte de verre de La Tène D1, de la série 37 de Gebhard (Gebhard, 1989, p. 80).

La forme du petit pendentif en alliage cuivreux rappelle un chaudron ou un panier (fig. 20, $\mathrm{n}^{\circ} 15$ ). Un exemplaire semblable était porté en collier par un jeune enfant inhumé dans le site d'Aulnat, secteur de Gandaillat (Puy-de-Dôme), à La Tène D1 (Orengo, 2002 p. 72-74 et pl. 55, no 12). Le même type de pendentif est connu en Berry par un exemplaire, dans le site des Arènes à Levroux (Indre), pour le $\mathrm{II}^{\mathrm{e}}$ s. av. J.-C. (Guillaumet, 2000, p. 111 et fig. 13, n ${ }^{\mathrm{o}}$ 5). Enfin, on peut mentionner l'existence, dans la nécropole de Wederath, de petits pendentifs en alliage cuivreux semblables à l'exemplaire des Rochereaux : tombes 1673 et 1493 de La Tène C2, et tombe 1216 de La Tène D1 (Haffner, 1989, p. 56 , fig. 35 , p. $66-68$, fig. $43-44$ et p. 70 , fig. 45 ).

\section{LA COUCHE D'ABANDON DE L'ATELIER}

Outre un petit fragment de barre de fer comportant une gorge centrale et un petit fragment de ferrure (fig. 20, $\mathrm{n}^{\text {os }} 17$ et 18), un couteau en fer, forgé dans un tronçon de forces, a été exhumé (fig. 20, $\mathrm{n}^{\circ} 16$ ). Le forgeron a aplani le rebord qui marque habituellement les lames des forces pour éviter qu'elles ne se croisent lors de leur utilisation; ceci a eu pour effet d'épaissir le dos de la lame en lui conférant une section triangulaire. Le manche a été constitué après découpe du ressort des forces, puis enroulé.

\section{LES COUCHES DU DÉPOTOIR}

Parmi les objets en fer, un fragment d'une tige de section quadrangulaire avec une extrémité en forme d'œillet rappelle le manche d'une clé et un fragment de ferrure comporte un trou pour qu'il puisse être fixé sur un montant en bois (fig. 20, $\mathrm{n}^{\text {os }} 19$ et 20). Parmi les objets en alliage cuivreux, un petit pendentif datable du $\mathrm{II}^{\mathrm{e}} \mathrm{s}$. av. J.-C. représente une faucille ou une serpe, un fragment de fibule présente une portion d'arc de forme triangulaire et un fragment de tôle mesure $1 \mathrm{~mm}$ d'épaisseur (fig. 20, $\mathrm{n}^{\text {os }} 21$ à 23).

\section{INDICATIONS GHRONOLOGIQUES}

Quelques éléments apportent des précisions intéressantes pour la datation de la fosse-atelier 1002 : les pendentifs (fig. 20, $\mathrm{n}^{\text {os }} 15$ et 21) datant de La Tène C2 ou de La Tène D1 ; le fragment de fibule de "schéma La Tène II " (fig. 20, $\mathrm{n}^{\mathrm{o}}$ 12), nécessairement antérieur à La Tène D1, donc aux trente dernières années du $\mathrm{II}^{\mathrm{e}} \mathrm{s}$. av. J.-C. ; et l'umbo de bouclier (fig. 19, $\mathrm{n}^{\mathrm{o}} 10$ ), qui semble appartenir à un type apparu dans la seconde moitié du $\mathrm{II}^{\mathrm{e}}$ s. av. J.-C., plus précisément au début de La Tène D1.

\section{LA PRODUCTION DE L'ATELIER DE FORGE}

La provenance du métal travaillé par les artisans des Rochereaux consistait, en partie, en la récupération de vieux objets en fer dont la matière était recyclée pour confectionner de nouveaux objets. C'est particulièrement visible avec le couteau fabriqué dans une moitié de forces (fig. 20, no 16). Il en est probablement de même pour le tranchant de l'herminette abondamment martelé et aminci (fig. 19, no 1). Le forgeron a pu chercher à récupérer de la matière à partir de cette masse de métal en l'étirant progressivement jusqu'à l'obtention d'un lopin d'un volume proche de l'objet projeté. On peut aussi envisager que le couteau à douille (fig. 19, $\mathrm{n}^{\circ} \mathrm{7}$ ) ait été fabriqué à partir d'un vieil objet récupéré (sa gracilité suggère un fragment de lame de faux dont le rebord aurait été rabattu par martelage).

Les deux umbos de bouclier (fig. $19, \mathrm{n}^{\text {os }} 10$ et 11 ) témoignent peut-être aussi d'une récupération de vieilles pièces 
métalliques, dans l'intention de les réutiliser sous une forme différente ou de récupérer une partie de la matière. La présence de rivets dans les trous situés en périphérie de la coque de l'objet $\mathrm{n}^{\mathrm{o}} 11$ figure 19 peut donner lieu à différentes interprétations. Il peut s'agir soit d'une tentative de réparation (bouchage de trous résultant d'un endommagement du bouclier), soit de la récupération d'une pièce d'arme à des fins complètement différentes (confection d'une ferrure ?), soit à l'inverse d'une tentative de fabrication d'un umbo à partir d'une pièce de tôle récupérée dans une ferrure ou une platine de serrure.

Les artisans qui ont travaillé le fer dans la fosse-atelier l'ont notamment fait à partir de demi-produits d'une qualité que l'on pourrait juger médiocre du fait de l'hétérogénéité de leur teneur en carbone. On sait qu'une partie au moins de l'activité de l'atelier consistait à découper des tôles de fer, mais leur destination finale reste inconnue. Le ciseau (fig. 19, $\mathrm{n}^{\circ} 5$ ) et la gouge (fig. 19, $\mathrm{n}^{\mathrm{o}}$ 9) conviennent très bien au travail de la tôle métallique. Le ciseau a également pu être utilisé pour diviser les grappes de flans en alliage cuivreux.

La présence de globules d'alliage cuivreux dans des scories peut faire penser que l'activité de forge était réalisée par les artisans qui élaboraient les alliages et fabriquaient les flans monétaires. Ils disposaient de deux sources d'approvisionnement. La première consistait en de vieux objets en fer retirés de la circulation puis déposés dans la fosse-atelier pour être reforgés sous une autre forme. La seconde était peut-être du tout-venant sous forme de demi-produits incomplètement travaillés et dont la teneur en carbone était toujours très hétérogène (des loupes, par exemple).

L. O.

\section{LES AMPHORES}

La masse totale des amphores recueillies sur le site s'élève à $129 \mathrm{~kg}$ pour un nombre minimum d'individus estimé à 26 . L'intégralité des fragments a été découverte sur l'emprise de l'enclos d'habitation, principalement dans les fossés et dans la fosse-atelier (tabl. V). Ce lot est très homogène du point de vue typologique et les remplissages des fossés et de la fosse-atelier permettent de proposer une fourchette chronologique d'occupation du site assez courte. Le comblement de la fosse-atelier paraît assez surprenant car il semble présenter une stratigraphie inversée, les amphores les plus anciennes ont été recueillies dans les strates les plus hautes et les plus récentes au fond de la structure.
Tabl. V - Tableau récapitulatif des fragments d'amphores découverts sur le site : NMI, nombre minimum d'individus; GRI, gréco-italique, Trans., transition gréco-italique/Dressel ; D, Dressel.

\begin{tabular}{|l|c|c|c|c|c|c|c|}
\hline \multirow{2}{*}{ Localisation } & \multirow{2}{*}{$\begin{array}{c}\text { Poids } \\
(\mathbf{k g})\end{array}$} & \multirow{2}{*}{$\begin{array}{c}\text { Nombre de } \\
\text { tessons }\end{array}$} & \multicolumn{6}{|c|}{ NMI } \\
\cline { 4 - 9 } & & GRI & Trans. & D1A & D1C & D1B \\
\hline Fossé & 67,5 & 472 & 5 & 3 & 6 & 1 & 4 \\
\hline Trou de poteau & 8 & 66 & - & - & - & - & - \\
\hline Fosse-atelier & 53,5 & 178 & 3 & 2 & 2 & - & - \\
\hline Total & $\mathbf{1 2 9}$ & $\mathbf{7 1 6}$ & $\mathbf{8}$ & $\mathbf{5}$ & $\mathbf{8}$ & $\mathbf{1}$ & $\mathbf{4}$ \\
\hline
\end{tabular}

\section{MÉTHODOLOGIE}

L'identification des tessons, principalement des lèvres, a été faite suivant le protocole mis en place durant l'étude des amphores découvertes sur les sites du Toulousain datés de la fin de l'âge du Fer (Benquet, 2002, t. 1, chap. 2). Les critères discriminants, afin d'identifier les gréco-italiques (GRI) et les Dressel 1, sont le rapport hauteur sur épaisseur de la lèvre $(\mathrm{HL} / \mathrm{EL})$ et son inclinaison ; les critères secondaires sont la hauteur de la lèvre et le diamètre à l'embouchure (Dr. 1C et Dr. 1B). L'appellation traditionnelle de Dr. 1A est actuellement remise en cause. Si les types Dr. 1B et Dr. 1C sont aisément reconnaissables grâce à des critères métriques et morphologiques (fig. 21), les lèvres qui ne répondent pas à ces indices sont regroupées sous le terme générique de Dr. 1. Les profils, en effet, ainsi que les paramètres métriques sont extrêmement variables et ne peuvent être mis en phase.

\section{LES AMPHORES DÉCOUVERTES DANS LES FOSSÉS EST ET NORD}

Un total de 472 tessons, pour un poids de $67,5 \mathrm{~kg}$, a été recueilli dans les fossés est et nord (fig. 22 et fig. 23), ils représentent un nombre minimum de 19 individus illustrés par :

- 5 lèvres de type GRI,

- 3 lèvres de transition GRI/Dr. 1,

- 6 lèvres de type Dr. 1 ,

- 1 lèvre de type Dr. 1C,

- 4 lèvres de type Dr. 1B.

Les lèvres d'amphores de type gréco-italique (fig. 22, $\mathrm{n}^{\text {os }} 1$ à 6 ) ont une hauteur comprise entre $23 \mathrm{~mm}$ et $32 \mathrm{~mm}$ pour un diamètre à l'embouchure compris entre $140 \mathrm{~mm}$ et $160 \mathrm{~mm}$. De section triangulaire, le profil de la face externe de ces objets est très incliné (entre $61^{\circ}$ et $75^{\circ}$ ) et peut parfois présenter une ou plusieurs moulures sous la lèvre. Dans 


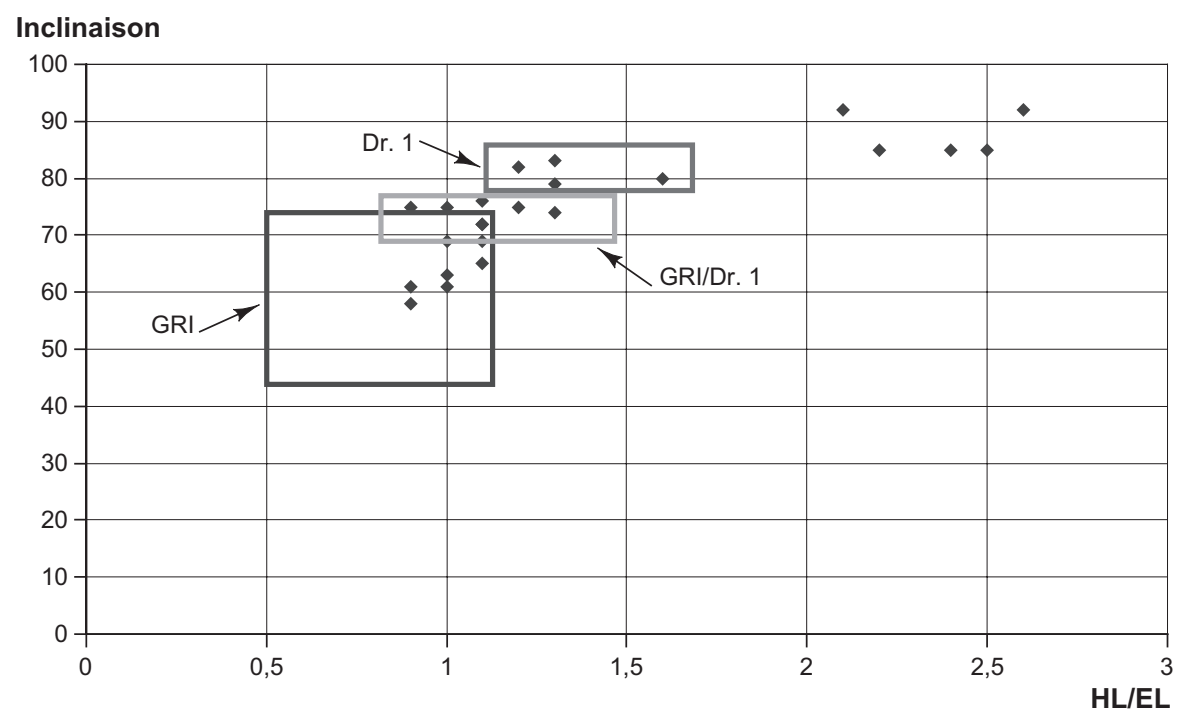

Fig. 21 - Diagramme de répartition des amphores présentant le rapport entre la hauteur et l'épaisseur de la lèvre en fonction de l'inclinaison: GRI, gréco-italique; Dr., Dressel.

ce cas, les attaches supérieures des anses sont fixées très haut sur le col, sur ces moulures. Les lèvres des amphores de transition GRI/Dr. 1 mesurent entre $30 \mathrm{~mm}$ et $35 \mathrm{~mm}$ (fig. 22, n ${ }^{\text {os }} 7$ à 10 ), pour une inclinaison supérieure à $75^{\circ}$ et un diamètre à l'embouchure compris entre $140 \mathrm{~mm}$ et $150 \mathrm{~mm}$. Les profils sont assez semblables à ceux des GRI, mais la lèvre est plus haute et son inclinaison moins forte. Une seule lèvre d'amphore peut être rattachée au groupe générique des Dr. 1 (fig. 22, $\mathrm{n}^{\circ} 11$ ) ; elle mesure $38 \mathrm{~mm}$ pour $150 \mathrm{~mm}$ de diamètre à l'embouchure et présente un profil peu incliné $\left(80^{\circ}\right)$, souligné d'une fine moulure.

À ces divers types de lèvres nous avons rattaché sans distinction les trois pieds complets (fig. 22, $\mathrm{n}^{\text {os }} 17$ et 18) ; il est malheureusement difficile d'associer lèvre et pied, la forme de ce dernier étant très variable selon la maîtrise du potier. Quelques fragments d'épaulements arrondis n'ont pu être attribués précisément à un type car leur état est trop fragmentaire.

Les deux derniers groupes de lèvres qui se distinguent très nettement sur le graphique (fig. 21) sont ceux des Dr. 1C (fig. 22, $\mathrm{n}^{\circ}$ 12) et des Dr. 1B (fig. 22, $\mathrm{n}^{\text {os }} 13$ à 16). Le premier n'est représenté que par un seul exemplaire, bien distinct par sa forme très élancée (hauteur $60 \mathrm{~mm}$ ) et son diamètre à l'embouchure relativement étroit, ce qui lui confère un profil en forme d'entonnoir inversé. Le second groupe est composé de quatre individus présentant une hauteur de lèvre comprise entre $57 \mathrm{~mm}$ et $60 \mathrm{~mm}$ et un large diamètre à l'embouchure de $190 \mathrm{~mm}$; leur face externe est légèrement débordante ou éversée. À ce type d'amphores peuvent être également associés un pied fragmentaire haut et massif, dont l'extrémité externe est plate, deux morceaux d'anse, au profil droit et à la section de forme ovale, et trois épaulements très marqués au profil à angle droit caractéristique, dont le diamètre n'a pu être déterminé.

Aucune estampille, ni aucune trace épigraphique n’a été découverte dans les fossés. En revanche, trois fragments, un pied, le haut d'une anse et une attache inférieure présentaient des marques digitées. Ces deux dernières ont dû être laissées par le potier au moment de l'assemblage des anses sur le col et l'épaule lorsque l'argile était encore fraîche. Les traces d'extrémités de doigts sur un pied sont consécutives au modelage de la partie finale du corps de l'amphore. Jusqu'à présent ces empreintes n'ont jamais été interprétées d'une autre façon que comme de simples traces du travail du potier.

\section{LES AMPHORES DÉCOUVERTES DANS LA FOSSE-ATELIER}

Le comblement lié à la fosse-atelier peut être subdivisé en deux stades bien distincts : l'aménagement-utilisation et l'abandon-comblement de cette structure. Le comptage des fragments découverts dans cette fosse-atelier a isolé sept individus pour un total de $53,5 \mathrm{~kg}$ de tessons. La diversité des types d'amphores n'est guère différente de celle du comblement des fossés, mais l'absence de Dr. 1B semble suggérer un abandon de l'activité des bronziers antérieur à la désertion du site. 


$$
\begin{array}{lll}
1 & 1 & 1 \\
1 & 1 & 1 \\
1 & 1 & 1 \\
1 & 1 & 1 \\
1 & 1 & 1 \\
1 & 1 & 1
\end{array}
$$




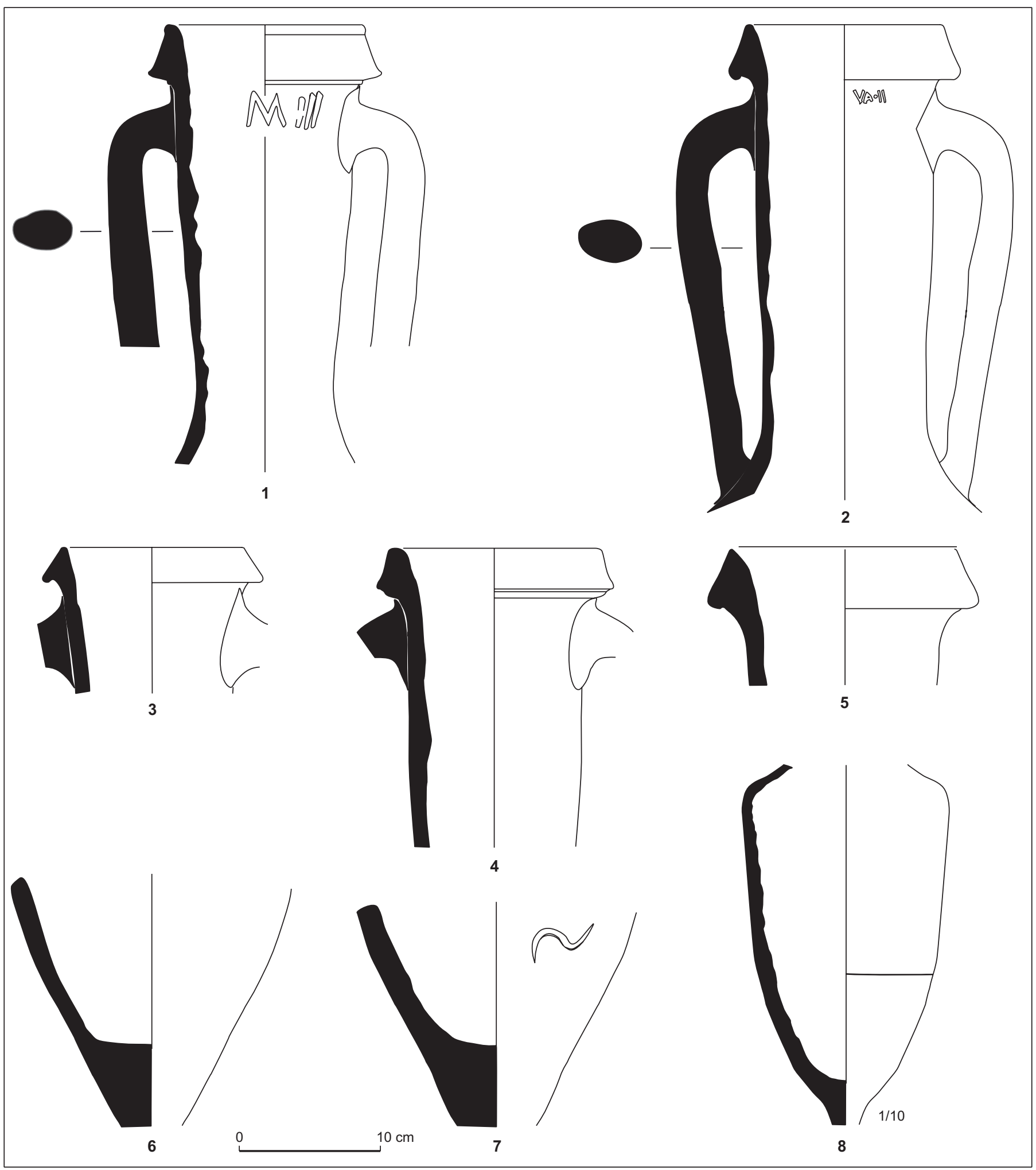

Fig. 23 - Les amphores (dessin et DAO : L. Benquet, INRAP). 


\section{LA PHASE D’AMÉNAGEMENT ET D'OCCUPATION}

Des fragments d'amphores ont été utilisés dans l'aménagement de l'atelier de bronziers à l'intérieur de la fosse. Une panse d'amphore décolletée entière (fig. 23, $\mathrm{n}^{\circ} 8$ ) servait de vide sanitaire ; de nombreux tessons de panses d'amphores associés à des plaquettes de calcaire étaient disposés par-dessus, sur le fond et contre les parois de la fosse, afin de stabiliser le plan de travail. En outre, divers autres fragments, plus volumineux, associés à l'activité artisanale même ont été découverts : deux cols entiers (fig. 23, $n^{\text {os }} 1$ et 2) et plusieurs pieds (fig. $23, n^{\text {os }} 6$ et 7 ), dont l'extrémité avait disparu. L'un des cols faisait partie du radier du foyer central de l'atelier métallurgique (fig. 23, $\mathrm{n}^{\circ}$ 2). L'autre, dépourvu des anses et de la partie basse du col, que l'on a retrouvées éparpillées dans le sol, était disposé à l'envers sur la bande périphérique du sol de l'atelier (fig. 23, $\mathrm{n}^{\circ} 1$ ). L'extrémité des pieds présentait des traces d'usure, résultant peut-être du frottement de l'objet pour le fixer au sol. Leurs parois internes et plus particulièrement le fond intérieur étaient lisses et exempts de toute trace de tournage.

La réutilisation des tessons d'amphores en tant que matériau de construction et le remploi d'amphores, souvent partiellement recoupées, sont courants. Les premiers sont utilisés dans des radiers de foyers ou de sols ; les seconds dans l'aménagement de vides sanitaires, d'égouts ou bien encore plantés dans le sol en tant que récipients (entre autres exemples : Toledo i Mur, 1997-1998, p. 116-118). La présence de panses d'amphores entières n'est pas rare dans les ateliers de forge (Feugère, Serneels, 1998), de réduction du fer ou dans les mines (Domergue, 1991 ; Benquet, Olmer, 2002, p. 329-330 ; Dieudonné-Glad, Parisot, 1999, p. 25).

Les deux cols d'amphores présentaient des inscriptions en caractères latins, peintes en rouge et situées entre les attaches supérieures des anses. Ce genre de marques est assez fréquent sur les amphores italiques des deux derniers siècles avant notre ère, si les conditions d'enfouissement ne sont pas trop acides. L'interprétation de ces traces épigraphiques est incertaine. Les exemples découverts à MignéAuxances présentent pour le premier (fig. 23, $\mathrm{n}^{\mathrm{o}} 1$ ) une lettre suivie d'un chiffre : "M. III ", tandis que le second (fig. 23, no 2) présente deux lettres suivies d'un chiffre : "VA. II ». Ces deux inscriptions s'insèrent parfaitement au sein des marques déjà connues sur les oppida, fréquentes principalement dans le sud-ouest de la Gaule, peintes lors du débarquement des amphores dans les ports par les négociants (ou leurs employés) chargés de leur redistribution vers les marchés situés à l'intérieur des terres.
Il est difficile d'interpréter les lettres comme l'abréviation d'un cépage ( $C I L, \mathrm{XV}, 4552$ sqq.), même si cela semble possible pour une des deux inscriptions, $M$ (assicum). Ces lettres peuvent être mises en parallèle avec les timbres codés à une, deux ou trois lettres, interprétés comme une méthode utilisée par le régisseur pour contrôler la gestion des fournées (Olmer, 2003, p. 164-178). Les lettres peintes ne se réfèrent pas à une abréviation de noms, mais à un système de comptabilité au moment du déchargement des amphores par le mercator au port. De cette façon, les lettres pourraient symboliser le personnage responsable de la surveillance du débarquement des amphores, mais la signification de la suite numérale reste encore problématique ${ }^{16}$.

\section{LES AMPHORES DU COMBLEMENT FINAL}

Les différentes couches de comblement de la fosse suivant l'abandon de l'activité des bronziers recèlent divers fragments d'amphores attribués aux types gréco-italique et de transition (fig. 22, $\mathrm{n}^{\text {os }} 3$ à 5). Les formes et profils des lèvres sont semblables aux découvertes faites dans les fossés de l'enclos I. Un pied ayant perdu sa pointe présentait un graffiti gravé dans l'argile encore humide lors de l'opération de séchage avant la cuisson de l'amphore. Cette marque peut être interprétée comme un signe justifiant le rendement journalier d'un potier et comme un indice, pour la personne qui chargeait les fours, du temps de séchage de chaque amphore. Cette hypothèse a été émise à partir de l'étude des graffitis relevés sur des amphores de type Dr. 20, par l'équipe espagnole travaillant sur le Monte Testaccio (García Brosa et al., 2001, p. 311-312).

\section{QUELQUES REMARQUES SUR L'ORIGINE DES AMPHORES}

Une observation sommaire a été faite sur des cassures fraîches effectuées sur les fragments de lèvres et de pieds,

16. Il est difficile d'avancer une interprétation de ces caractères à valeur numérale puisque nous ne disposons que de peu de comparaisons bibliographiques. Toutefois, nous avons déjà noté, lors de l'étude des inscriptions en caractères ibériques, que leur présence pourrait être l'indication d'un prix. Sur le site d'Ensérune à Nissanlez-Ensérune (Hérault), de nombreux artefacts portent des lettres ibériques incisées, après cuisson, à valeur numérale. Elles ont été interprétées comme des indications de poids ou de volume, gravées à la réception par les commerçants importateurs (Jannoray, 1955, p. 430-431). Dans le cas des inscriptions en caractères latins, il semble bien qu'il s'agisse également d'un système de comptabilité pouvant être appliqué avant ou après le débarquement des marchandises sur les lieux de redistribution. Ce système semble avoir aussi été utilisé lors des opérations comptables dans les officines. 
à l'aide d'une loupe de grossissement 8. Quatre grands groupes d'argiles ont été individualisés.

Groupe 1 : la pâte sableuse, beige rosé à l'aspect marbré, contient de nombreux granules ferreux, de grosses inclusions de roches volcaniques, quelques grains de chamotte et de fines inclusions blanches. Il se rapproche des productions attribuées à l'atelier d'Astura situé dans le Latium méridional (Ricq de Boüard et al., 1989, p. 265).

Groupe 2 : la pâte est sableuse, de couleur beige ; aucune inclusion n'est visible à l'œil nu, à l'exception de quelques rares gros granules ferreux ; à la loupe, quelques petits minéraux arrondis gris se détachent de la matrice.

Groupe 3 : la pâte sableuse, de couleur orangée, contient de nombreuses particules calcaires blanches et de petits granules ferreux.

Groupe 4 : la pâte argileuse, de couleur rouge, contient de très nombreux minéraux volcaniques noirs en baguette (type pyroxène) et des nodules de calcaire pouvant être apparentés à des foraminifères. Il semble assez proche du type Loba, individualisé à partir de l'étude des amphores découvertes sur le site éponyme espagnol et dont l'origine supposée est celle de la Campanie du nord (Benquet, Olmer, 2002, p. 299-302).

\section{FOURCHETTE CHRONOLOGIQUE}

D'après l'étude de ce lot d'amphores, il semble que la durée d'occupation de l'établissement des Rochereaux ne perdure pas plus de 50 ans. La présence simultanée des trois types d'amphores, gréco-italique, Dr. 1 et de transition, dans la fosse-atelier en stratigraphie inversée, permet de dater l'activité aux environs de 130 av. J.-C. La présence de lèvres de type Dr. 1B dans les fossés de l'enclos I indique une datation de l'occupation finale du site au cours du premier tiers du $\mathrm{I}^{\mathrm{er}}$ s. av. J.-C. Cette fourchette chronologique est justifiée par la présence, en égale proportion, des types GRI, de transition et Dr. 1, qui cohabitent au cours du troisième quart du $\mathrm{II}^{\mathrm{e}} \mathrm{s}$. av. J.-C., et par le faible pourcentage de Dr. 1B, forme qui apparaît au cours du premier quart du $\mathrm{I}^{\mathrm{er}}$ s. av. J.-C.

L. B.

\section{ÉTUDE NUMISMATIQUE}

Cinq monnaies gauloises ont été découvertes sur le site des Rochereaux (fig. 24). Deux proviennent des couches en contact avec le foyer de l'atelier et deux autres des niveaux supérieurs de comblement de la fosse 1002 (fig. 3). La cinquième a été exhumée dans le comblement du fossé nord. Il convient d'en étudier la typologie, identique pour tous les exemplaires, et d'apporter les arguments qui militent en faveur de l'hypothèse de leur frappe - éphémère ou durable - à Migné-Auxances.

\section{TYPOLOGIE}

Il s'agit de monnaies de bronze frappées sur flans coulés en chapelet au type unique suivant (BnF 4298-4303) 17 :

- droit : tête à droite, à la chevelure constituée d'une grosse mèche à la pointe recourbée ; de type dit « aquitanique » ${ }^{18}$; présence d'un grènetis ;

- revers : cheval galopant à droite, la tête retournée vers l'arrière, la queue dressée en $\mathrm{S}$; sous le ventre, à l'emplacement du sexe, grand rinceau en forme de crosse courbée vers le bas.

Les poids et les diamètres sont : $1,8 \mathrm{~g}$ et $16,5-14 \mathrm{~mm}$; $2,4 \mathrm{~g}$ et $17-13 \mathrm{~mm} ; 1,6 \mathrm{~g}$ et $15-14 \mathrm{~mm} ; 2,1 \mathrm{~g}$ et $16-14 \mathrm{~mm}$; $1,1 \mathrm{~g}$ et $15-12 \mathrm{~mm}$.

Ce type a été signalé pour la première fois en 1846 par le docteur Teilleux, de Niort, qui voulut voir dans l'ornement du revers " un énorme phallus, plus long que [les] pieds de devant [du cheval], et se courbant sous le ventre, presque à toucher le flanc de la médaille, ou à se trouver à la hauteur de ses pieds de derrière » (Teilleux, 1848, p. 28 et fig. 1-2). Ce détail allait consacrer l'appellation erronée de type «au cheval ithyphallique ", souvent reprise jusqu'à nos jours ${ }^{19}$. Ces monnaies, comme la plupart des pièces gauloises en alliage cuivreux, sont fort mal connues. Contrairement aux espèces en or et en argent, elles n'ont guère intéressé les collectionneurs, sont absentes des planches de La Tour (La Tour, 1892), figurent très rarement dans les grands

17. Teilleux, 1848, fig. 1-2 ; Hucher, 1852, pl. V, no 12 ; Lambert, 1864, p. 79, n 27 (et pl. IV, 27) (anc. coll. M. A. Le Boucher ; 46 grains) ; Barthélemy, 1873, p. 504, no 21 ; Muret, Chabouillet, 1889, p. 96 ; Nash, 1978, I, p. 233, nos 611-613 (et II, pl. 25, fig. 611-613) ; Castelin, 1978, p. 78, no SLM 703 (et p. 171, fig. 703) ; Castelin, 1985, p. 125 ; Scheers, 1996, p. 101, no 658 (et pl. XXV, fig. 658) ; Sarthre, 2002, I, p. 79, fig. 36-1, et II, cat. p. 37, n ${ }^{\text {os }} 887-892$; Depeyrot, 2004b, p. 76, no 90.

18. La tête est parfois qualifiée de « casquée (?) » (Barthélemy, 1873, p. 504).

19. Barthélemy, 1873, p. 504 : «le signe sexuel de l'animal est volontairement très exagéré "; Muret, Chabouillet, 1889, p. 96 : " cheval à dr. regardant en arrière ; les parties sexuelles extrêmement développées »; Scheers, 1996, p. 101 : « cheval au galop à dr., la tête retournée, le sexe exagéré "; Sarthre, 2002, t. I, p. 79 : " cheval "ithyphallique" à dr. »; Depeyrot, 2004b, p. 76 : « cheval regardant derrière, parties sexuelles développées". 


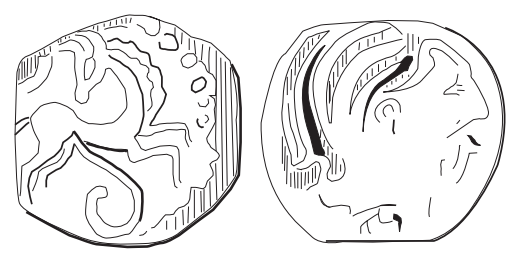

1
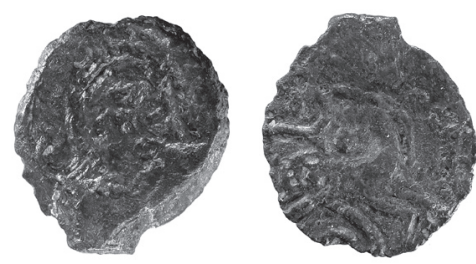

4

$1007-2$
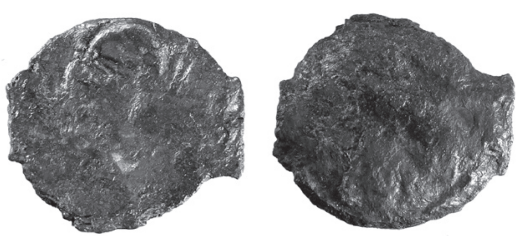

7

1376-3

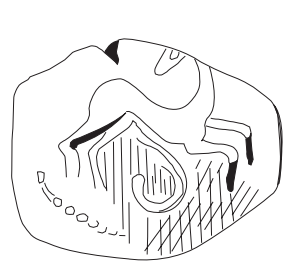

2
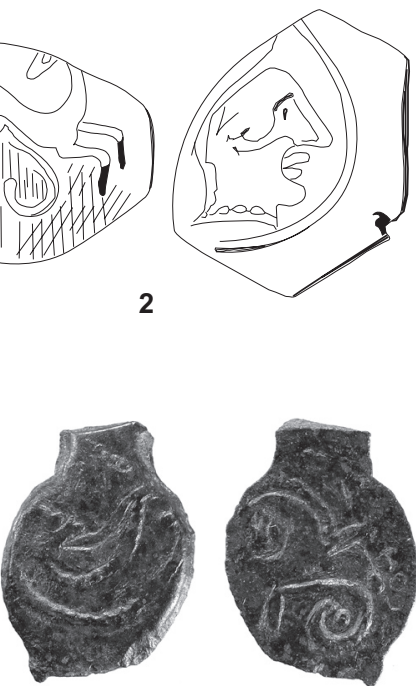

5

1253
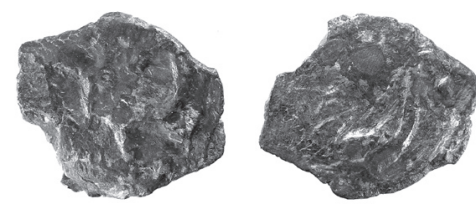

8

1397

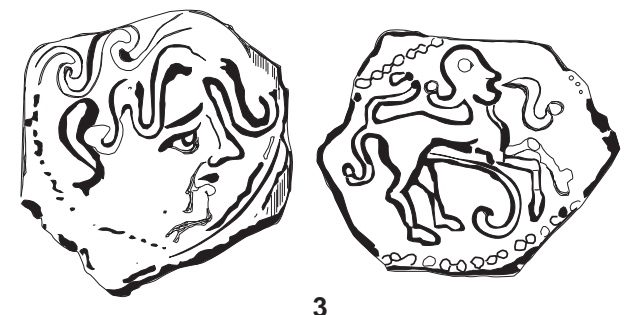

3
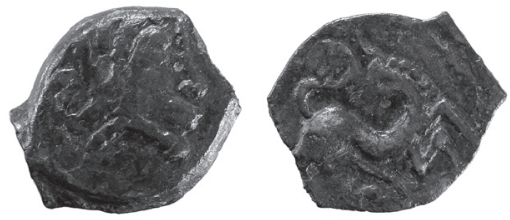

6

1350

Fig. 24 - Monnaies : 1, type BnF 42984303, trouvée à Rom (Deux-Sèvres) (extrait de Teilleux, 1848) ; 2, type BnF 4298-4303, trouvée à Niort (Deux-Sèvres) (extrait de Teilleux, 1848); 3, bronze à l'« androcéphale » proche de BnF 4298-4303 (d'après Blanchet, 1905, p. 298, fig. 181) ; 4-8, monnaies découvertes sur le site des Rochereaux (clichés : P. Ernaux, INRAP). musées 20 et n’ont presque jamais été identifiées (ou publiées) par les archéologues.

\section{DATATION ET ATTRIBUTION AUX PICTONS}

Leur datation était jusqu'à présent inconnue ; on les considérait comme des monnaies tardives, en se fondant sur leur fréquente présence dans les strates de l'époque de la conquête. D. Nash propose le $\mathrm{I}^{\mathrm{er}}$ s. av. J.-C., G. Depeyrot la période 100-50 av. J.-C. Les débuts de leur production sont donc désormais datables d'entre 130 et 100 av. J.-C. Leur

20. Exemplaires connus : Paris, BnF : 6 ex. (BnF 4298-4303 : 2,62 g, 3,29 g, 2,42 g, 3,11 g, 1,95 g, 1,88 g) ; Lyon (musée des Beaux-Arts) : 1 ex. (anc. coll. de La Saussaye ; Scheers, 1996, p. 101, $\mathrm{n}^{\circ} 658,3,39 \mathrm{~g}$; pl. XXV) ; Bourges (musée du Berry) : 1 ex. (D 965.1.4902, 1,70 g) ; Zurich (Schweizerisches Landesmuseum) : 1 ex. (Castelin, 1978, p. 78, no 703, 2,64 g; Castelin, 1985, p. 171). Il est à noter que les deux exemplaires signalés au musée de Rennes par Depeyrot, 2004b, p. 76 n'existent pas. attribution à un peuple précis est également fluctuante, bien qu'un certain consensus se soit établi, surtout depuis l'étude de D. Nash, en faveur des Bituriges Cubi ${ }^{21}$, fondé en réalité sur une seule provenance publiée ${ }^{22}$.

Les découvertes de Migné-Auxances nous incitent fortement à proposer une réattribution de ces monnaies aux Pictons (fig. 25). En effet, si rien n'oblige à les considérer

21. Laissons de côté l'attribution par le docteur Teilleux aux Cambolectri (Teilleux, 1846, p. 25 et pl.) et celle de E. Lambert aux Rèmes (Lambert, 1864, p. 79, no 27) ; mais, plus récemment, K. Castelin proposait encore une attribution aux Senones (?) (Castelin, 1978, p. 78 ; Castelin, 1985, p. 125). En faveur des Bituriges Cubi: Muret, Chabouillet, 1889, p. 95 ; Nash, 1978, I, p. 233 (Coinage of the Bituriges Cubi in the first century BC) ; Hiernard, 1987, p. 736 ; Scheers, 1996, p. 101 (avec une hésitation : «ce bronze $[\ldots]$ appartient à l'Ouest, mais l'attribution reste à préciser ») ; Sarthre, 2002, I, p. 79 ; Depeyrot, 2004b, p. 76.

22. Il s'agit de l'exemplaire BnF 4303 découvert à Levroux dans l'Indre (Muret, Chabouillet, 1889, p. 96). Ajoutons que le musée du Berry (Bourges) possède également un exemplaire, de provenance inconnue (D 965.1.4902) : Nash, 1978, I, p. 233, nº 613 et pl. 25. 


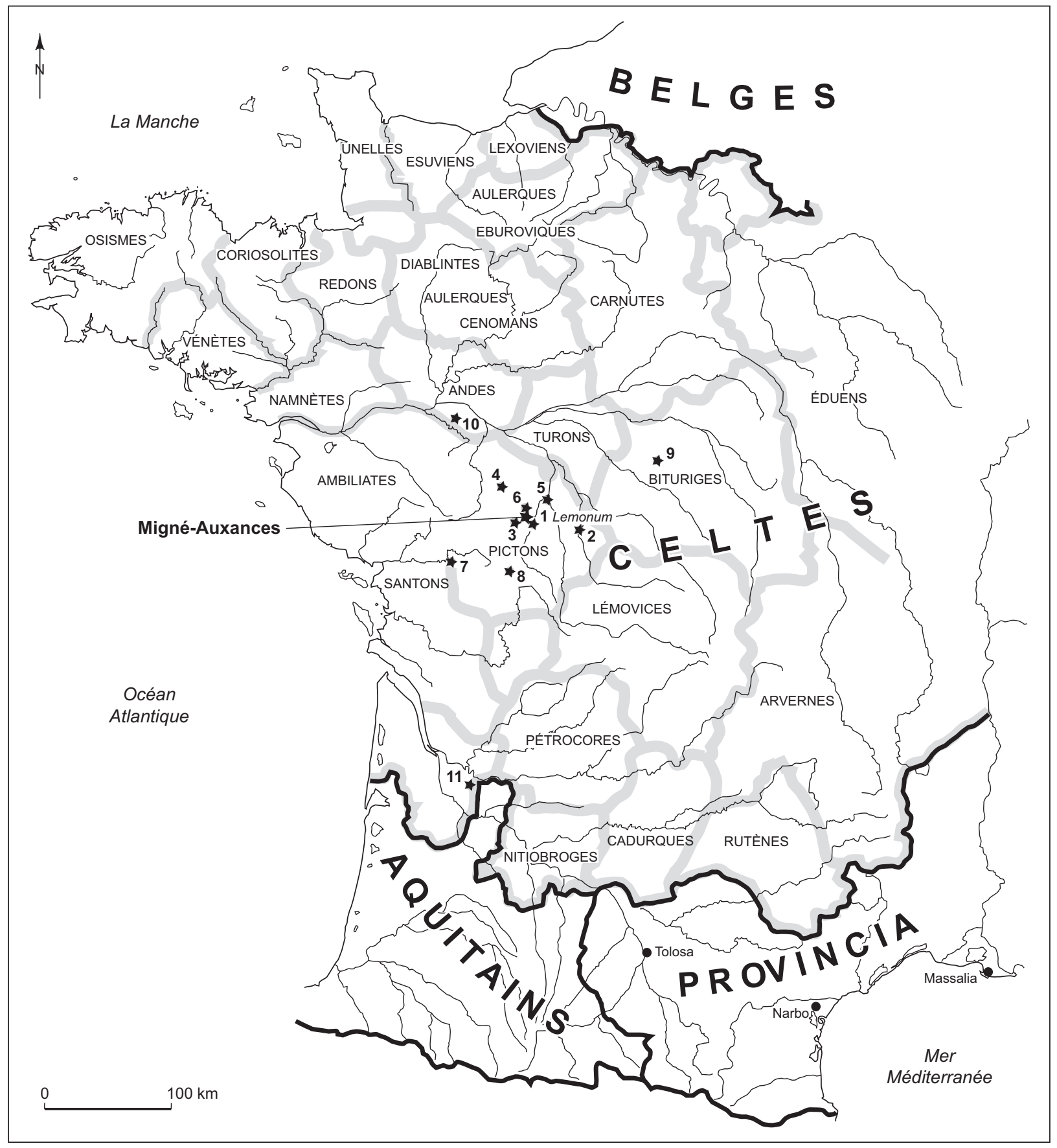

Fig. 25 - Carte de répartition des bronzes Bnf 4298-4303 dans la Gaule de l'Ouest à l'époque de César (fond de carte : J. Hiernard; DAO : S. Dalle, INRAP).

Territoire picton : 1, Poitiers (Vienne), 6 ex. ; 2, le Gué-de-Sceaux à Antigny (Vienne), 7 ex. et 1 autre possible ; 3, Verger-Bonnet à Béruges (Vienne), 1 ex. ; 4, Thouary à Moncontour (Vienne), 1 ex. ; 5, Naintré(Vienne), Vieux-Poitiers, la Fond des Berthons, maison Goulet, 1 ex., la Fond des Berthons, terrain Lacroix, 1 ex., les Groseilliers, 1 ex., théâtre romain, 1 ex. ; 6, les Tours-Mirandes à Vendeuvre-du-Poitou (Vienne), 1 ex. ; 7, Niort (Deux-Sèvres), 1 ex., rue de Fontenay, 1 ex., dépôt cultuel de Pain-Perdu (1977), 1 ex. et peut-être 6 autres ; 8, près de Rom (Deux-Sèvres), 1 ex.

Hors territoire picton: 9, Levroux (Indre) ; 10, les Pichelots aux Alleuds (Maine-et-Loire), 2 ex. ; 11, Mouliets-et-Villemartin (Gironde), 2 ex. 
comme issues de l'atelier situé dans ou à proximité de la fosse 1002, rien ne s'oppose non plus, on l'a vu, à ce que les flans qui y ont été trouvés aient pu servir à frapper ces pièces. Le fait que les quatre monnaies recueillies dans le comblement de la fosse appartiennent à un seul type est un premier argument en ce sens : il ne semble pas s'agir d'un échantillon faisant partie du tout-venant de la circulation, car en ce cas, même sur un nombre limité d'exemplaires, on était en droit d'attendre un numéraire plus varié.

Le métal ${ }^{23}$, le module et le poids des flans et des monnaies sont par ailleurs tout à fait comparables (tabl. III).

Enfin l'hypothèse de l'appartenance de ce type aux monnayages pictons n'est pas contredite (et est même corroborée, dans l'état actuel de nos connaissances) par la géographie des trouvailles ${ }^{24}$ : sur 29 exemplaires formellement identifiés, 24 ont été découverts à l'intérieur du territoire picton (fig. 25).

Provenances sur le territoire picton

- Poitiers (Vienne) : 6 ex. ${ }^{25}$;

- Antigny (Vienne), le Gué-de-Sciaux : 7 ex. et 1 autre possible $^{26}$;

- Béruges (Vienne), Verger-Bonnet : 1 ex. ${ }^{27}$;

- Moncontour (Vienne), Thouary : 1 ex. ${ }^{28}$;

- Naintré (Vienne), Vieux-Poitiers :

. la Fond des Berthons, maison : 1 ex. ${ }^{29}$;

. la Fond des Berthons, terrain Lacroix : 1 ex. ${ }^{30}$;

23. Les analyses des monnaies et des flans de Migné-Auxances ont été effectuées par M. Pernot et F. Adamski (voir supra, p. 242-245). Les exemplaires de la Bibliothèque nationale de France ont été étudiés par le laboratoire de l'Iramat d'Orléans et les résultats ont été extraits de la thèse inédite de C. Sarthre (Sarthre, 2002, I, p. 289 et II, p. 37-38 : série 23.

24. Pendant longtemps on n'a connu qu'un seul site de découverte : Levroux (Indre). Les inventaires et les identifications de monnaies de fouilles que nous effectuons depuis plusieurs décennies en Poitou ont apporté de nouvelles provenances, empruntées à notre thèse inédite (Hiernard, 1987), auxquelles il faut ajouter les monnaies publiées des Alleuds (Maine-et-Loire) et de Mouliets-et-Villemartin (Gironde).

25. Ramassages effectués en divers endroits de la ville (monnaies étudiées au XIX ${ }^{\mathrm{e}} \mathrm{s}$. dans des collections privées) : Barthélemy, 1873, p. $504, n^{\circ} 21$; Hiernard, 1987 , p. 599.

26. Fouille du fanum carré no 3 : Hiernard, 1987, p. 330, 297/2D, $\mathrm{n}^{\text {os }} 78-84$ et, probablement, $\mathrm{n}^{\circ} 85$.

27. Fouille 1980 : Hiernard, 1987, p. 342, 302/4, no 3.

28. Découverte fortuite avant 1980 : Hébras, 1980, p. 388 (mal décrite) ; Hiernard, 1987, p. 388, 350/4, $\mathrm{n}^{\circ} 1$

29. Cave romaine (1969) : Hiernard, 1987, p. 391, 355/1B, n 5 (2,38 g, d. 16/15).

30. Habitat de La Tène III (1974) : Hiernard, 1987, p. 391, 355/1C, nº 6 (musée archéologique de Châtellerault).
. les Groseilliers : 1 ex. ${ }^{31}$;

. théâtre romain : 1 ex. ${ }^{32}$;

- Vendeuvre (Vienne), les Tours-Mirandes : 1 ex. ${ }^{33}$;

- Niort (Deux-Sèvres) :

. Bessac : 1 ex. ${ }^{34}$;

. rue de Fontenay : 1 ex. ${ }^{35}$;

. dépôt cultuel de Pain-Perdu (1977) : 1 ex. et peut-être 6 autres ${ }^{36}$;

- Rom (Deux-Sèvres) (près de) : 1 ex. ${ }^{37}$.

\section{Provenances hors du territoire picton}

- les Alleuds (Maine-et-Loire), les Pichelots : 2 ex. ${ }^{38}$;

- Levroux (Indre) : 1 ex. ${ }^{39}$;

- Mouliets-et-Villemartin (Gironde) : 2 ex. ${ }^{40}$.

\section{QUELQUES TYPES PROCHES}

\section{Premier cas}

Il existe des monnaies de bronze propres au Poitou, de taille inférieure à celles qui nous intéressent ici, mais de technologie et de style identiques, qui peuvent constituer des pièces divisionnaires de celles-ci. C'est pourquoi nous nous permettons de les évoquer ici.

\section{Type BnF $4296^{41}$}

- droit : tête à droite, les cheveux formés de trois grosses mèches ; grènetis ;

31. Temple gallo-romain (fouilles 1982) : Hiernard, 1987, p. 395, 355/3A, no 2 (d. 16/15, musée archéologique de Châtellerault).

32. Hiernard, 1987, p. 397, 355/6, nº 9 (musée archéologique de Châtellerault).

33. Au pied de l'escalier du grand temple rond monumental (19731974) : Hiernard, 1987, p. 640,392/30, nº 8 (d. 16) (dépôt archéologique de Vendeuvre)

34. Teilleux, 1848, fig. 2 ; Hiernard, 1984, p. 103, n 34 ; Hiernard, 1987 , p. $158,139 / 5 \mathrm{~A}, \mathrm{n}^{\mathrm{o}} 13$.

35. Fouille 1976 : Hiernard, 1984, p. 103, n 30 ; Hiernard, 1987, p. 161, $139 / 11, n^{\circ} 1$.

36. Hiernard, 1984, p. 77, $\mathrm{n}^{\circ} 21$ (1,40 g ; fig. 21, p. 78) et peut-être 22-27 ; Hiernard, 1987, p. 170, 139/31C, no 14 et peut-être $n^{\text {os }} 15-19$.

37. Teilleux, 1848, fig. 1 ; c'est l'une des monnaies citées par Breuillac, 1889 , p. $307, \mathrm{n}^{\mathrm{o}} 14$; Hiernard, 1987, p. 198, 151/7, no 1 .

38. Aubin et al., 1982, p. 187.

39. BnF 4303 (1,89) ; Nash, 1978, I, p. 233, nº 612 et II, pl. 25, fig. 612 ; Scheers, 1996, p. 101

40. Sireix et al., 1983, p. 44 ( $\mathrm{n}^{\circ} 229,1,38 \mathrm{~g} ; \mathrm{n}^{\circ} 26,2,77 \mathrm{~g}$; figures, p. 45).

41. Muret, Chabouillet, 1889, p. 96 ; Nash, 1978, I, p. 222, no 530 et II, pl. 22, fig. 530 ; Sarthre, 2002, I, p. 80, nº 893 et II, p. 38 ; Scheers, 1996, p. 101, n ${ }^{\text {os }} 659-660$. 
- revers : cheval galopant à droite, surmonté d'un cercle pointé ; sous son ventre, un croissant dont la concavité est tournée vers le bas.

\section{Provenances sur le territoire picton}

- Sanxay (Vienne) : 1 ex. ;

- Niort (Deux-Sèvres), temple de Pain-Perdu : 1 ex. ;

- La Meilleraie-Tillay (Vendée), trésor : 1 ex. ;

- Antigny (Vienne) : 1 ex. ;

- Pouillé (Vienne), la Croix d'Asnière : 1 ex. ;

- Vendeuvre-du-Poitou (Vienne), trésor (?) : 1 ex.

\section{Type BnF $4297^{42}$}

- droit : identique à BnF 4296 ;

- revers : cheval galopant à droite ; au-dessus et au-dessous : cercle pointé.

Aucune provenance n'est connue.

\section{Second cas}

Un bronze celtique dit « à l'androcéphale » 43 , très proche du type BnF 4298-4303, et aussi mal connu que lui, est enfin, depuis A. Blanchet, attribué aux Pictons :

- droit : tête à droite, avec plusieurs rangs de boucles fortement ondulées ;

- revers : cheval androcéphale à droite, la chevelure recourbée sur la nuque; de sa bouche sort un « $\mathrm{S}$ »; queue bifide en accolade ; sous le ventre, à l'emplacement du sexe, un grand rinceau en forme de crosse recourbée vers le bas tout à fait identique à celui de BnF 4298-4303 ${ }^{44}$.

Provenances sur le territoire picton

- Niort (Deux-Sèvres), Bessac : 2 ex. ;

- Niort (Deux-Sèvres), dépôt cultuel de Pain-Perdu : 1 ex. ;

- Antigny (Vienne), Gué-de-Sciaux : 1 ex. ;

- Basses (Vienne), trésor : 2 ex. ;

- Béruges (Vienne) : 1 ex. ;

- Naintré (Vienne) : 2 ex. ;

- Poitiers (Vienne) : 2 ex. ;

- Vendeuvre-du-Poitou (Vienne) : 1 ex. ;

- Migné-Auxances (Vienne), Verneuil : 1 ex. ;

42. Muret, Chabouillet, 1889 , p. 96 ; Nash, 1978, I, p. 222, n ${ }^{\text {os }} 531-533$ et II, pl. 22, fig. 531-533 ; Sarthre, 2002, I, p. 80, no 894 et II, p. 38 ; Scheers, 1996, p. 101, $\mathrm{n}^{\circ} 661$.

43. Teilleux, 1848, fig. 3 ; Blanchet, 1905, p. 298 et fig. 181 ; Hiernard, 1987, p. 715 et fig. 26 ; Depeyrot, 2004a, p. 112, no 83 et pl. 3, fig. 83.

44. La description proposée par Depeyrot, 2004a, p. 112 ( cheval androcéphale, queue bifide se prolongeant en longue crosse sous le ventre ») est bien meilleure que celle qu'il donne du type BnF 4298 4303.
- Brioux-sur-Boutonne (Deux-Sèvres) (près de) : 1 ex. ;

Provenances hors du territoire picton

- Trésor de Fondettes (Indre-et-Loire) : 1 ex. ;

- Le Fief-Sauvin (Maine-et-Loire), la Ségourie : 1 ex. ;

- Bailleul-le-Soc (Oise), Mont-César : 1 ex. ;

- Amboise (Indre-et-Loire) : 1 ex.

\section{UNE DÉCOUVERTE INÉDITE DU XIX ${ }^{\mathrm{e}} \mathrm{S}$.}

Une découverte comparable à celle de Migné-Auxances a eu lieu dans le passé, mais elle est restée inédite. On trouve en effet, dans les comptes domestiques de F. Bonsergent, directeur de la bibliothèque municipale de Poitiers, collectionneur et numismate, la note suivante, datée du 25 février $1837^{45}$ :

«Vers cette époque, on trouva dans les fouilles [c'està-dire les tranchées de fondation] de la maison Guérineau [à Poitiers] un grand ensemble de petites pièces gauloises en bronze attachées toutes ensemble par les petits morceaux de métal de cette façon [suit un dessin représentant un chapelet de 5 monnaies ou flans]. Ces médailles d'un métal mou étaient tellement oxydées qu'un de mes amis,... [mot illisible] Benoît, qui avait acheté deux rangées de ces pièces ne put guère en trouver une seule satisfaisament (sic) conservée parmi celles qu'il me céda. A l'obvers était une tête d'un assez bon style ; au revers un cheval libre avec une couronne de points au-dessus. »

Cette découverte est évidemment comparable à la nôtre, avec quelques différences toutefois. Nous sommes ici sur l'oppidum de Poitiers ; la propriété Guérineau correspond en effet, sur le cadastre napoléonien (section L), aux parcelles 481-483, situées dans l'actuelle rue Jean-Jaurès, près de son intersection avec la rue Arsène-Orillard. D'autre part, la description de F. Bonsergent ne permet guère de savoir d'emblée si ces monnaies étaient des potins coulés en chapelet ou des pièces frappées sur flans coulés en chapelet, comme aux Rochereaux ${ }^{46}$. La découverte semble en tout cas avoir consisté non en flans vierges, mais en monnaies liées entre elles avant séparation, ce qui pourrait certes convenir à des potins, si la description sommaire du type monétaire n'orientait vers des bronzes frappés, dont le

45. Archives départementales de la Vienne, I6J (Société des Antiquaires de l'Ouest) 132 , ex-carton $n^{\circ} 5$, pièce 1250 .

46. On notera qu'il pouvait arriver qu'un même atelier produise des potins coulés (en chapelets) dans des moules bivalves et des flans coulés en chapelets, mais destinés à être frappés : Sarrazin, 1989, p. $132, \mathrm{n}^{\circ} 173$ 
type pourrait correspondre à BnF 4371-4381 (Nash, 1978, $\left.\mathrm{n}^{\mathrm{o}} 697\right)^{47}$. En ce cas, et contrairement aux données des fouilles des Rochereaux, la frappe aurait eu lieu sur des chapelets non encore cisaillés.

\section{LA DÉCOUVERTE DES ROCHEREAUX ET LA NUMISMATIQUE POITEVINE}

Il ne paraît pas inutile d'insérer les données issues de la fouille de Migné-Auxances dans le cadre général de nos connaissances sur la numismatique du Poitou préromain, très imparfaites, comme on le sait.

Les monnaies gauloises que l'on rencontre habituellement en Poitou (c'est-à-dire, en gros, dans les départements actuels de la Vienne et des Deux-Sèvres, et dans une partie de la Vendée) sont attribuées depuis le $\mathrm{XIX}^{\mathrm{e}} \mathrm{s}$. au peuple des Pictons, attesté seulement par César et son lieutenant Hirtius au milieu du $\mathrm{I}^{\mathrm{er}}$ s. av. J.-C. Cela revient à préjuger de l'ancienneté de cet État et de la stabilité des structures géopolitiques de la région, car ces monnaies sont susceptibles de remonter assez haut dans le passé. Comme partout en Gaule, les séries rencontrées sont frappées en or (ou plutôt en or allié, autrefois dit « électrum »), en argent et en bronze (ou alliages cuivreux divers). C'est l'ordre chronologique proposé par la vulgate numismatique, le système originel ne comportant que des monnaies d'or, et se complétant par la suite, en une sorte de «tuilage », par introduction de monnaies d'argent et enfin, peu avant la guerre des Gaules, de monnaies fiduciaires de bronze.

Excepté pour une émission de monnaies d'argent au nom de IVLIOS DVRAT(ios) ${ }^{48}$, chef (ou magistrat) picton figurant dans le dernier livre du De bello Gallico, les séries particulières à l'espace poitevin ne comportent aucune indication explicite d'appartenance ethnique ni de datation.

Seule la cartographie des découvertes d'attribuer certains types monétaires aux Pictons (ou à leurs prédécesseurs éventuels). C'est le cas de deux séries frappées dans des métaux « nobles », qui ont depuis toujours retenu l'attention des collectionneurs et figurent donc en bonne place dans les grandes collections de référence :

47. Liste des trouvailles, presque toutes poitevines, dans Hiernard, 1987 , p. 712 et carte, fig. 25 (p. 713).

48. BnF 4478-4482, La Tour, 1892, pl. XIII, 4478 ; Hiernard, 1987, p. $716-718$.
- des «statères " d'or allié dont les revers portent, comme différent ethnique, une main ouverte placée sous un cheval androcéphale ${ }^{49}$;

- des «drachmes » d'argent au cavalier ailé surmontant une sorte de fleur de lis ${ }^{50}$.

Ces attributions, fondées sur un grand nombre de trouvailles isolées et sur plusieurs trésors, sont les seules actuellement sûres.

La situation, en Poitou comme ailleurs, est beaucoup moins claire en ce qui concerne les monnayages de métaux cuivreux ( bronzes »). Paradoxalement en effet, ces pièces, de valeur intrinsèque très réduite, dotées d'un pouvoir libératoire sans doute assez faible et frappées évidemment en quantités considérables, sont beaucoup moins bien connues - au moins pour les attributions - que les espèces en métaux « nobles ». Les collectionneurs les ayant méprisées, beaucoup d'entre elles sont absentes des grands corpus de base et, en conséquence, les archéologues peinent à les identifier, d'autant plus qu'elles leur parviennent presque toujours dans un état d'oxydation avancé.

Seuls les exemplaires appartenant aux séries de laiton pourvues des légendes ATECTORI (pour Atectorix) (BnF 4345-4352, La Tour, 1892, pl. XII, 4349) et CONTOVTOS (BnF 4316-4324, La Tour, 1892, pl. XII, $4316^{51}$ ont pu être attribués avec un très fort degré de vraisemblance, les premiers aux Pictons, les seconds aux Santons, mais leur typologie très romanisée et les contextes de découverte de ces monnaies incitent à les dater de l'époque d'Auguste, ce qui fait d'elles des pièces véritablement gallo-romaines.

Pour tout le reste, très varié, les attributions sont loin d'être établies et les datations demeurent improbables, la tendance générale consistant à les situer à la fin de l'indépendance, juste avant ou pendant la guerre des Gaules, car ces monnaies se rencontrent, le plus souvent, abandonnées dans des strates archéologiques tardives, contemporaines de l'installation des Romains, où elles font partie d'un matériel qualifié de plus ou moins « résiduel».

Comme on pouvait s'y attendre, les fouilles permettent de réviser ces vues impressionnistes. Celles des Rochereaux viennent éclairer d'un jour nouveau l'une de ces séries de

49. BnF 4393-4426A, La Tour, 1892, pl. XIII, 4395 ; Hiernard, 1987, p. 694-703.

50. BnF 4461-4470, La Tour, 1892, pl. XIII, 4461 ; Hiernard, 1987, p. 708-711.

51. Hiernard, 1984 et 1987, p. 722-729. 
bronze, traditionnellement attribuée aux Bituriges Cubi et datée du milieu du $\mathrm{I}^{\mathrm{er}}$ s. av. J.-C. (ou de la première moitié de ce siècle). En réalité, il s'agit selon toute vraisemblance d'un monnayage picton, frappé probablement entre 130 et 100 av. J.-C., en tout cas sensiblement plus tôt qu'on ne le pensait jusqu'à présent. Cette révision ressemble assez à celle qui a été naguère proposée pour certaines émissions de potins et qui était fondée sur les résultats des fouilles de Bâle ${ }^{52}$. Une nouvelle fois est démontrée l'importance des données archéologiques pour la résolution des questions d'attribution et de datation liées aux monnayages préromains.

J. H.

52. Furger-Gunti, von Kaenel, 1976 ; Furger-Gunti, Berger, 1980.

\section{BIBLIOGRAPHIE}

$\begin{array}{ll} & \text { ABRÉVIATIONS } \\ \text { BAR } & \text { British Archaeological Reports. } \\ \text { DAF } & \text { Documents d'archéologie française. } \\ \text { DFS } & \text { Document final de synthèse. } \\ \text { MSH } & \text { Maison des sciences de l'homme. }\end{array}$

AUbin G., Gruet M., SiraudeaU J.

1982 : « Les monnaies gauloises des Pichelots, commune des Alleuds (Maine-et-Loire) et la chronologie des potins ", Bulletin de la Société française de numismatique, 37, p. 186-188.

\section{BARON Y.}

1996 : Les Plantes sauvages et leurs milieux en Poitou-Charentes : un guide écologique régional pour l'approche des groupements végétaux, Poitiers, dactylographié, 263 p.

\section{BARON Y., DUPIAS G., VILKS A.}

1982 : Châteauroux, Toulouse, CNRS Éditions (coll. Carte de la végétation de la France, 39), 1 carte à $1 / 250000$.

\section{BARTHÉLEMY A. DE}

1873 : «Étude sur des monnaies gauloises trouvées en Poitou et en Saintonge ", Mémoires Mémoires de la Société des antiquaires de l'Ouest, $1^{\text {re }}$ série, XXXVII, p. $493-532$.

\section{BEAUSOLEIL J.-M., BERNARD R.,}

Courtay E.

2004: Les Rochereaux, Migné-Auxances (Vienne), DFS, Campagne de diagnostic archéologique, Poitiers, 13 p., 14 fig.

\section{BENQUET L.}

2002 : Les Amphores du Toulousain : production et commercialisation, thèse de Doctorat, Université Toulouse-le-Mirail, 4 t.

(Oise) du III e au II ${ }^{e}$ s. av. J.-C., Paris, éd. de la MSH (coll. DAF, 64), p. 93-97.

\section{BenOUET L., OLMER F.}

2002 : « Les amphores, La Loba (Fuenteovejuna, Cordoue, Espagne) : la mine et le village minier antique ", in Domergue C., Sillières P. (DIR.), La Loba (Fuenteovejuna, Cordoue, Espagne) : la mine et le village minier antique, Bordeaux, Fédération Aquitania (coll. Mémoires Ausonius), p. 295- 332

\section{BLANCHET A.}

1905 : Traité des monnaies gauloises, Paris, Ernest Levoux, 650 p., 3 pl., 1 dépliant.

\section{BREUILLAC E.}

1889 : «Catalogue des monnaies gauloises appartenant à la Société de statistique, sciences, lettres et arts des Deux-Sèvres", Bulletin de la Société de statistique, sciences, lettres et arts du département des Deux-Sèvres, VII, p. 303-314.

\section{BRIANE D., DOAT J.}

1985 : Guide technique de la carbonisation, la fabrication du charbon de bois, Aix-enProvence, Edisud, 177 p.

\section{BRUNAUX J.-L., LEJARS T.}

1997 : « Le métal et les parures », in Brunaux J.-L., MÉniel P. (DIR.), La Résidence aristocratique de Montmartin

\section{Castelin K.}

1978 : Keltische Münzen. Katalog der Sammlung des Schweizerischen Landesmuseums Zürich, vol. I, Stäfa, Verlag Th. Gut \& Co, 235 p.

1985 : Keltische Münzen. Katalog der Sammlung des Schweizerischen Landesmuseums Zürich, vol. II, Kommentar, Stäfa, Verlag Th. Gut \& Co, 172 p.

\section{Chabal L.}

1997 : Forêts et sociétés en Languedoc (Néolithique final, Antiquité tardive), Paris, éd. de la MSH (coll. DAF, 63), 188 p.

Chardron-Picault P., PERnot M. (DIR.) 1999 : Un Quartier d'artisanat antique à Autun : le site du lycée militaire, Paris, éd. de la MSH (coll. DAF, 76), 316 p.

\section{DABAS M., DieUdonNÉ-GLAD N.,} POIRIER P.

2002 : «Caractérisation des structures d'une forge antique : approche archéologique, géophysique et anthracologique ", Revue d'archéométrie, 26, p. 141-153.

\section{DEPEYROT G.}

2004a : Le Numéraire celtique-III-De l'Atlantique aux Arvernes, Wetteren, Moneta (coll. Moneta, 36), 246 p. 
2004b : Le Numéraire celtique -IV- Bituriges, Éduens, Séquanes, Lingons, Wetteren, Moneta (coll. Moneta, 41), $326 \mathrm{p}$.

DIDEROT D., D'ALEMBERT J.

2002 (rééd.) : « Recueil de planches sur les sciences, les arts libéraux et les arts mécaniques avec leur explication ; travail du fer " in Encyclopédie, Bibliothèque de l'image.

\section{Dieudonné-Glad N., Parisot J.}

1999 : « À propos des récipients à liquide retrouvés dans les ateliers de forge ", Instrumentum, 10, p. 25-26.

\section{DOMERGUE C.}

1991 : «Les amphores dans les mines antiques du sud de la Gaule et de la péninsule Ibérique », Internationale Archäologie, 1, p. 99-119.

\section{DUBOIS C.}

1990 : Archéologie de l'environnement forestier en milieu métallurgique et minier, en Ariège : orientation de recherches diachroniques, mémoire de DEA, Université de Provence, 303 p.

\section{DUnikowski C., CABboi S.}

1995 : La Sidérurgie chez les Sénons : les ateliers celtiques et gallo-romains des Clérimois (Yonne), Paris, éd. de la MSH (coll. DAF, 51), $186 \mathrm{p}$.

DUPIAS G., VILKS A.

1979 : Poitiers, Toulouse, CNRS Éditions (coll. Carte de la végétation de la France, 45), 1 carte à $1 / 250000$.

\section{Duvauchelle A., Augustoni C.}

2002 : "Couper du fer : outils et gestes des forgerons d'hier et d'aujourd'hui ", Annuaire de la Société suisse de préhistoire et d'archéologie, 85, p. 261-266.

ESCHENLOHR L., SERNEELS V. avec la collab. de HiLTPOLD B.

1991 : Les Bas Fourneaux mérovingiens de Boécourt, les Boulies (Jura, Suisse), Porrentruy, Société jurassienne d'émulation (coll. Cahiers d'archéologie jurassienne, 3), $143 \mathrm{p}$.

ESPÉROU J.-L., AMBERT P., BOURHIS J.-R., Roques P., Gilot E., Chabal L.

1994 : « La fosse chalcolithique Pioch-Farrus 448 (Cabrières, Hérault) : datation ${ }^{14} \mathrm{C}$ et documents métallurgiques », Bulletin du musée d'Anthropologie préhistorique de Monaco, 27, p. 53-62.

FABRE L.

1996 : Le Charbonnage historique de la chênaie de
Quercus ilex L. (Languedoc, France) : conséquences écologiques, thèse de Doctorat, Université Montpellier-II, 364 p.

FeUGÈre M., SerneElS V. (DIR.)

1998 : Recherche sur l'économie du fer en Méditerranée nord-occidentale, Montagnac, Monique Mergoil (coll. Monographie Instrumentum, 4), $248 \mathrm{p}$.

\section{FichtL S.}

2000: La Ville celtique (les oppida de 150 av. J.-C. à 15 apr.J.-C.), Paris, Errance, 238 p.

FULFORD M. G., ALLEN J. R. L.

1992 : «Iron-Making at the Chesters Villa, Woolaston, Gloucestershire : Survey and Excavation 1987-1991 ", Britannia, XXII, p. $159-215$.

FURGER-GUNTI A., BERGER L.

1980 : Katalog und Tafeln der Funde aus der spätkeltischen Siedlung Basel-Gasfabrik, Derendingen (coll. Basler Beiträge zur Ur- und Frühgeschichte, 7), $450 \mathrm{p}$.

\section{FURGER-GUNTI A., KAENEL H.-M. VON}

1976 : «Die keltischen Fundmünzen aus Basel. Mit Untersuchungen zur Chronologie der Potinmünzen bei den Helvetiern und Raurikern Aufgrund der Funde von BernEngehalbinsel und Basel ", Schweizerische Numismatische Rundschau, 55, p. 35-76, pl. 2-8.

García Brosa G., García Morcillo M., OZCÁRIZ GIL P., ROVIRA GUARDIOLA R.

2001 : « Los grafitos del Siglo III (campañas de 1989, 1991 y 1992) », in Estudios sobre el Monte Testaccio (Roma) II, Barcelone, Publicacions Universitat de Barcelona, p. $305-365$

\section{GEBHARD R.}

1989 : «Pour une nouvelle typologie des bracelets », in FEUGÈRE M. (DIR.), Le Verre préromain en Europe occidentale, Montagnac, Monique Mergoil, p. 73-83.

GEBHARD R., LEHRBERGER G., MORTEANi G., RAUb C., STEFFGeN U., WAGNER U.

1999 : «Production techniques of celtic gold coins in Central Europe ", in CAUUET B. (DIR.), L'Or dans l'Antiquité : de la mine à l'objet, Bordeaux, Fédération Aquitania (coll. Suppl. à Aquitania, 9), p. 217-233.

GIOT P.-R., BRIARD J., PAPE L.

1979 : Protohistoire de la Bretagne, Rennes, Université de Rennes (coll. Ouest France), $437 \mathrm{p}$.
GUILLAUMET J.-P.

2000 : "Le mobilier métallique ", in BUCHSENSCHUTZ O., COLlin A., FIRMIN G., FISCHER B., GUILLAUMET J.-P., KraUsz S., LEVÉRY M., MARINVAL P., Orellana L., Pierret A. (DIR.), Le Village celtique des Arènes à Levroux. Synthèses, Levroux, Ferac/Adel (coll. Levroux, 5), p. 101-119.

\section{Guillaumet J.-P., NiLlesSe O.}

2000 : "Les objets de quelques fermes gauloises : approche méthodologique ", in MARION S., BLANCQUAERT G. (DIR.), Les Installations agricoles de l'âge du Fer en France septentrionale, Paris, éd. Presses de l'École normale supérieure (coll. Études d'histoire et d'archéologie, 6), p. 251-276.

\section{HAFFNER A.}

1978 : Das keltisch-römische Gräberfeld von Wederath - Belginum, 3, Teil : Gräber 885-1260 Ausgegraben 1958-1960, 1971 u. 1974, Mayence, Philipp von Zabern (coll. Trierer Grabungen und Forschungen, VI-2).

1989 : Gräber - Spiegel des Lebens. Zum Totenbrauchtum der Kelten und Römer am Beispiel des Treverer-Gräberfeldes Wederath, Belginum, Mayence, Philipp von Zabern (coll. Rheinisches Landesmuseum Trier, 52), $447 \mathrm{p}$.

HAMON T. avec la collab. de RIQUIER S., Agogue $O$.

1997 : Saumeray "le Bas des Touches", campagne de fouille 1996, DFS inédit, Orléans.

\section{HÉBRAS C.}

1980 : « Recherches préhistoriques à Moncontour ", Bulletins de la Société des antiquaires de l'Ouest, $4^{\mathrm{e}}$ série, t. XV, $1^{\text {er }}$ trim. p. 385-394.

\section{HIERNARD J.}

1984 : «Les monnaies antiques de Niort (Deux-Sèvres) ", Aquitania, 2, p. 59-104.

1985 : Numismatique et protohistoire : existe-t-il un monnayage picton?, Bordeaux, Fédération Aquitania (coll. Suppl. à Aquitania, 1), p. 113-121.

1987 : Les Monnaies du Poitou antique : circulation monétaire et histoire, thèse d'État, Université Bordeaux-III, 5 vol., 1181 p.

\section{HUCHER E.}

1852 : «Étude sur le symbolisme des plus anciennes médailles gauloises, $3 \mathrm{e}$ article ", Revue numismatique, XVII, p. 165-191.

JACOBI G.

1974 : Werkzeug und Gerät aus dem Oppidum von 
Manching, Die Ausgrabungen in Maching, Wiesbaden, t. 5, Römisch-Germanische Kommission des deutschen archäologischen Instituts zu Frankfurt am Main, 368 p., 107 fig., 102 pl.

\section{JANNORAY J.}

1955 : Ensérune : contribution à l'étude des civilisations préromaines de la Gaule méridionale, Paris (coll. Bulletin des Écoles françaises d'Athènes et de Rome, 181), 490 p.

\section{LAMBERT E.}

1864 : Essai de numismatique gauloise du nordouest de la France, seconde partie, ParisBayeux, E. Derache, 139 p., 19 pl.

\section{LAMbot B., Friboulet M., MéNiel P.}

1994 : Le Site protohistorique d'Acy-Romance (Ardennes) -II- Les Nécropoles dans leur contexte régional (Thugny-Trugny et tombes aristocratiques) 1986, 1988, 1989, Reims, Société archéologique champenoise (coll. Mémoire de la Société archéologique champenoise, 8 , Suppl. au bulletin, 2), $315 \mathrm{p}$.

\section{LA TOUR H. DE}

1892 : Atlas de monnaies gauloises, Paris, Plon.

\section{LEJARS T.}

1997 : " Le mobilier métallique ", in BrunauX J.-L., MÉniel P. (DIR.), La Résidence aristocratique de Montmartin (Oise) $d u I I I^{e}$ au II ${ }^{e}$ s. av. J.C.C., Paris, éd. de la MSH (coll. DAF, 64), p. 151-160.

\section{LUDEMANN T.}

2002 : "Anthracology and forest sites : the contribution of charcoal analysis to our knowledge of natural forest vegetation in south-west Germany », in THIÉBAULT S. (DIR.), Charcoal Analysis : Methodological Approaches, Palaeoecological Results and Wood Uses, Proceedings of the Second International Meeting of Anthracology, Paris, sept. 2000, Oxford, Archaeopress (coll. BAR, International Series, 1063), p. 209-217.

\section{MARGUERIE D.}

1992 : Évolution de la végétation sous limpact humain en Armorique du Néolithique aux périodes historiques, Rennes, Université Rennes-I (coll. Travaux du laboratoire d'anthropologie, préhistoire, protohistoire et quaternaire armoricains, 40), 313 p.

\section{Marziani G., Citterio S.}

1999 : " The effects of human impact on the arboreal vegetation near ancient iron smelting sites in Val Gabbia, northern Italy ", Vegetation History and Archaeobotany, 8, p. 225-229.

MAUfRAS O., FABRE L. avec la collab. de SOlOMER G., SEKRAOUI Z.

1998 : " Une forge tardive (fin $\mathrm{IV}^{\mathrm{e}}-\mathrm{V}^{\mathrm{e}}$ s.) sur le site de la Ramière (Roquemaure, Gard) ", in FeUgère M., SERneEls V. (DIR.), Recherches sur l'économie du fer en Méditerranée nord-occidentale, Montagnac, Monique Mergoil (coll. Monographies Instrumentum, 4), p. 210-221.

MaUVilly M., ANTENen I., García Cristobal E., RUfFieUX M., Serneels V.

1998 : "Sévaz, Tudinges : chronique d'un atelier de métallurgistes du début de La Tène dans la Broye ", Archéologie suisse, 21, 4, p. 144-153.

\section{Muret E., Chabouillet M.-A.}

1889 : Catalogue des monnaies gauloises de la Bibliothèque Nationale, Paris, Plon.

\section{NASH D.}

1978 : Settlement and Coinage in Central Gaul c. 200-50 B.C., 2 vol., Oxford, Archaeopress (coll. BAR Supplementary Series, 39 i-ii), 353 p., 34 pl., 4 index.

\section{NELLE O.}

2002: " Charcoal burning remains and forest stand structure : examples from the Black Forest (south-west Germany) and the Bavarian Forest (south-east Germany)", in THIÉBAult S. (DIR.), Charcoal Analysis : Methodological Approaches, Ppalaeoecological Results and Wood Uses, Proceedings of the Second International Meeting of Anthracology, Paris, sept. 2000, Oxford, Archaeopress (coll. BAR, International Series, 1063), p. 201-208.

\section{OLMER F.}

2003 : Les Amphores de Bibracte 2 : le commerce $d u$ vin chez les Éduens d'après les timbres d'amphores, Glux-en-Glenne, Bibracte, Centre archéologique européen du MontBeuvray (coll. Bibracte, 7), 375 p.

\section{ORENGO L.}

2002 : «Annexe 3 : le petit mobilier» in Vermeulen C. (DIR.), Puy-de-Dôme, Clermont-Ferrand (63), Gandaillat, Rapport de l'opération préventive de fouille archéologique, Clermont-Ferrand, Service régional de l'archéologie, vol. 1 et vol. 2, 128 p. et 58 pl.

2003 : Forges et forgerons dans les habitats laténiens de la Grande Limagne d'Auvergne : fabrication et consommation de produits manufacturés en fer en Gaule à l'âge du Fer, Montagnac, Monique Mergoil (coll. Monographies Instrumentum, 26), 261 p., $63 \mathrm{pl}$.

\section{ORENGO L., BONNON J.-M.,}

\section{BEVILACQUA D.}

2000 : "L'emploi des blocs-tuyères dans les forges du centre de la Gaule (Auvergne, Lyonnais et Forez au deuxième âge du Fer et à l'époque romaine) : découvertes archéologiques et expérimentation ", in FEUGÈRE M., GUŠTIN M. (DIR.), Iron, Blacksiths and Tools : Ancient European Crafts, Actes du colloque de l'association Instrumentum, Podsreda (Slovénie), 15-17 avril 1999, Montagnac, Monique Mergoil (coll. Monographies Instrumentum, 12), p. 59-80.

Passelac M. avec les contrib. de CHabal L., LEBLANC J.-C.

1998 : " Installations pour le travail du fer dans le Vicus Eburomagus (Bram, Aude) ", FEUgÈRE M., SERnEELS V. (DIR.), Recherches sur l'économie du fer en Méditerranée nord-occidentale, Montagnac, Monique Mergoil (coll. Monographies Instrumentum, 4), p. 129-141.

\section{PERNAUd J.-M.}

1997 : Paléoenvironnements végétaux et sociétés à l'Holocène dans le nord du Bassin parisien : anthracoanalyses de sites archéologiques d'Îlede-France et de Picardie, méthodologie et paléoécologie, thèse de Doctorat, Université Paris-I, 197 p.

\section{PERNOT M.}

1993 : «Approche de l'artisanat du "bronze" au Mont-Beuvray : la fabrication de fibules et l'organisation d'un atelier ", Revue d'archéométrie, 17, p. 41-49.

1998 : " L'organisation de l'atelier du bronzier ", in MORDANT C., PERNOT M., RYCHNER V. (DIR.), L'Atelier du bronzier en Europe du $\mathrm{XX}^{e}$ au VIII ${ }^{e}$ siècle avant notre ère : du minerai au métal, du métal à l'objet, Actes du colloque international "Bronze 96 ", Neuchâtel et Dijon, 1996, t. II (session de Dijon), Paris, Comité des travaux historiques et scientifiques et Centre de recherches sur les techniques gréco-romaines de l'université de Bourgogne, p. 107-113.

1999 : «La métallographie », in À la recherche du métal perdu : les nouvelles technologies dans la restauration des métaux archéologiques, Musée archéologique du Val-d'Oise, Errance, p. 65-67.

\section{PERRIN F.}

1990 : Un dépôt d'objets gaulois à Larina, 
Hières-sur-Amby, Isère, Lyon, Lyon, Circonscription des Antiquités historiques (coll. Documents d'archéologie en Rhône-Alpes, 4), 174 p.

\section{POHANKa R.}

1986 : Die eisernen Agrargeräte der Römischen Kaiserzeit in Österreich. Studien zur römischen Agrartechnologie in Rätien, Noricum und Pannonien, Oxford, Archaeopress (coll. BAR, International Series, 298), 390 p., $65 \mathrm{pl}$.

\section{POIRIER P.}

1999 : Anthracologie et environnement de la période gallo-romaine à la période médiévale en Poitou-Charentes, thèse de Doctorat, Université Montpellier-II, 2 vol., 334 p.

\section{Poirier P., Ali A.}

2003 : «Approvisionnement et économie du bois dans le quartier des thermes ", in BoueT A. (DIR.), Les Thermes de Barzan (Charente-Maritime) et les thermes des provinces gauloises, Bordeaux, Fédération Aquitania (coll. Mémoires Ausonius, 10), p. 525-537.

PouX M. avec la collab. de Demierre M., Foucras S., GARCIA M., GASC J., PASQUier D., VerRier G.

2004 : «Sanctuaire de Corent (Puy-deDôme) : bilan de trois années de fouille ", Bulletin de l'Association française pour l'étude de l'âge du Fer, 22, p. 45-51.

\section{RICQ DE BOÜARD M., MEILlE E., VICHY M.,} PICON M.

1989 : «Les argiles utilisées dans la fabrication des amphores en Italie », in Amphores romaines et histoire économique : 10 ans de recherche, Actes du colloque de Sienne, mai 1986, Paris, De Boccard, p. 257-268.

\section{ROVIRA C.}

1998 : « Le travail du fer en Catalogne du VII ${ }^{\mathrm{e}}$ $\mathrm{au} \mathrm{I}^{\mathrm{er}}$ s. avant notre ère ", in FEUGÈRE M., SERNEELS V. (DIR.), Recherches sur l'économie du fer en Méditerranée nord-occidentale, Montagnac, Monique Mergoil (coll. Monographies Instrumentum, 4), p. 65-75.

\section{SARRAZIN J.-P.}

1989 : « Sens, quartier Saint-Paul », in L'Yonne et son passé: 30 ans d'archéologie, Catalogue d'exposition, Sens, p. 132.

\section{SARTHRE C.-O.}

2002 : Autour des monnayages d'argent et des monnayages cuivreux du centre-ouest de la Gaule avant la conquête : études numismatiques et analytiques, thèse de Doctorat, Université Paris-IV, vol. 1 : texte, 367 p. ; vol. II : catalogue, 106 p., $64 \mathrm{pl}$.

\section{SCHEERS S.}

1996 : "Monnaies celtiques ", in BRENOT C., SCHEers S. (DIR.), Musée des BeauxArts de Lyon : les monnaies massaliètes et les monnaies celtiques, Louvain, Peeters, p. 49-182, pl. IX-XLIV.

\section{SCHWEINGRUBER F. H.}

1990 : Anatomy of European Woods : an Atlas for the Identification of European Trees, Shurbs and Dwarf Shurbs, Berne, Paul Haupt, $800 \mathrm{p}$.

\section{SIEVERS S.}

1992 : "Die Kleinfunde ", in MAIER F., GEILENBRÜGgE U., HAHN E., KÖHLER H.-J., SIEVERS S. (DIR.), Ergebnisse der Ausgrabungen 1984-1987 in Manching, Stuttgart, Franz Steiner Verlag, Römisch-Germanische Kommission des deutschen archäologischen Instituts zu Frankfurt am Main, p. 137-213.

SireiX M., NOldin J.-P., COlberT DE BEAUlieU J.-B., NONY D., RICHARD J.-C.

1983 : « Les monnaies de Mouliets-etVillemartin, Gironde (1954-1982) », Gallia, 41, p. 25-57.

\section{TEILleUX $\mathbf{D}^{\mathrm{r}}$}

1848 : "Essai d'attribution de quelques médailles gauloises trouvées dans le département des Deux-Sèvres ", Mémoires de la Société de statistique du département des Deux-Sèvres, XI, 1846-1847, p. 20-32.

\section{TEREYGEOL F., DUboIS C.}

2003 : «Mines et métallurgie carolingiennes à Melle (Deux-Sèvres, France) : l'apport des charbons de bois archéologiques ", Archéologie médiévale, 33, p. 91-102.
TOLEDO I MUR A.

1997-1998 : « La Croix du Buis (Arnacla-Poste, Haute-Vienne) : un entrepôt du $\mathrm{I}^{\mathrm{er}}$ siècle a.C. ", Aquitania, XV, p. 109-140.

2007a : «Les Rochereaux, Migné-Auxances (Vienne) ", in BERTRAND I., MAgUER P. (DIR.), De pierre et de terre : les Gaulois entre Loire et Dordogne, Catalogue d'exposition, Chauvigny, mai-oct. 2007, Chauvigny, Association des publications chauvinoises, p. 75-77 et p. 228-231.

2007b : « Les Rochereaux, MignéAuxances (Vienne) ", in CAVAILlÈs M., CLAIRAND A., GENDRON C., HiERNARD J., TÉREYGEOL F. (DIR.), Argent caché... et retrouvé : les trésors monétaires découverts en Deux-Sèvres, Catalogue d'exposition, Musée municipal de Parthenay, oct. 2007-2009, Parthenay, p. $30-32$.

TOLEDO I MUR A. avec la collab. de BENQUET L., BERNARD R., DALLE S., ERNAUX P., Fouilloud C., Galtié E., HIERNARD J., JAMOIS M.-H., MILOR F., Orengo L., PERnot M., POIRIER P., VALLET C., VIGNERON M.

2005 : Les Rochereaux, Migné-Auxances (Vienne) : un habitat rural du II $\hat{e}$ âge du Fer caractérisé par un atelier spécialisé dans la fabrication de flans monétaires, DFS, inédit, Poitiers, $120 \mathrm{p}$.

VALLET C.

2005 : " La faune ", in TOLEdo I MUR A. ET AL. (DIR.), Les Rochereaux, MignéAuxances (Vienne) : un habitat rural du II ${ }^{e}$ age du Fer caractérisé par un atelier spécialisé dans la fabrication de flans monétaires, DFS, inédit, Poitiers, p. 92-107.

Vernet J.-L., Ogereau P., Figueiral I., MACHADO YANES C., UZQUiANO P.

2001 : Guide didentification des charbons de bois préhistoriques et récents. Sud-ouest de l'Europe : France, péninsule Ibérique et îles Canaries, Paris, CNRS Éditions, 395 p.

VIAND A. (DIR.)

2008 : Nanterre et les Parisii : une capitale aux temps des Gaulois ?, Catalogue d'exposition, Nanterre, Espace Paul-Éluard, avriljuin 2008, Paris, Somogy, 125 p. 